\title{
DISCI.AIMER
}

This report was prepared as an account of work sponsored by an enency of the United States Government. Neither the United States Government nor any anency thereof, nor any of their employes, mates any werranty, expreas or implied, of asumes any lezal liability or responsibility for the accurnoy, completeneme, or usefulness of any informution, apparatus, product, or process diuclosed, or represents that its use would not infringe privately owned rights. Reference herela to eny epecilic commercial product, procses, or service by trade name, trademark, manulacturer, of otherwive does not necesanrily conatitute or imply its endorsement, recom. meadation, or favoring by the United State Government of any atency thereof. The view and opinions of author expreaced herein do not necouarily state or reflect those of the United States Government or any agency thereof.

\section{Instrumentation Report No. 3: Performance and Reliability of Instrumentation Deployed for the Spent Fuel Test-Climax}

\author{
W. C. Patrick \\ N. L. Rector \\ J. J. Scarafiotti
}

Manuscript date: December 1984

\section{LAWRENCE LIVERMORE NATIONAL LABORATORY University of California - Livermore, California - 94550}




\section{Contents}

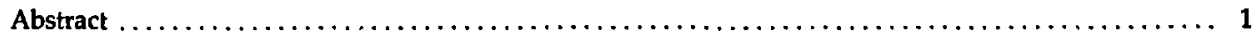

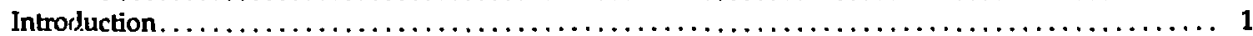

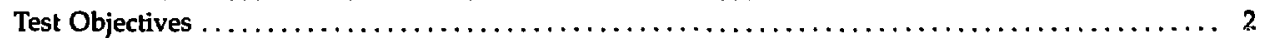

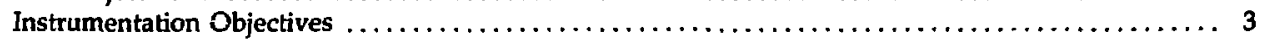

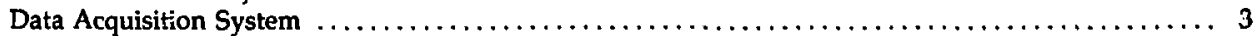

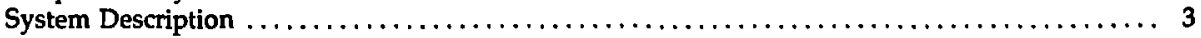

System Performance and Reliability $\ldots \ldots \ldots \ldots \ldots \ldots \ldots \ldots \ldots \ldots \ldots \ldots \ldots \ldots \ldots \ldots \ldots, \ldots \ldots$

Radiation Monitors $\ldots \ldots \ldots \ldots \ldots \ldots \ldots \ldots \ldots \ldots \ldots \ldots \ldots \ldots \ldots \ldots \ldots \ldots \ldots \ldots \ldots \ldots, \ldots, \ldots$

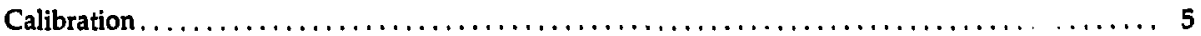

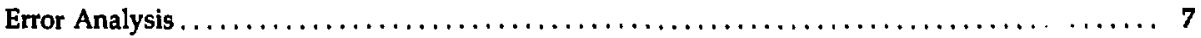

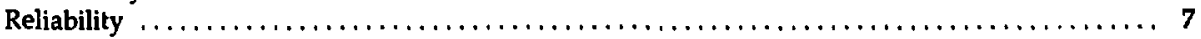

Radiation Dosimeters $\ldots \ldots \ldots \ldots \ldots \ldots \ldots \ldots \ldots \ldots \ldots \ldots \ldots \ldots \ldots \ldots \ldots \ldots \ldots \ldots \ldots, \ldots \ldots$

Performance, Reliability, and Error Analysis $\ldots \ldots \ldots \ldots \ldots \ldots \ldots \ldots \ldots \ldots \ldots \ldots \ldots \ldots \ldots$

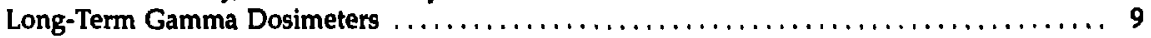

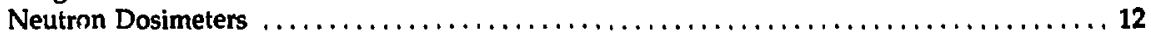

Short-Term Gamma Dosimeters $\ldots \ldots \ldots \ldots \ldots \ldots \ldots \ldots \ldots \ldots \ldots \ldots \ldots \ldots \ldots \ldots \ldots, \ldots \ldots$

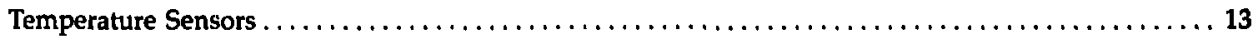

Resistance Temperature Devices $\ldots \ldots \ldots \ldots \ldots \ldots \ldots \ldots \ldots \ldots \ldots \ldots \ldots \ldots \ldots \ldots \ldots \ldots \ldots$

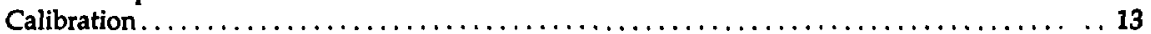

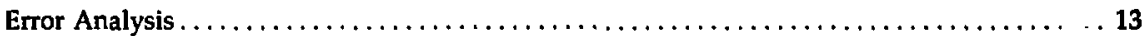

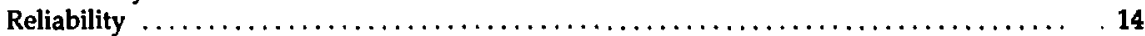

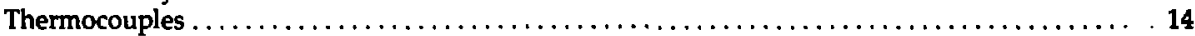

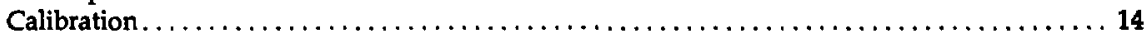

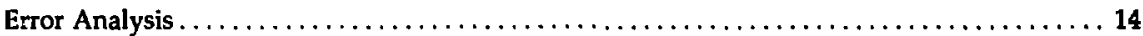

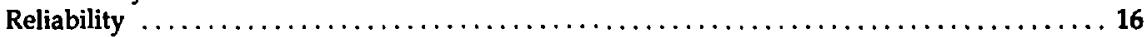

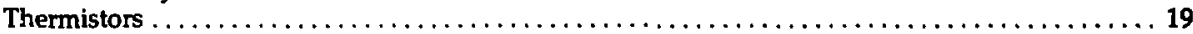

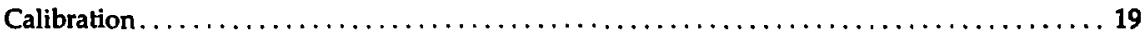

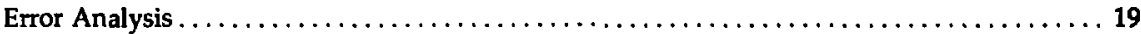

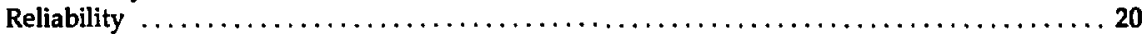

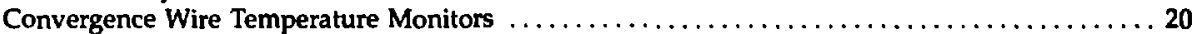

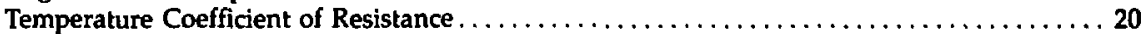

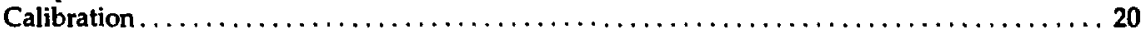

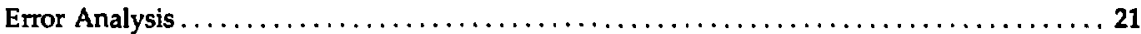

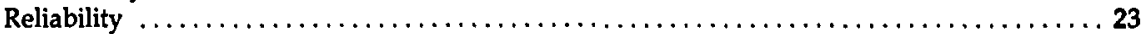

Ventilation System Instrumentation $\ldots \ldots \ldots \ldots \ldots \ldots \ldots \ldots \ldots \ldots \ldots \ldots \ldots \ldots \ldots \ldots \ldots \ldots, 23$

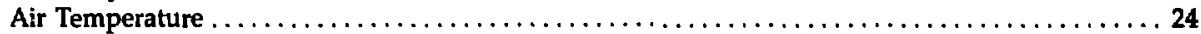

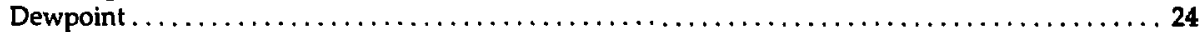

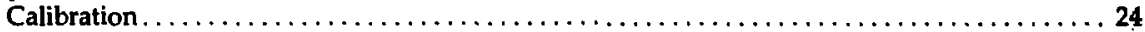

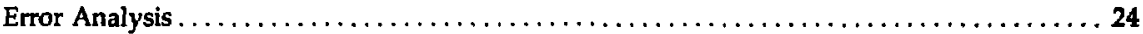

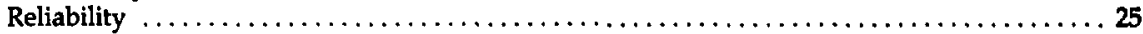

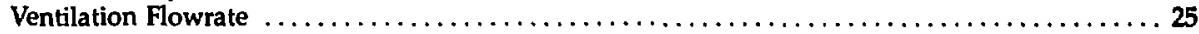

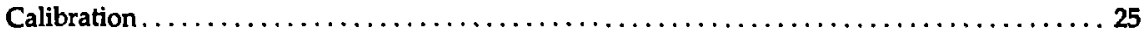

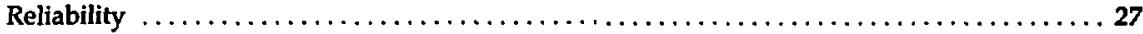

Energy Removal Calculation $\ldots \ldots \ldots \ldots \ldots \ldots \ldots \ldots \ldots \ldots \ldots \ldots \ldots \ldots \ldots \ldots \ldots \ldots \ldots \ldots \ldots \ldots \ldots, 28$

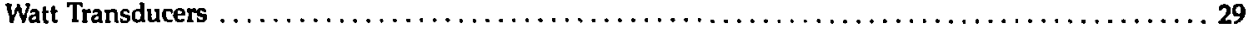

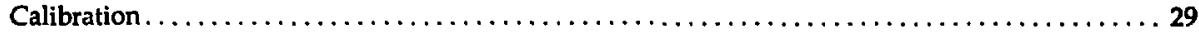

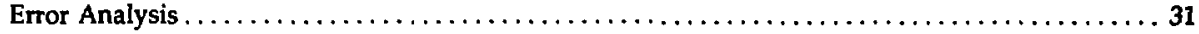

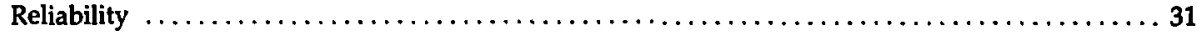

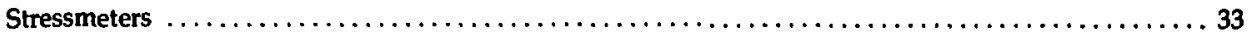

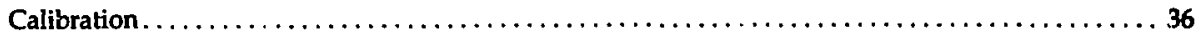

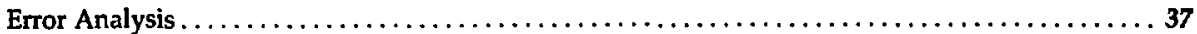

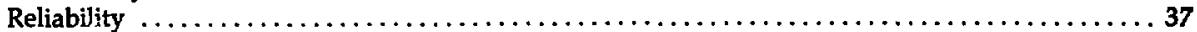


Rod Extensometers $\ldots \ldots \ldots \ldots \ldots \ldots \ldots \ldots \ldots \ldots \ldots \ldots \ldots \ldots \ldots \ldots \ldots \ldots \ldots \ldots \ldots \ldots \ldots \ldots, 40$

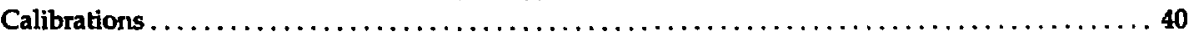

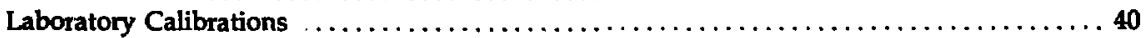

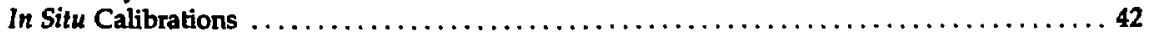

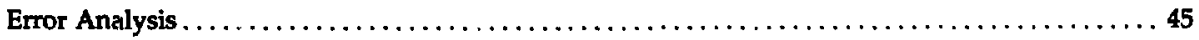

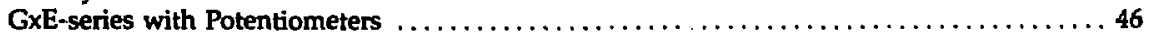

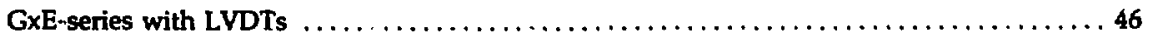

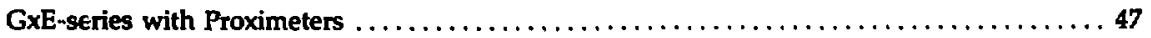

MBI-series with Potentiometers $\ldots \ldots \ldots \ldots \ldots \ldots \ldots \ldots \ldots \ldots \ldots \ldots \ldots \ldots \ldots \ldots, \ldots \ldots$

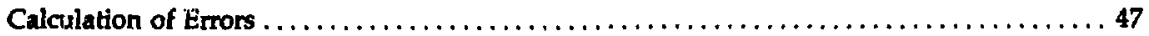

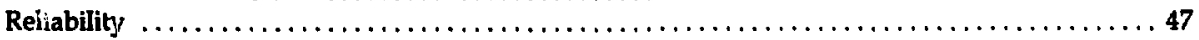

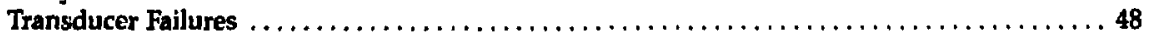

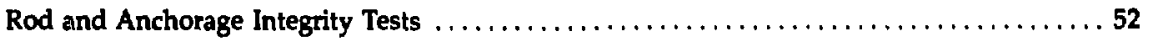

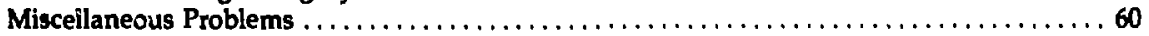

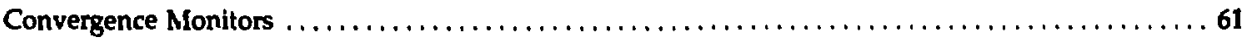

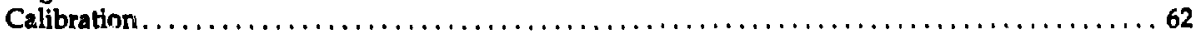

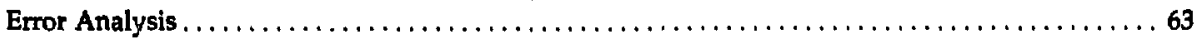

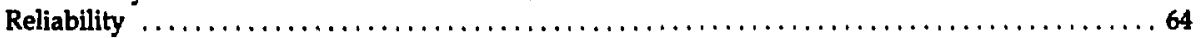

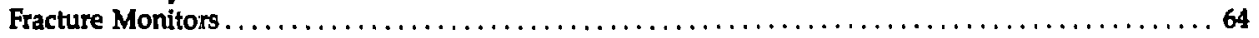

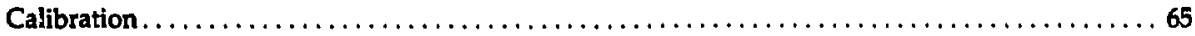

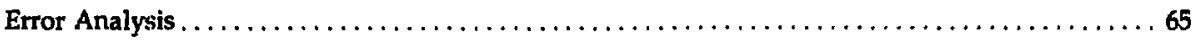

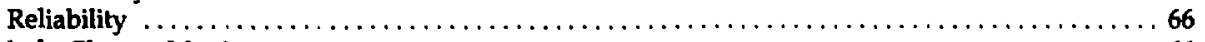

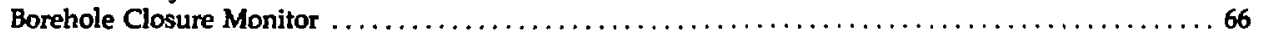

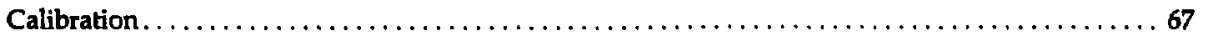

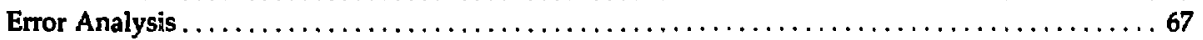

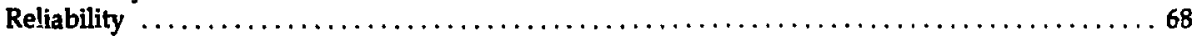

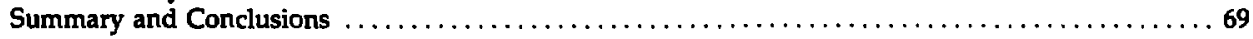

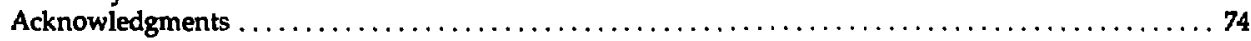

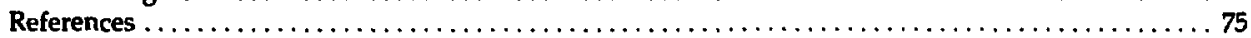




\title{
Instrumentation Report No. 3: Performance and Reliability of Instrumentation Deployed for the Spent Fuel Test-Climax
}

\begin{abstract}
A demonstration of the short-term storage and subsequent retrieval of spent nuclear fuel assemblies was successfully completed at the U.S. Department of Energy's Nevada Test Site. Nearly 1000 instruments were deployed to monitor the temperature of rock, air, and metallic components of the test; displacements and stress changes within the rock mass; radiation dosage to personnel and to the rock; thermal energy input; characteristics of the ventilation airstream; and the operational status of the test. Careful selection, installation, calibration, and maintenance of these instruments ensured the acquisition of about $15.3 \times 10^{6}$ high-quality data points. With few exceptions, the performance and reliability of the instrumentation and associated data acquisition system (DAS) were within specified acceptable limits. Details of the performance and reliability of the instrumentation are discussed in this report.
\end{abstract}

\section{Introduction}

A suite of instrumentation was deployed and operated for a period of 3-1/2 years to monitor the Spent Fuel Test-Climax (SFT-C). This test was conducted under the technical direction of the Lawrence Livermore National Laboratory (LLNL) for the U.S. Department of Energy as part of the Nevada Nuclear Waste Storage Investigations (NNWSI).

The SFT $-C$ consists of three parallel drifts connected at their ends (Fig. 1), and is located $420 \mathrm{~m}$ below the surface in a granitic intrusive. Although the facility is about $150 \mathrm{~m}$ above the regional water table, water seeps into the underground workings along geologic fractures, shears, and faults (Wilder and Yow, 1981). As a result of the test, the temperatures of a large volume of the rock and various test components were increased to as high as 85 and $145^{\circ} \mathrm{C}$, respectively. The re- . mote location of the SFT-C in the northeast corner of the Nevada Test Site placed it at the end of the power distribution grid where significant fluctuations in line voltage were common. These conditions provided additional challenges to the task of long-term monitoring of the facility.

The objectives of this report are to document the performance, reliability, and errors associated with the instrumentation deployed on the SFT-C and to assess its adequacy in meeting the overall objectives of the SFT-C. This is being done for three reasons. First, the performance and reliability statistics, together with error analyses, will be used directly in analyses and interpretations of the data acquired with the instruments described in this report. Second, our experiences provide an important data base for the performance of various types of instruments in a simulated repository environment. Researchers who are responsible for obtaining field data at future repository sites or at generic underground research facilities can use this data base to guide specification and modification of their instrumentation. Third, we present certain advances in instrumentation technology that should prove useful to other researchers. Included are development of a microprocessorcontrolled rod extensometer calibration device, design and deployment of a strain-gauged proving-ring assembly for measuring displacements in large diameter boreholes in rock, and application of optical absorbance and thermoluminescent dosimetry techniques to in situ measurement of radiation dose to rock.

This report presents performance and reliability data for each of the types of instruments deployed on the SFT-C. Objective measures of performance and reliability and rigorous error analyses are used to the extent possible. The 


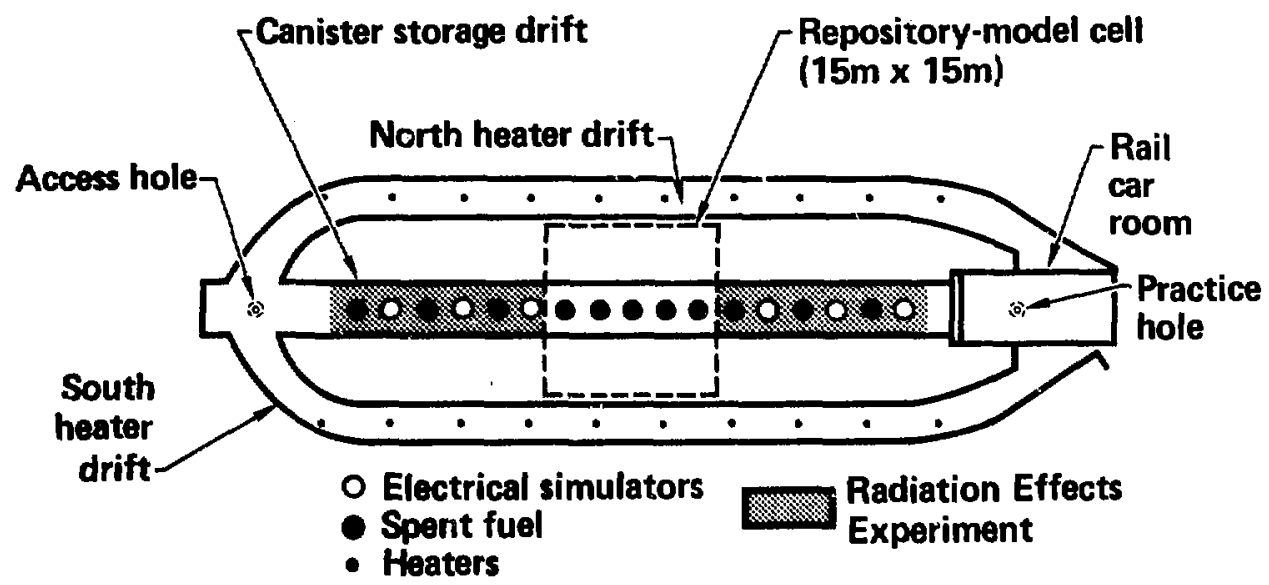

Figure 1. Plan view of the Spent Fuel Test-Climax showing location of spent fuel and related heat sources.

breadth of discussion is in proportion to the complexity of the particular instrument or problems associated with it. For example, those instruments requiring sophisticated temperature correction schemes and individual calibration coefficients are discussed in greater detail. The depth of discussion is uniform to the extent practical. The objectives of the SFT-C and of the instrumentation plan as well as an evaluation of the data acquisition system are summarized to provide a context for the instrumentation evaluations.
To keep this document within a reasonable size, we have not included detailed descriptions of the various instruments, their specifications and design, or the techniques used to install them. The reader is assumed to have available anct to be familiar with the two previous reports in this series (Patrick et al., 1981, and Brough and Patrick, 1982), which present these items of information.

\section{Test Objectives}

The principal objective of the SFT $-\mathrm{C}$ was demonstration of the feasibility of short-term storage and subsequent retrieval of spent nuclear-fuel assemblies in a deep geologic environment (Ramspott et al., 1979). Technical objectives focused on the response of the rock mass to excavation processes and to the heat generated by radioactive decay. Specific objectives iricluded:

- Documentation of displacements and stress changes in the rock comprising the pillars between the central and side drifts caused by the mechanical disturbance of mining the central drist.

- Comparison of that response to the results of existing computational modeling to assess the validity of those models in terms of mechanical effects alone.

- Documentation of the temperature and radiation dose in the close-in heated zone to infer both the total power level of the spent-fuel assemblies and the proportion of that power transported out of the canisters by nuclear radiation, as opposed to thermal processes.

- Documentation of displacement and stress effects in the intermediate heated zone caused by the thermal disturbance from the fuel and heaters.

- Comparison of measured thermomechanical responses with romputational modeling to assess the validity of those thermomechanical models. 
- Documentation of the amount of heat removed by ventilation.

- Documentation of the thermal field (both close-in and intermediate) and comparison with calculational models.

- Documentation of the relative effect of existing fractures on rock response by duplicating all mechanical measurements in either fractured or relatively unfractured regions, and by direct instrumentation of selected, prominent geologic fractures.

- Evaluation of displacement and stress instrumentation under simulated repository conditions. Note that this objective was added because of instrumentation failures early in the test (Patrick et al., 1981).

\section{Instrumentation Objectives}

The objective of the instrumentation program was to ensure that the appropriate quantity and quality of data were obtained for three purposes. First, instrumentation had to provide data to meet the technical objectives of the SFT-C. Second, it had to ensure radiation safety. Third, it was required to monitor the status of the test, including measurements of the ventilation airstream, the power distribution system, and the data acquisition system. The instrumentation plan led to the successful specification, design, calibration, and installation of the instrumentation required to meet these three objectives (Brough and Patrick, 1982).

\section{Data Acquisition System}

The DAS has a profound, direct effect on the quality and quantity of test data produced by the instrumentation. The effect on data quality is primarily a function of the precision and accuracy of the digital multimeters and the resolution provided by the digital system. The effect on data quantity is a function of the system failure characteristics.

\section{System Description}

The DAS deployed in support of the SFT-C is based on two Hewlett-Packard 21MX E-Series (HP1000) minicomputers. Specifications and documentation of the DAS are provided by Nyholm et al. (1982) and by Nyholm (1983).

The DAS hardware configuration is shown in Fig. 2. In the normal operational mode, the two computers (Node 100 and Node 200) share the task of acquiring, processing, and archiving about 500 data points per hour from nearly 1000 individual channels of instrumentation. An HP-IB bus extender switching network was designed to minimize the adverse effect of a malfunction of one computer node. When a malfunction occurs on one node, the other node switches the bus extenders by means of an HP-3495 scanner so that no loss of data occurs.

The two major subsystems of the DAS are separated by about $650 \mathrm{~m}$. The surface portion of the system includes the two computers, disc drives, magnetic tape units, system terminals, and related peripherals, and is located in an air conditioned room of a trailer complex. The subsurface portion includes the scanners and digital multimeters and is located $420 \mathrm{~m}$ below ground surface in an air conditioned alcove. In operation, one of the computers commands appropriate scanner relays to close via the HP-IB bus. The HP3455 digital multimeter converts the analog signal from the instrument to digital format and sends it up the bus. The data packet is processed and written to a disc buffer from which it is written to magnetic tape for archiving and subsequent data analysis. By digitizing data at the subsurface location, we were able to limit the length of cables carrying the relatively small analog signals to about $60 \mathrm{~m}$.

\section{System Performance and Reliability}

Although the digital multimeters (DMM) are capable of making measurements over a broad range, most of the data is represented by dc voltage readings in the millivolt range and four-wire resistance readings in the $125-\Omega$ range. In these ranges, the DMMs provide measurements accurate to $1 \mu \mathrm{V}$ and $0.0042 \Omega$ with 90 -day drifts not to exceed $4 \mu \mathrm{V}$ and $0.005 \Omega$, respectively. Resolutions of $1 \mu \mathrm{V}$ and $0.001 \Omega$ are specified. Long-term accuracy of the measurement system was achieved by performing regular (90-day interval) 


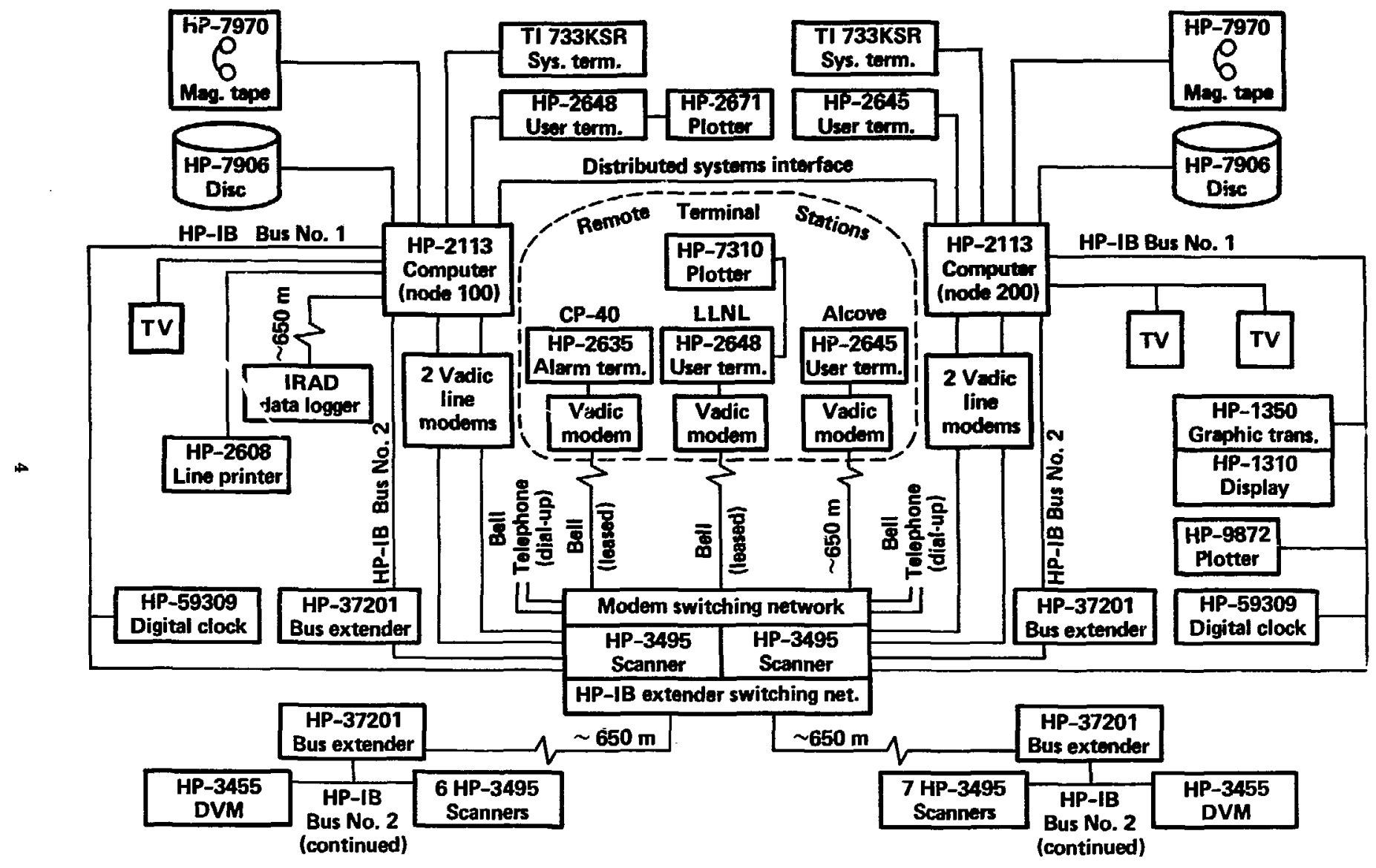

Figure 2. Data acquisition system hardware configuration. 
calibrations of the DMMs, by operating them in a controlled environment at about $23^{\circ} \mathrm{C}$ and $50 \%$ relative humidity, and by providing for continuous secondary calibrations of the DMMs between calibrations. The secondary calibrations were accomplished by measuring the following four types of "standards" at intervals ranging from five minutes to one hour:

- A precision $1-\mathrm{mV}$ source accurate to $1 \mu \mathrm{V}$.

- Two precision $120-\Omega$ resistors accurate to $0.00018 \Omega$.

- One thermocouple and one resistance temperature device (RTD) in a $0^{\circ} \mathrm{C}$ Kaye ice bath.

- Three thermocouples and one RTD located deep in a borehole away from the effects of the test.

The alarm function of the DAS was used throughout the te! t to alert us when these "system standard" data values deviated outside acceptable limits. Based on measurements of the 1-mV precision voltage source, Patrick et al. (1984) concluded that the DMMs operated inside an envelope of 0.996 to $1.004 \mathrm{mV}$ at all times. Several periods were noted when four-wire resistance measurements deviated outside the $\pm 0.0092-\Omega$ specification. When such deviations occurred, the malfunctioning DMM was replaced and returned for recalibration or maintenance, as necessary.

System availability may be expressed in terms of a "functionally disabled index" (FDl) (Nyholm et al., 1982). The FDI is a measure of the probability that data cannot be properly acquired and archived when desired. The average FDIs for Node 100 and Node 200 were 14.98 and $8.79 \%$, respectively. The bus extender switching network described above reduced the system FDI to $4.06 \%$. Thus, the DAS was able to acquire data when requested $96 \%$ of the time for the 41 -month acquisition period.

A total of $15.3 \times 10^{6}$ data values were recorded during this period of data acquisition. About $6.6 \times 10^{6}(43 \%)$ of these represent radiation dosimetry data that were archived but not entered into the scientific data base for detailed analysis. Only $2.5 \times 10^{5}(1.6 \%)$ of the data records were unreadable or sufficiently flawed as to be unusable in the analyses.

\section{Radiation Monitors}

Radiation monitors were deployed to measure ionizing radiation as well as airborne gaseous and particulate forms of radioactive materials. Monitoring was provided continuously during the three year spent-fuel storage period. Results and discussion of these measurements are p.ovided by Raschke et al. (1983).

Remote area monitors (RAMs) were used to measure gamma radiation levels in the SFT-C underground complex and at the surface where the spent fuel assemblies were received and lowered to the storage level (Figs. 3 and 4). RAMs were in place at the surface locations only during handling operations. Eleven Nuclear Measurements Corp. Model GA-3M RAMs were procured for this purpose (Brough and Patrick, 1982); manufacturer's specifications indicate a precision of $\pm 15 \%$.

Continuous air monitors (CAMs) were emplaced to sample for potential release of ${ }^{3} \mathrm{H}$ and ${ }^{85} \mathrm{Kr}$, gaseous products that would be released if the spent fuel assembly canisters and zircalloy cladding were breached by corrosion or an accident. In addition to the continuously monitored locations (Fig. 3), ports were also provided to permit sampling from the canister/liner and liner/ rock annuli of each canister emplacement borehole. Two Overhoff and Associates, Inc., Betatec Model 210 CAMs were procured for this purpose (Brough and Patrick, 1982). The use of two CAM chambers permitted redundant sampling from each port. These units have a specified sensitivity of $0.6 \mu \mathrm{Ci} / \mathrm{m}^{3}$.

\section{Calibration}

The RAMs are provided with a pulsed lightemitting diode (LED) as an internal calibration source that can be turned on and off at the control module. More meaningful and accurate calibrations were performed in situ before each spentfuel handling operation by using $\mathrm{a}^{226} \mathrm{Ra}$ source up to $100 \mathrm{mR} / \mathrm{h}$ and a ${ }^{60} \mathrm{Co}$ source up to $1000 \mathrm{mR} / \mathrm{h}$. In addition, laboratory calibration of the highlevel RAMs was performed with a $225-\mathrm{Ci}{ }^{137} \mathrm{Cs}$ source. Accuracy is not as critical as with the scientific instrumentation being used, the main concern being adequate sensitivity.

The purpose of the in situ calibrations was to determine that the units were functioning properly and that they were performing at the same 


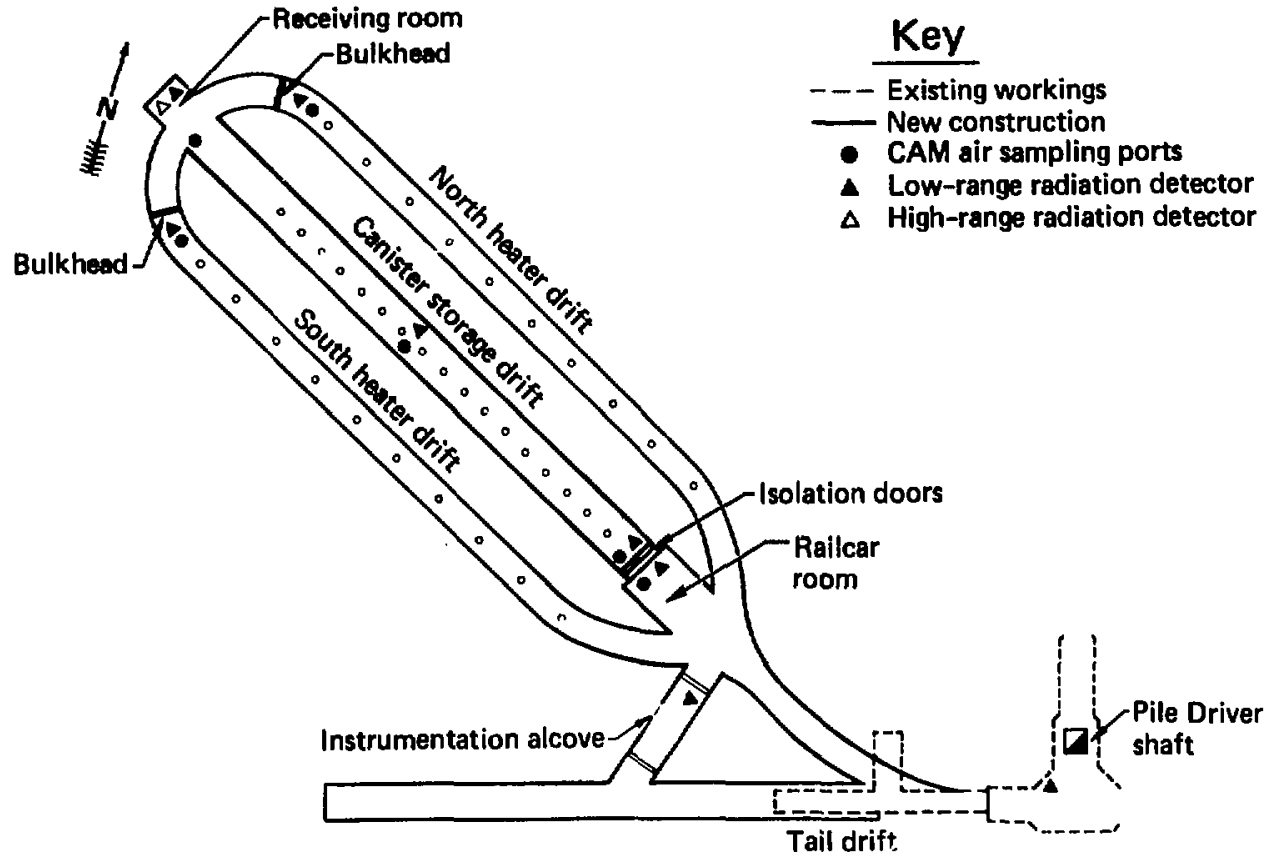

Figure 3. Underground radiation monitor locations.

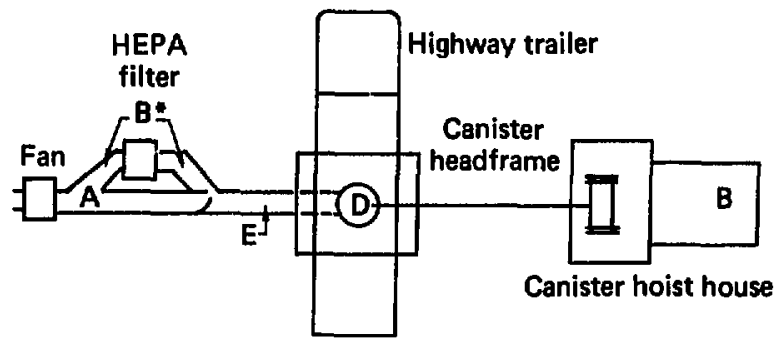

Figure 4. Surface radiation

$A=$ Fixed CAM sampling ports.

$B=$ Low-level RAM detectors ( $B^{*}=$ normal mode).

$D=$ High-level RAM detectors.

monitor locations.

$\mathrm{E}=$ Particulate sampling port. 
level of accuracy as when they were procured from the manufacturer. The high sensitivity of these units, which is required to measure low levels of radioactivity, makes it very difficult to achieve accuracy better than the specified $\pm 15 \%$ of reading. Changes in calibration coefficient " $K$ " are listed in Table 1 . Note that the RAMs were adjusted when the $K$ factors exceeded by 0.50 the nominal 2.00 value used in the data conversion algorithms.

Calibration of the CAM units used an internal radiation source. The chambers for the Betatec $\mathbf{2 1 0}$ CAM units (CAMs 101-107 and 201-207) were modified to include a ${ }^{90} \mathrm{Sr}$ calibration source for this purpose. When placed in the calibrate mode, a $0.4-\mu \mathrm{Ci}$ source is exposed at the chambor, producing a reading equivalent to $\sim 180 \mu \mathrm{Ci} / \mathrm{m}^{3}$. The NMC ${ }^{\mathrm{H5}} \mathrm{Kr}$ CAM (CAM 108 and 208) and the portable CAM units were calibrated at LLNL using radioactive sources. Minor adjustments were made to compensate for instrument drift. Changes in calibration coefficients are noted in Table 2.

\section{Error Analysis}

The role of the radiation instrumentation was to detect and monitor for the presence of radiation and radioactive materials rather than to provide high-accuracy measurements for analysis. Higher accuracy data were obtained using portable detectors and personnel dosimetry, as reported by Raschke et al. (1983). Therefore, detailed error analyses were not performed for the RAMs and CAMs.

The relationship between output voltage readings and converted value is of the form

$R=A \cdot 10^{V / K}-B$,

where

$A=0.1$ for RAMs 101-108, 110-111, 201-208 and 210-211,

$=10$ for RAMs 109 and 209,

$=0.1$ for CAMs 101-107 and 201-207,

$=0.28$ for CAMs 108 and 208;

$B=-0.2$ for RAMs 101-108, 110-111, 201208, and 210-211,

$=-20$ for RAMs 109 and 209,

$=0$ for all CAMs;

$\mathrm{K}=2.0$ for all RAMs and CAMr 108 and 208.

$=2.5$ for CAMs 101-107 and 201-207;

$\mathrm{V}$ is in volts;

$R$ is in $R / h$ for $R A M s$ and in $\mu \mathrm{Ci} / \mathrm{m}^{3}$ for CAMs.
Table 1. Low-level RAM "K" values at various times since deployment of the instruments.

\begin{tabular}{cccccc}
\hline & \multicolumn{5}{c}{ K value at callbration and time } \\
\cline { 2 - 6 } RAM & $6 / 26 / 80$ & $7 / 1 / 81$ & $10 / 6 / 81$ & $7 / 29 / 82$ & $2 / 16 / 83$ \\
\hline 1 & 2.06 & 2.23 & 2.13 & 2.19 & $2.04^{4}$ \\
2 & 2.02 & 2.32 & 2.35 & 2.29 & 2.36 \\
3 & 2.06 & 2.41 & 2.40 & 2.38 & 2.49 \\
4 & 1.95 & 2,11 & 2.28 & 2.30 & $2.03^{a}$ \\
5 & 1.93 & 2.09 & 2.19 & 2.18 & $2.12^{n}$ \\
6 & 1.99 & 2.28 & 2.24 & 2.29 & 2.23 \\
7 & 1.99 & 2.24 & 2.26 & 2.25 & 2.26 \\
8 & 2.03 & 2.37 & 2.39 & Replaced & 2.03 \\
9 & - & 2.20 & 2.13 & 2.21 & 2.22 \\
10 & - & 2.16 & 2.13 & 2.17 & 2.13 \\
\hline
\end{tabular}

a Readjusted RAM unit.

Table 2. CAM " $K$ " values at various times during the SFT-C.

\begin{tabular}{lcccc}
\hline & \multicolumn{4}{c}{ K volue at calibration time } \\
\cline { 2 - 5 } Instrument & $1 / 16 / 81$ & $10 / 6 / 81$ & $7 / 29 / 82$ & $2 / 16 / 83$ \\
\hline CAM 101 & 2.48 & 2.48 & 2.48 & 2.45 \\
CAM 201 & 2.46 & 2.53 & 2.46 & 2.51 \\
CAM 102 & 2.51 & 2.55 & 2.52 & 2.56 \\
CAM 202 & 2.50 & 2.59 & - & 2.48 \\
CAM 103 & 2.48 & 2.46 & 2.47 & 2.51 \\
CAM 203 & 2.45 & 2.48 & 2.46 & 2.49 \\
CAM 104 & 2.47 & 2.49 & 2.46 & 2.48 \\
CAM 204 & 2.41 & 2.46 & 2.49 & 2.49 \\
CAM 105 & 2.61 & 2.46 & 2.61 & 2.46 \\
CAM 205 & 2.48 & 2.52 & 2.45 & 2.45 \\
CAM 106 & 2.45 & 2.42 & 2.45 & 2.52 \\
CAM 206 & 2.49 & 2.42 & 2.42 & 2.42 \\
CAM 007 & - & 2.23 & 2.23 & 2.23 \\
CAM 00B & - & 2.03 & 2.05 & 1.96 \\
\hline
\end{tabular}

\section{Reliability}

The RAM and CAM units performed satisfactorily throughout the spent-fuel storage period. Specific problems and associated corrective actions are noted in Table 3. Aging of the RAM photomultipliers and CAM circuitry caused the DAS to generate spurious alarms (on the low side of the alarm limit). Because of the high single-unit reliability of the RAMs and the application of redundancy in the CAMs, radiation monitoring was provided continuously without a significant period of downtime. 
Table 3. Occurrence of problems with radiation monitors deployed at the SFT-C.

\begin{tabular}{|c|c|c|}
\hline Effected units & Problem dewcription & Corrective action \\
\hline All RAM: & Photomuthiplier aging & $\begin{array}{l}\text { Performed periodic calibrations, adjusted for } \\
\text { change in " } \mathrm{K} \text { " }\end{array}$ \\
\hline RAM 108 & Noity outpdt & Photomultiplier circuit replaced \\
\hline All CAMs & MInor circuit drift & $\begin{array}{l}\text { Adjualed circuit }(7 / 28 / 82) \text { and performed } \\
\text { periodic calibrations }\end{array}$ \\
\hline All CAM: & Nolev & Resoldered bad electric connections. \\
\hline CAM $100 \& 200$ & Sensitlvity to tranitent nolse & $\begin{array}{l}\text { Lockted and repaired break in a lrace of the } \\
\text { count-rate-meter printed circuil }\end{array}$ \\
\hline
\end{tabular}

\section{Radiation Dosimeters}

Radiation-dose-to-granite measurements were made to document the exposure of the granite to ionizing radiation and for comparison with radiation transport calculations (Wilcox and Van Konynenburg, 1981). These measurements were obtainer' 'der subcontract to LLNL by EG\&GSanta Batuura Operations.

Four types of passive dosimeters were deployed at the SFT-C to obtain the required data. Long-term gamma dosimetry used optical grade ${ }^{7} \mathrm{LiF}$ detectors that operate on the principal that optical absorbance of the crystals increases as they are irradiated. Individual ${ }^{7} \mathrm{LiF}$ chips were enclosed in stainless steel holders that were in turn joined together with sections of braided stainless steel cable to make seven dosimeter assemblies (Fig. 5). These assemblies were installed in $6.35-\mathrm{mm}$-diam stainless steel tubes. Four tubes were attached to emplacement borehole walls where spent nuclear fuel was stored (Table 4). The fifth and sixth tubes were grouted into boreholes located 508 and $660 \mathrm{~mm}$ radially outward from one of the emplacement boreholes, and the seventh was attached to the emplacement borehole wail where an electrical simulator was stored. The latter installation allowed examination of thermal annealing of pre-irradiated dosimeters (Quam and DeVore, 1981). These dosimeters were deployed during three time intervals: April 18, 1980, to January 12, 1981; January 12, 1981, to October 23, 1981; and October 23, 1981, to March 8, 1983.

Lorig-term neutron dosimetry was performed in conjunction with the long-term gamma dosimetry outlined above. The primary purpose of these measurements was to document the neutron dose for use in corrections if the gamma dosimeters were found to be neutron sensitive. The five dosimeter assemblies located on emplacement
Table 4. Dosimeter locations in the fleld instaliation.

\begin{tabular}{|c|c|c|c|}
\hline CEH No." & $\begin{array}{l}\text { Verlical distance } \\
\text { of do simetero } \\
\text { from centerline }(m)^{b}\end{array}$ & $\begin{array}{l}\text { Lithium } \\
\text { fluoride } \\
\text { number }\end{array}$ & $\begin{array}{l}\text { Cobalt foll } \\
\text { number }\end{array}$ \\
\hline \multirow[t]{3}{*}{1 (wall) } & +1.22 & 14 & - \\
\hline & $\mathbf{0}$ & 15 & 5,6 \\
\hline & -1.22 & 16 & - \\
\hline \multirow[t]{7}{*}{3 (wall) } & +1.83 & 7 & - \\
\hline & +1.22 & 8 & - \\
\hline & +0.61 & 9 & - \\
\hline & 0 & 10 & 3,4 \\
\hline & -0.61 & 11 & - \\
\hline & -1.22 & 12 & - \\
\hline & -1.83 & 13 & - \\
\hline \multirow[t]{3}{*}{$3(20 \mathrm{~cm})$} & +1.22 & 84 & - \\
\hline & 0 & $\mathbf{5}$ & 1,2 \\
\hline & -1.22 & 6 & - \\
\hline \multirow[t]{3}{*}{$3(36 \mathrm{~cm})$} & +1.22 & 20 & - \\
\hline & $n$ & 21 & 7,8 \\
\hline & -1.22 & 22 & - \\
\hline \multirow[t]{3}{*}{4 (wall, heater) } & +1.22 & 1 & - \\
\hline & 0 & 2 & 9,10 \\
\hline & -1.22 & 3 & - \\
\hline \multirow[t]{3}{*}{7 (wall) } & +1.22 & 17 & - \\
\hline & 0 & 18 & - \\
\hline & -1.22 & 19 & - \\
\hline \multirow[t]{3}{*}{11 (wall) } & +1.22 & 23 & - \\
\hline & 0 & 24 & 一 \\
\hline & -1.22 & 25 & - \\
\hline
\end{tabular}

- CEH derotes canister emplacement hole number. Data in parentheses are used to denote radial locations of dosimeters relative to the boreholc wall.

b The midheight of the opent-fuel assembly is taken as zero, positive numberw are above and negative numbers are below this cenler position.

' CEHO4 is an elecirical simulator used as a nonradiative control. 


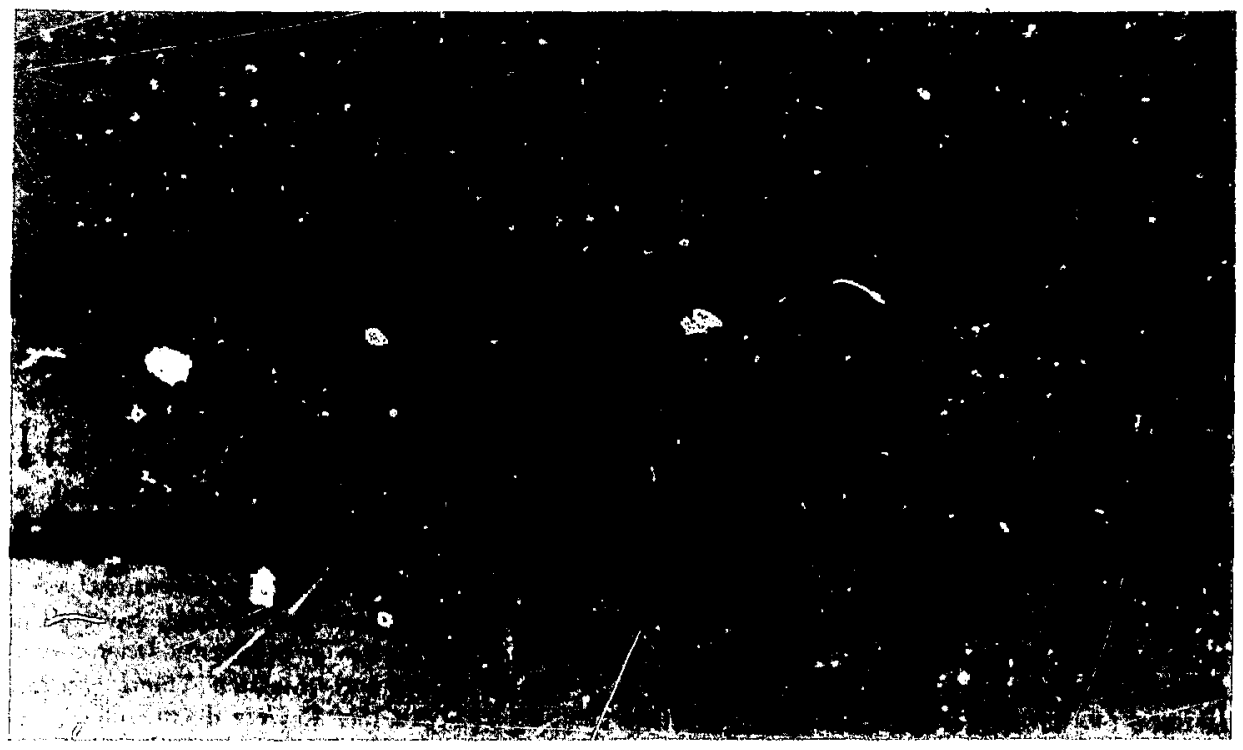

Figure 5a. Exploded view of dosimeter subassembly.

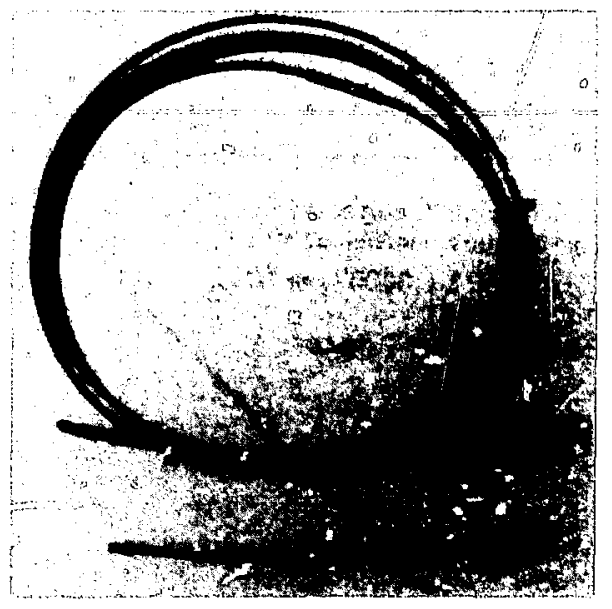

Figure 5b. Complete dosimeter assembly ready for installation.

borehole walls had provisions for cobalt and silver foils. In addition, the nickel and manganese present in the 303-series stainless steel dosimeter holders were also used to help establish neutron dose (Quam and DeVore, 1981). The measurement f-riods were the same as for long-term gamma dosimetry.

Both $\mathrm{MgB}_{4} \mathrm{O}_{7}$ and $\mathrm{CaF}_{2}$ short-term thermoluminescent dosimeters were deployed to provide information on the long-term fade characteristics of the ${ }^{7} \mathrm{LiF}$ dosimeters. Short-term ( one hour) measurements were obtained on August 13, 1982, and on March 8, 1983. These measurements were obtained at the borehole wall and at positions 508 and $660 \mathrm{~mm}$ radially outward from the spent fuel assembly in canister emplacemert borehole (CEH) number $\mathrm{CEH} 03$.

\section{Performance, Reliability, and Error Analysis}

\section{Long-Term Gamma Dosimeters}

One set of long-term gamma dosimeters was deployed for a 9-month period, read in the laboratory, and deployed for a subsequent 17-month period. The other set was deployed for a single 9month period while the first set was cut of service to be read. Temperatures at the dosimeters ranged from about 60 to $80^{\circ} \mathrm{C}$, depending on the time 
interval and exact location of the dosimeter. The mechanical design and fundamental approach proved to work reliably for the duration of the SFT-C.

Calibrations of the ${ }^{7} \mathrm{~L}$ iF chip were performed at two facilities: the EGeG-Santa Barbara Operations ${ }^{60} \mathrm{Co}$ source range at various controlled temperatures up to $60^{\circ} \mathrm{C}$ at exposures as high as $10^{7}$ rada-LiF; and at the Sandia Gamma Irradiation Facility at an uncontrolled temperature near $60^{\circ} \mathrm{C}$ at expostire up to $10^{8}$ rads-LiF. The $247-\mathrm{nm}$ peak in the absorption spectrum was used in the range of $2 \times 10^{3}$ to $9 \times 10^{6}$ rads-LiF, and the $374-\mathrm{nm}$ peak was used in the range of $2 \times 10^{6}$ to $10^{8}$ rads-LiF.

A Beckman 5270 epectrophotometer was used for all the 374-nm data and for the 247-nm data produced by exposures up to about $9 \times 10^{5}$ radLiF-about 1.5 absorbance units (AU). An IL 500, modified with a high-preasure mercury vapor light, was ueed to obtain the 247-nm data for exposures ranging from about $10^{4}$ to $10^{7}$ rads-LiF (about 0.1 to $4.5 \mathrm{AU}$ ) because the optical density ivas so great at these exposures. The data from. these two instruments agree vrry well in the overlapping portion of their ranges.

The high quality of the calibration data is evident in Figs. 6 and 7 for the 374- and 247-nm peaks, respectively. These calibration curves relate known expcsures in rads-LiF to observed AU readings. The $A U$ is the cornmon logarithm of the reciprocal of optical transzission. The calibration coefficients and associaited one-standarddeviation error bands are provided in Tables 5 and 6 for the 374- and 247-nm peaks, respectiveiy.

Temperature effects on dosimetor sensitivity were found to be a serious problem with the ${ }^{7} \mathrm{LiF}$ dosimeters. Two types of sensitivity were observed. First, irradiated chips were found to fade when held at elevated temperatures following irradiation. Fade factors were determined for temperatures of 50,100 , and $150^{\circ} \mathrm{C}$ (Quam and DeVore, 1981a). Fade at the 374-nm peak was generally less than $5 \%$ for temperatures of interest here (1tp to $85^{\circ} \mathrm{C}$ ). However, fade at the $247-\mathrm{nm}$ peak was nearly $30 \%$, so fade corrections were applied to the $247-\mathrm{nm}$ data. Second, the chips also exhibited a change in sensitivity when simultaneously heated and irradiated. Changes in sensitivity of about $1 \% /{ }^{\circ} \mathrm{C}$ were documented for the 374-nm peak. Changes in sensitivity of the 247$\mathrm{nm}$ peak appear to be about $5 \%$ at exposures up to $10^{5}$ rads-LiF over a temperature range of $25-$ $60^{\circ} \mathrm{C}$. Rather than document sensitivity as a function of temperature and exposure for the $247-\mathrm{nm}$
Figure 6. Calibration data for the 374-nm peak, poliohed LiF, 2-mm thicknew (after Quam. and DeVore, 1984).

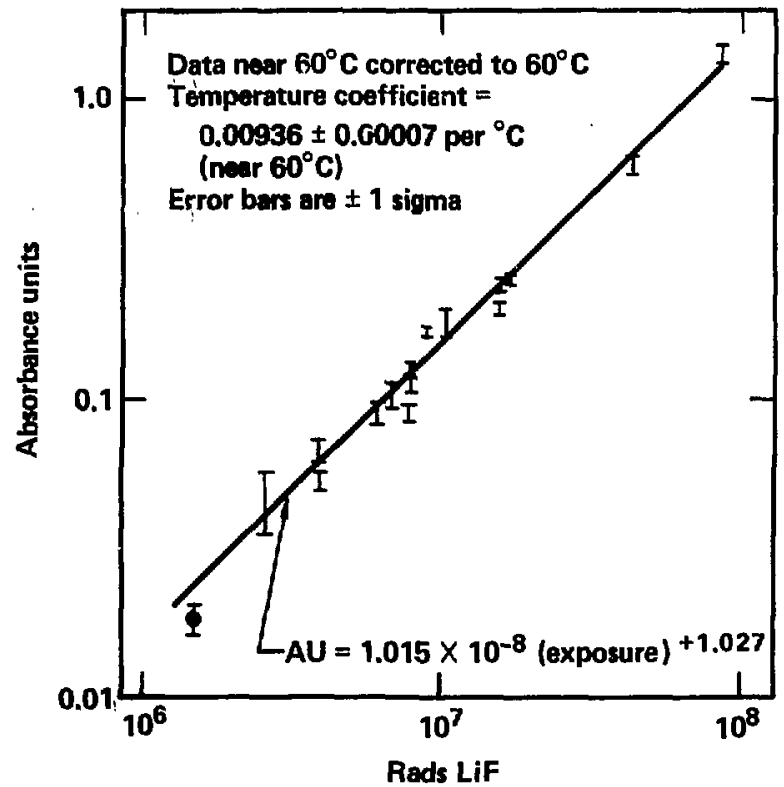




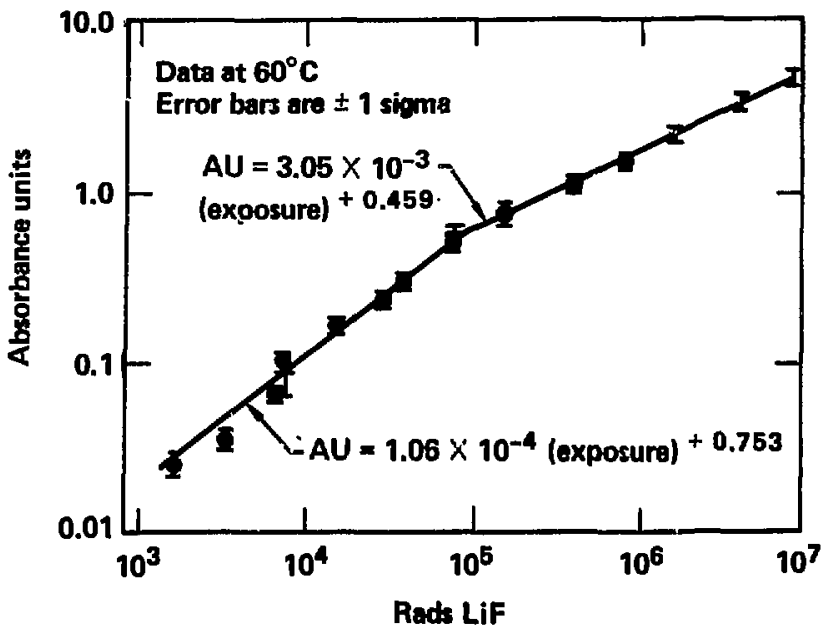

Figure 7. Calibration data for the 247-nm peak, polished LiF, 2-mm thickness (after Quom and DeVore, 1984).

Table 5. The 374-nm calibration data at $60^{\circ} \mathrm{C}$ (after Quam end DeVore, 1984 ).

\begin{tabular}{|c|c|c|c|c|c|}
\hline $\begin{array}{l}\text { Rads-Lif } \\
\text { exposure" }\end{array}$ & $\begin{array}{c}\text { Holder } \\
\text { material }\end{array}$ & $\begin{array}{l}{ }^{+0} \mathrm{Co} \\
\text { nource }\end{array}$ & $\begin{array}{l}\text { Exposure } \\
\text { dave }\end{array}$ & $\begin{array}{l}\text { Beckman } 5270 \\
A U \pm 1 \text { sigma }\end{array}$ & $\begin{array}{l}\text { Dosimeters } \\
\text { per polnt }\end{array}$ \\
\hline $1.55(6)$ & Al & $\mathbf{R S 2}^{\mathbf{b}}$ & Jun 82 & $0.018 \pm 0.002$ & 10 \\
\hline $2.55(6)$ & Al & RS2 & Apr 82 & $0.045 \pm 0.011$ & 2 \\
\hline $3.87(6)$ & Al & RS2 & 2 Jun 83 & $0.065 \pm 0.008$ & 9 \\
\hline $3.87(6)$ & Al & RS2 & Jun 82 & $0.052 \pm 0.003$ & 10 \\
\hline $5.90(6)$ & Al & RS2 & $6 \mathrm{Jun} 83$ & $0.008 \pm 0.006$ & 10 \\
\hline $6.74(6)$ & Al & GIF & 31 Aus 83 & $0.099 \pm 0.006$ & $\mathbf{5}$ \\
\hline $6.00(6)$ & ss & RS2 & 6 Jun 83 & $0.697 \pm 0.011$ & 10 \\
\hline $6.77(6)$ & ss & G1F & 31 Aug 83 & $0.009 \pm 0.006$ & $\mathbf{5}$ \\
\hline $7.74(6)$ & Al & RS2 & Apr 82 & $0.125 \pm 0.002$ & 2 \\
\hline $7.74(6)$ & Al & RS2 & Jun 82 & $0.103 \pm 0.004$ & 10 \\
\hline $7.90(6)$ & Al & RS2 & 31 May 83 & $0.109 \pm 0.004$ & 5 \\
\hline $7.77(6)$ & SS & RS2 & 22 Aug $B 3$ & $0.163 \pm 0.005$ & 5 \\
\hline $1.03(7)$ & Al & RS2 & Apr 82 & $0.178 \pm 0.019$ & 2 \\
\hline $1.55(7)$ & Al & RS2 & Apr 82 & $0.236 \pm 0.006$ & 2 \\
\hline $1.56(7)$ & Al & RS2 & Jun 82 & $0.199 \pm 0.007$ & 10 \\
\hline $1.48(7)$ & SS & G1F & 17 Apr 80 & $0.243 \pm 0.006$ & 1 \\
\hline $3.71(7)$ & ss & G1F & 17 Apr 80 & $0.594 \pm 0.037$ & 3 \\
\hline $7.42(7)$ & ss & G1F & 17 Apr 80 & $1.398 \pm 0.87$ & 1 \\
\hline
\end{tabular}

a $1.55(6)$ means $1.55 \times 10^{6}$, elc.

b EGEG/EM Santa Barbara Operations source array.

' Sandia Corporation source array. 
Table 6. The $247-\mathrm{nm}$ callbration data at $60^{\circ} \mathrm{C}^{2}$ (after Quam and DeVore, 1989).

\begin{tabular}{|c|c|c|c|}
\hline Rodo-1.fF & $\begin{array}{l}\text { c0 Co } \\
\text { source }\end{array}$ & $\begin{array}{l}\text { Beckman 5270 } \\
\text { AU } \pm 1 \text { sigma }\end{array}$ & $\begin{array}{c}\text { IL500 } \\
\mathrm{AU} \pm 1 \text { sigma }\end{array}$ \\
\hline $1.64(3)$ & RS1 & $0.026 \pm 0.004$ & - \\
\hline $3.29(3)$ & RS1 & $0.036 \pm 0.005$ & - \\
\hline $6.5 \%(3)$ & RS1 & $0.066 \pm 0.007$ & - \\
\hline $7.67(3)$ & RS2 & $0.103 \pm 0.006$ & $0.080 \pm 0.016$ \\
\hline $1.53(0)$ & R52 & $0.165 \pm 0.018$ & $0.155 \pm 0.024$ \\
\hline $2.93(4)$ & RS1 & $0.233 \pm 0.025$ & - \\
\hline $3.65 \times(4)$ & RS2 & $0.298 \pm 0.030$ & $0.280 \pm 0.030$ \\
\hline $7.66(4)$ & RS2 & $0.490 \pm 0.050$ & $0.500 \pm 0.050$ \\
\hline $1.53(5)$ & RS2 & $0.704 \pm 0.058$ & $0.780 \pm 0.070$ \\
\hline $3.63(5)$ & RS2 & $1.09 \pm 0.10$ & $1.14 \pm 0.10$ \\
\hline $7.66(5)$ & R52 & $1.49 \pm 0.11$ & $1.55 \pm 0.11$ \\
\hline $1.53(6)$ & RS2 & - & $2.06 \pm 0.14$ \\
\hline $3.63(6)$ & R52 & - & $3.28 \pm 0.14$ \\
\hline $7.66(6)$ & RS2 & - & $4.41 \pm 0.08$ \\
\hline
\end{tabular}

'For all exposures, holder material wat aluminum; 10 dosimeters per point used for all data.

b 1.8 (3) means $1.89 \times 10^{3}$, etc.

peak, Quam and DeVore (1934a) develsped a calibration curve at the proper temperature to eliminate the need for such corrections. Quam and DeVore (1984a) report the overall accuracy of the ${ }^{7} \mathrm{LiF}$ dosimeters as $\pm 11 \%$.

\section{Neutron Dosimeters}

The neutron dosimeters were operated at the lower limit of their usable range of exposures. Quam and DeVore (1982) report that the foil counting rates were very low. Exposure rates were measured to be less than $1.09 \times 10^{-4} \mathrm{rem} / \mathrm{s}$ with overall errors of at least $\pm 30 \%$. Since the gamma dosimeters were confirmed to be insensitive to neutrons [as was indicated in the literature (McLaughlin et al., 1978)], accurate knowledge of neutron dose was relatively unimportant. No further efforts were made to reduce the observed errors or to deploy a more accurate neutron dosimetry technique.

\section{Short-Term Gamma Dosimeters}

An initial 1-h exposure of both $\mathrm{CaF}_{2}$ and $\mathrm{MgB}_{4} \mathrm{O}_{7}$ thermoluminescent dosimeters (TLDs) was conducted on August 13, 1982. Calibrations were made at 60 and $25^{\circ} \mathrm{C}$ for both types of TLDs. The ratios of these calibration values were $1.01 \pm$ 0.085 for the $\mathrm{CaF}_{2}$ TLDs and $1.03 \pm 0.103$ for the $\mathrm{MgB}_{4} \mathrm{O}_{7}$. Therefore, no temperature corrections to the data were required.

The magnesium borate TLD material was selected because of its low- $Z$, which should produce little trouk ie in terms of low energy response, in contrast to the high- $Z$ calcium fluoride TLD, which has a known response problem to energies in the $\sim 80-\mathrm{keV}$ range (Quam and DeVore, 1984b). In addition, it has a relatively hightemperature trap at $200^{\circ} \mathrm{C}$, which should make it more stable at the $60^{\circ} \mathrm{C}$ irradiation temperature. However, the $\mathrm{MgB}_{4} \mathrm{O}_{7}$ dosimetry provided data that steadily decreased in quality during this phase of calibrating and initial field measurements. Therefore, only $\mathrm{CaF}_{2}$ dosimeters were deployed for the second set of short-term measurements. The calibration data and initial field data showed that the stainless steel holders used to encapsulate the dosimeters trimmed the low-energy photons sufficiently so that the response of the two types of TLDs was essentially the same.

The second 1-h exposure used only $\mathrm{CaF}_{2}$ dosimeters in the same design stainless steel holders as are used for long-term dosimetry. A postexposure calibration of each individual TLD chip was performed so that average sensitivity values did not have to be relied upon. In addition, this approach to calibration eliminates the need to make corrections for nonlinearity, which occurs at high exposures. This calibration was performed in a thick aluminum holder, the temperature of which was controlled to the field irradiation temperature of $60^{\circ} \mathrm{C}$. Exposure rates were controlled to be the same as those calculated to occur in the field. Both ${ }^{137} \mathrm{Cs}$ and ${ }^{60} \mathrm{Co}$ sources were used in the calibrations to confirm that TLD response was not 
energy-dependent. Calibration dose rates were measured with a Keithley Modei 616 electrometer and related precision resistors and voltage source. This set of instruments has been shown to be within $1 \%$ of the NBS values at one standard deviation. The standards themselves are $\pm 1-1 / 2 \%$, and Quam and DeVore (1984b) estimate the total system error (including positioning relative to the source) as $\pm 5 \%$.
The short-term gamma dosimeters proved to be an important adjunct to the originally planned long-term dosimeters. The calcium fluoride TLDs exhibited better accuracy and, because exposure times were short, could be post-exposure calibrated in a manner that eliminates the uncertainties associated with the long-term dosimeters.

\section{Temperature Sensors}

\section{Resistance Temperature D. rices}

RTDs were selected to measure the temperature of thermocouple reference-junction isothermal blocks and to be used as system standards to verify the quality of four-wire resistance measurements made by DMMs. The reference block RTDs experienced temperatures in the range of 18 to $40^{\circ} \mathrm{C}$ at relative humidities of 50 to $70 \%$. One RTD was immersed in a Kaye icebath to provide a system standard as noted in the "Data Acquisition System" section. Standard, industrial-grade platinum Degussa Model 2101 RTDs were procured from C. S. Gordon, Co. for these applications (Brough and Patrick, 1982).

\section{Calibration}

Pre- and post-test laboratory calibrations of the RTDs were performed using HP3455A digital multimeters, a Kaye Instruments Model 374 temperature probe, a Rosemount Co. Model 911A1 calibration bath, a Kaye Instruments Model UTRAS isothermal reference block, and a Delta Design Model $6400 \mathrm{C}$ environmental chamber. Values of $R_{0}$ were established at $0^{\circ} \mathrm{C}$, and calibrations were obtained at temperatures of approximately 23 anc. $38^{\circ} \mathrm{C}$. The results of these calibrations are provided in Table 7.

Table 7. Results of pre- and post-test laboratory calibration of RTD's.

\begin{tabular}{lccccr}
\hline & \multirow{2}{*}{$\begin{array}{c}\text { Number } \\
\text { Calibration }\end{array}$} & \multicolumn{3}{c}{ Calibration errors $\left({ }^{\circ} \mathrm{C}\right)$} \\
\cline { 3 - 6 } \\
\cline { 4 - 6 }
\end{tabular}

\section{Exror Analyole}

The algorithm for calculating temperature from resistance is of the form

$T=\frac{\left[\left(A^{2}-4 B\left(1-\frac{R}{R_{0}}\right)\right)^{1 / 2}-A\right]}{2 B}$,

where

$A$ and $B$ are coefficients provided by the manufacturer,

$R_{0}$ is the $0^{\circ} \mathrm{C}$ resistance of the RTD,

$R$ is the measured resistance of the RTD at temperature $\mathrm{T}$.

The sensitivity factors are calculated by differentiating Eq. (2) with respect to each of the two resistances:

$$
\begin{aligned}
& \theta_{R_{0}}=\frac{d T}{d R_{0}}=-\frac{R}{R_{0}^{2}}\left[A^{2}-4 B\left(1-\frac{R}{R_{0}}\right)\right]^{-1 / 2} \\
& g_{R}=\frac{d T}{d R}=\frac{\left[A^{2}-4 B\left(1-\frac{R}{R_{0}}\right)\right]^{-1 / 2}}{R_{0}} .
\end{aligned}
$$

For an error in resistance $R_{0}$ of $0.010 \Omega$, temperature errors of $0.026^{\circ} \mathrm{C}$ (at $0^{\circ} \mathrm{C}$ ) and $0.030^{\circ} \mathrm{C}$ (at $40^{\circ} \mathrm{C}$ ) are calculated using Eq. (3). Likewise, for an error in resistance $R$ of $0.611 \Omega$, temperature errors of $0.028^{\circ} \mathrm{C}$ occur in the range of 0 to $40^{\circ} \mathrm{C}$. Combining these two sources of error gives a maximum roor-qum-square* (RSS) uncertainty in temperature that ranges from $0.038^{\circ} \mathrm{C}$ (at $0^{\circ} \mathrm{C}$ ) to $0.041^{\circ} \mathrm{C}$ (at $40^{\circ} \mathrm{C}$ ).

\footnotetext{
- This calculation squares each individual error, sums these squares, and takes the square root of the resulting sum.
} 


\section{Relinbility}

All 20 RTDs functioned reliably throughout the period of deployment.

\section{Thermocouples}

Type K Chromel-Alumel thermocouples (TCs) were selected as the principal temperature measuring device for the SFT-C and were procured from C. S. Gordon, Co. These devices were sheathed in Inconel 600 with $\mathrm{MgO}$ insulation, and each TC junction was grounded to its sheath.

As described by Brough and Patrick (1982), thermocouples were deployed under a variety of operating conditions for periods of up to $3-1 / 2$ years. Temperaiure environments ranged from an amlient $23^{\circ} \mathrm{C}$ in far-field applications (Fig. B) to abolit $450^{\circ} \mathrm{C}$ on the electric heaters (Fig. 9). A combination of temperatures up to $145^{\circ} \mathrm{C}$ and intense ionizing radiation up to $50,000 \mathrm{rad} / \mathrm{hov}$ r were present near the spent-fue? assemblies (Fig. 10). Depending on location within the test facility, relative humidity ranged from about $\mathbf{5 0}$ to $100 \%$. Many TCs were in contact with the chloride- and sulphate-rich groundwater (Isherwood et al., 1982).

Most TCs were installed in guide tubes so that they could be removed for field calibration using the central DAS. Pre- and post-test calibrations of all these units were conducted. A total of $56 \mathrm{TCs}$ were permanently located in borehole extensometers. Therefore, only pretest laboratory calibrations were conducted for these units.

\section{Calibration}

Field calibrations were conducted at temperatures appropriate to the application of the individual TC. A Rosemount Model 911A1 ice bath was used for $0^{\circ} \mathrm{C}$, a Kaye Model HTR150 temperature reference for 50 and $100^{\circ} \mathrm{C}$, and a Procedyne Model TH050 dry bath for the $150^{\circ} \mathrm{C}$ measurements. Actual bath temperatures were measured with laboratory-calibrated RTDs that were scanned in sequence with the TCs.

The results of the pre- and post-test calibrations are displayed in Figs. 11 through 14. Three thermocouples were found to operate outside the $\pm 1.1^{\circ} \mathrm{C}$ ISA special limits of error. Most of the thermocouples were deployed where temperatures were in the range of 20 to $60^{\circ} \mathrm{C}$. As indicated by the calibration results, errors in this temperature range are generally limited to $\pm 0.25^{\circ} \mathrm{C}$ and are symmetrically distributed at around $0^{\circ} \mathrm{C}$. However, at higher temperatures, such as those observed in canisters, liners, and heaters, the errors become somewhat larger and are skewed toward positive values.

\section{Error Analysis}

Temperature and TC voltage are related by the equation

$T=A_{0}+A_{1} V+A_{2} V^{2}+A_{3} V^{3}+A_{4} V^{4}$,

where $A_{i}$ are constants calculated from the NBStabulated values of voltage vs temperature (Powell et al., 1974), and

$V=V_{R}+B_{1} T_{k}+B_{2} T_{R}^{2}+B_{3} T_{k}^{3}$,

where

$V_{k}$ is the thermocouple voltage at the reference block,

$T_{R}$ is the reference block temperature recorded by an RTD,

$B_{1}$ are constants provided by the NBS (Powell et a!., 1974).

Equation (6) cortains three sources of error. First, the NBS documents (Powell et al, 1974) that the conversion of RTD temperature to equivalent thermocouple voltage is accomplished with an accuracy of -0.06 to $+0.14 \mu \mathrm{V}$ in the range 0 to $50^{\circ} \mathrm{C}$. Second, error in the RTD temperature was calculated to be about $\pm 0.04^{\circ} \mathrm{C}$ in this range (see previous section). The voltage equivalent of this error is $\pm 1.67 \mu \mathrm{V}$. Third, the TC voltage reading at the reference block has an associated error in the range of 4.00 to $4.42 \mu \mathrm{V}$ for temperatures between 40 and $200^{\circ} \mathrm{C}$. The RSS error for these three error sources is at most $4.73 \mu \mathrm{V}$.

Equation (5) contains two sources of error, that are due to the total RSS voltage error and residual errors in the temperature vs voltage equation. Differentiating Eq. (5) with respect to voltage, we have

$\theta_{V}=\frac{d T}{d V}=A_{1}+2 A_{2} V+3 A_{3} V^{2}+4 A_{4} V^{3}$

The higher order terms are very small so the equation may be evaluated using the NBStabulated values of $A_{1}$ (Powell et al., 1974) and the RSS voltage errors calculated above. The maximum uncertainty in temperature resulting from these errors is calculated to be $\pm 0.12^{\circ} \mathrm{C}$.

Residual errors in the temperature vs voltage equation wore minimized by fitting quartics to four segments of the temperature range of interest. Initial break points were selected at 100,200 , 

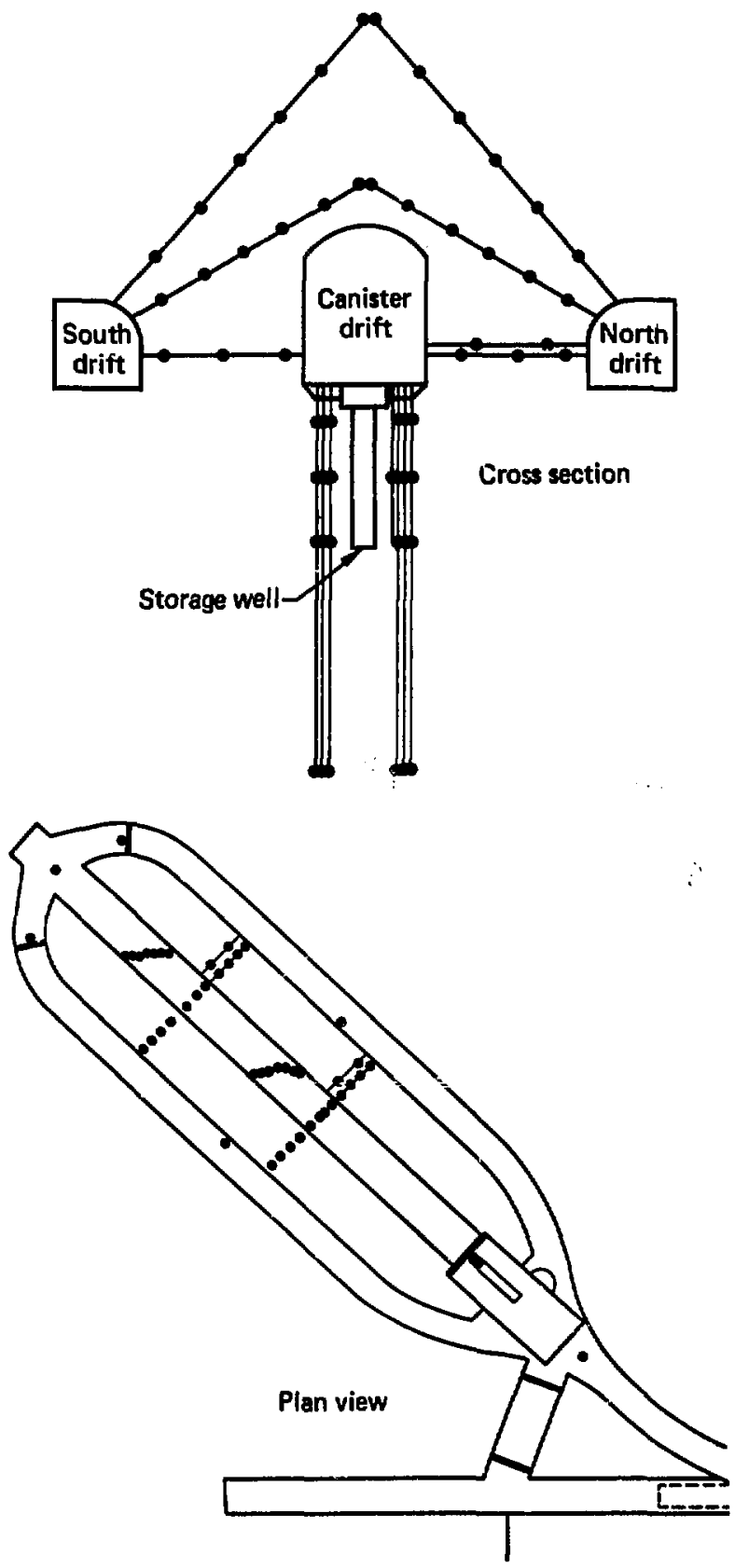

Figure 8. Intermediate- and far-tield thermocouples. Locations in the storage facility are indicated by dots. 


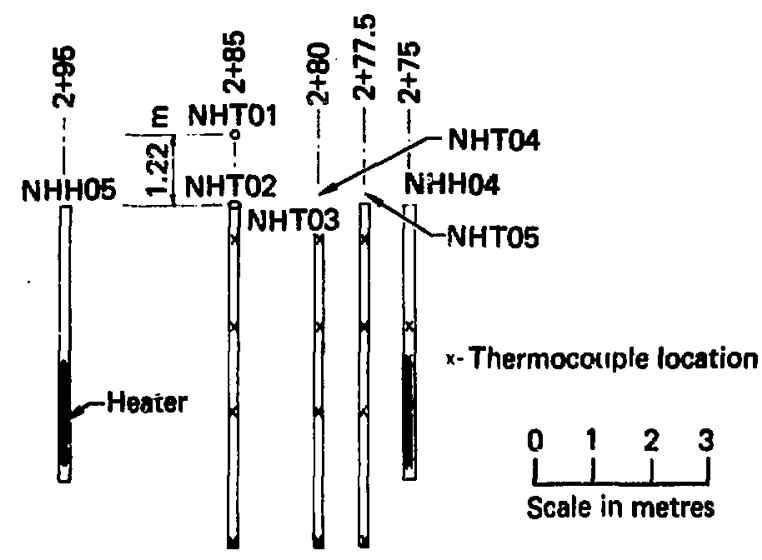

Longitudinal view

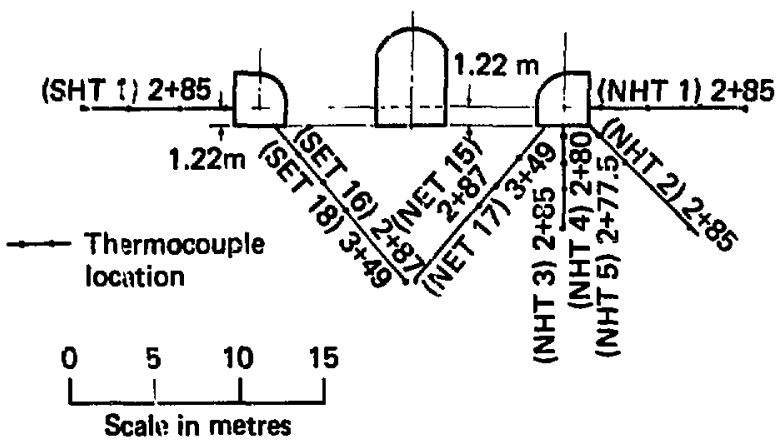

Axial view

Figure 9. Additional intermediate-field thermocouple locations associaterl with auxiliary heaters.

400 , and $1000^{\circ} \mathrm{C}$. Best-fit quartics were then obtained for NBS-tabulated paired values of temperature and voltage (Powell et al., 1974). The break points were then adjusted to coincide with the intersections of adjoining quartics, thus providing a smeoth transition in the errors. The adjusted break points are 96.49, 200.39, 407.21; and $1000^{\circ} \mathrm{C}$. Residual errors for the four segments were calcuiated to be $0.0004,0.0023,0.0102$, and $0.02^{\circ} \mathrm{C}$, resfectively. These are minor cuntributions to the RSS error calculated above.

\section{Reliability}

The TCs performed reliably throughcut the measurement period. Performance was evaluated on a continuing basis during the SFT $-C$ by means of a loop-resistance check and through the DAS alarm system. The resistance checks were conducted on all TCs at about 6-month intervals. Comparison of the current resistance with the pretest value served as a guide in determining if moisture was invading the TC or if the wire connections at the zone box were degrading. Such problems did occur and were promptly corrected by reterminating and drying the TC or by cleaning and tightening the reference block connections, respectively. The DAS alarin system, which was described previously, also provided for prompt recognition and correction of such prcblems. Since anticipated temperatures were well known, 


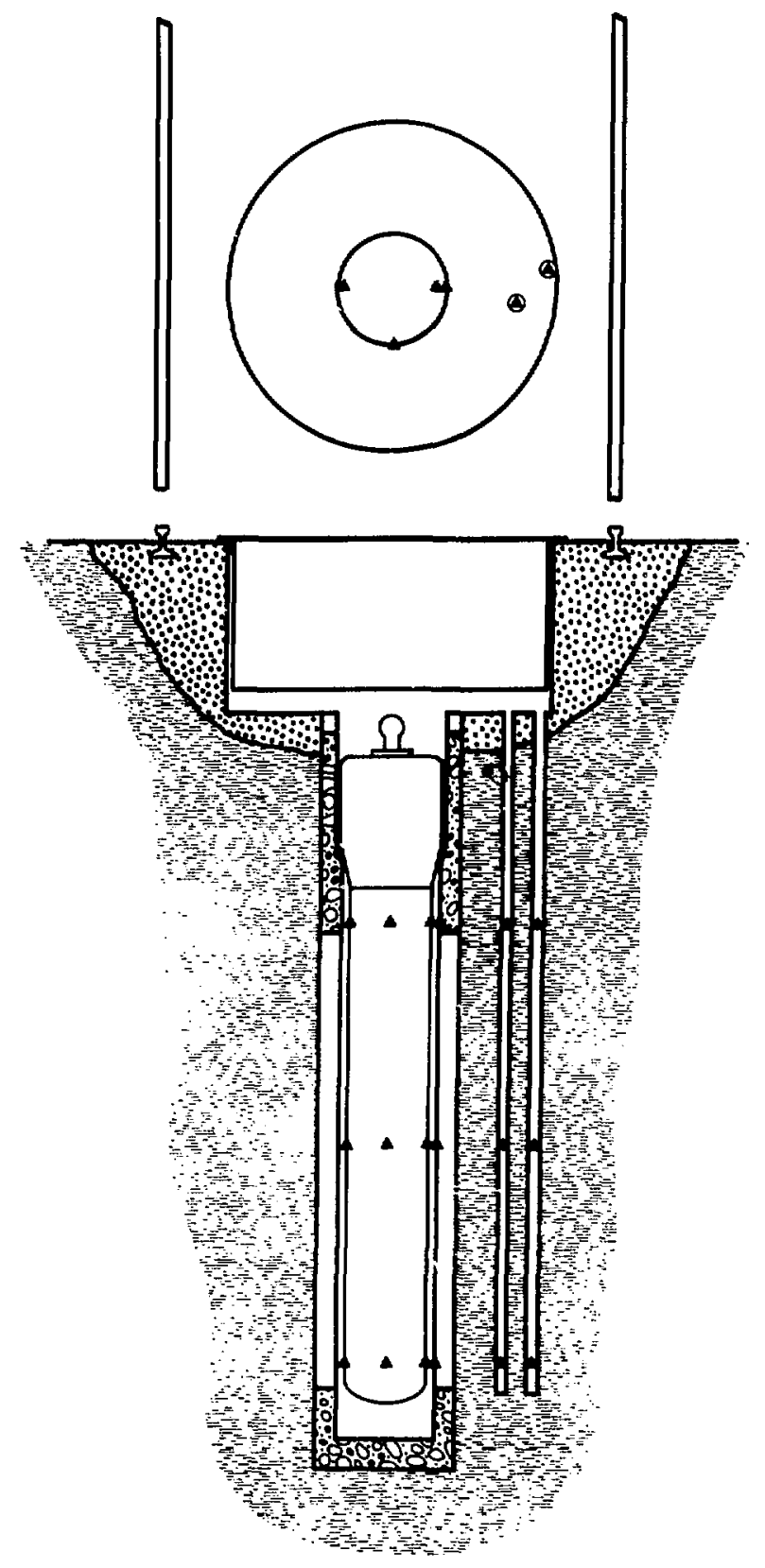

Figure 10. Near-field thermocouples. Locations are designated with triangles. 
Figure 11. Thermocouple callbration results at $0^{\circ} \mathrm{C}$.

Figure 12. Thermocouple calibration results at $50^{\circ} \mathrm{C}$.

Figure 13. Thermocouple callbration results at $100^{\circ} \mathrm{C}$.

Figure 14. Thermocouple callbration results at $150^{\circ} \mathrm{C}$.
Pretest (open) and post-test (stippled) thermocouple calibration
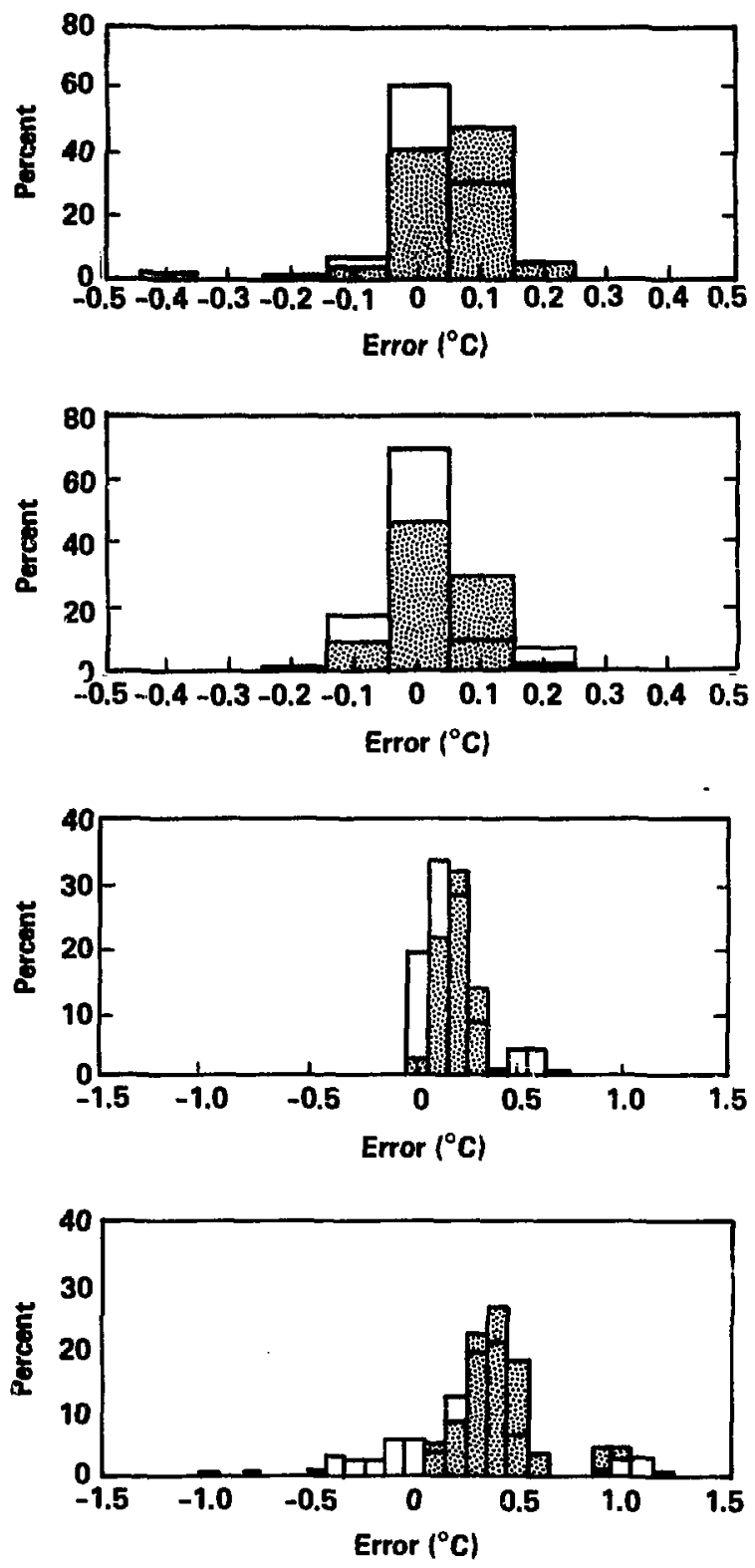
based on thermal calculations, alarm limits were set quite narrow. As a result, problems (which were expressed as temperatures that were out of expected limits) were quickly observed and corrected.

Four thermocouple sheaths were found to be corroded when they were recovered for post-test calibrations. However, none of these units exhibited abnormal behavior in service. All four were located in spent-fuel storage boreholes. Three (SLT 144, SLT 164, and SLT 166)" were located on the outer surface of emplacement borehole liners where temperatures were in the range of 80 to $100^{\circ} \mathrm{C}$ and radiation doses were about $2 \times 10^{8} \mathrm{rad}$ for the 3-year storage period. The fourth TC (CDT $035)^{+}$was likewise in this environment for three years (as SLT 036), was subsequently deployed for an additional six months to monitor the temperature of a borehole deformation gauge, and was found to be corroded after the second deployment. Temperatures decreased from about 60 to $30^{\circ} \mathrm{C}$ during this second period.

Metallurgical analyses of the corroded TC sheaths revealed that two were Inconel 600 , as specified, but the other two were 304-series stainless steel. We speculate that the latter units were erroneously sheathed in the manufacturing process. The extent of the problem of incorrect sheathing was not confirmed by further sampling and testing because none of the remaining TCs exhibited either corrosion or any othe: problem.

\section{Thermistors}

Two arrays of thermistors were deployed within the canister storage drift to document nonuniformities in the air temperature distribution. Nominal 340-k $\Omega$ YSI Model 44014 thermistors were attached to two large crosses that were constructed from sections of $19-\mathrm{mm}$-diam PVC pipe. The crosses were positioned so that five temperature measurements could be obtained along both vertical and transversely horizontal axes of the drift cross section. Nine thermistors were used at each of two locations in the drift (the center thermistor was common to the vertical and horizontal profiles). In addition, anether thermistor was located on the outer surface of a NEMA enclosure containing TC reference blocks to provide

\footnotetext{
- SLT xxx is the instrument designator for storage borehole liner thermocouples.

' CDT $x \times x$ is the instrument designator for canister emplacement borehole deformation gauge thermocouple.
}

a comparison between temperatures recorded by the thermistor and the RTDs. Temperatures in the ventilation airstream varied from about 18 to $40^{\circ} \mathrm{C}$ during the SFT-C, with temperatures near $30^{\circ}$. most of the time.

\section{Calibration}

Pretest calibrations were performed at a nominal $23^{\circ} \mathrm{C}$ ambient temperature and post-test calibrations were performed at nominal temperatures of 19,23 , and $30^{\circ} \mathrm{C}$. All calibrations were performed in the laboratory using an Instrulab Model 841-12 temperature sensor, an Instrulab Model 4202-13-1506 temperature monitor, and a Fluke Model 8B60A DMM. Accuracy of the temperature sensor is $\pm 0.02{ }^{\circ} \mathrm{C}$, and accuracy of the DMM is $\pm 0.014 \%$ of reading plus three counts. All calibrations were performed with lead wires and cabling attached to the thermistors. Calibration results, which were obtained using Eq. (8) to calculate temperatures from resistance readings, are shown in Table 8.

The thermistor calibrations show that both the mean errors and the standard deviations of those errors have increased substantially between the time of pretest calibrations in May 1981 and post-test calibrations in December 1983. However, examination of individual calibration records shows that only one thermistor had an error outside the desired $\pm 0.1^{\circ} \mathrm{C}$ window at $30^{\circ} \mathrm{C}$, and none had an error this large at $23^{\circ} \mathrm{C}$.

\section{Error Analysis}

The algorithm for calculating temperature from resistance is

$$
T=A_{0}+A_{1} R+A_{2} R^{2}+A_{3} R^{3}+A_{4} R^{4} .
$$

where

$A_{i}$ are coefficients of the polynomial, $R$ is the thermistor resistance.

The sensitivity factor is calculated by differentiating Eq. (8) with respect to resistance, such that

$\Theta_{R}=\frac{d T}{d R}=A_{1}+2 A_{2} R+3 A_{3} R^{2}+4 A_{4} R^{3}$.

The maximum RSS uncertainty in temperature is calculated by evaluating this equation for appropriate values of $R\left(423.2 \mathrm{k} \Omega\right.$ at $18^{\circ} \mathrm{C}$ to $149.4 \mathrm{k} \Omega$ at $40^{\circ} \mathrm{C}$ ) and $A_{\mathrm{i}}$. The maximum error in resistance reading in this range is about $55 \Omega$, giving a maximum uncertainty in temperature of $0.022^{\circ} \mathrm{C}$. 
Table B. Reaults of pre- and post-test labora'cory calibration of YSI Model 44014 thermistors.

\begin{tabular}{|c|c|c|c|c|}
\hline \multirow[b]{2}{*}{ Calibration $\left({ }^{\circ} \mathrm{C}\right)$} & \multirow{2}{*}{$\begin{array}{l}\text { Number } \\
\text { calibrated }\end{array}$} & \multicolumn{3}{|c|}{ Calibration errors $\left({ }^{\circ} \mathrm{C}\right)$} \\
\hline & & Mean & Std dev & Range \\
\hline Preteat, mean temp. $=22.55$ & 19 & 0.006 & 0.005 & -0.0087 to 0.0205 \\
\hline Post-test, mean temp. $=19.13$ & 18 & 0.091 & 0.036 & 0.048 to 0.138 \\
\hline Posl-test, mean temp. $=22.73$ & 18 & 0.015 & 0.032 & -0.046 to 0.078 \\
\hline Post-teat, mean temp. $=29.58$ & 18 & -0.019 & 0.114 & -0.437 to 0.086 \\
\hline
\end{tabular}

\section{Reliability}

Nineteen thermistors were deployed in the two arrays. All functioned without failure during the measurement period. One lead wire was broken at the thermistor bead during handling and could not be repaired for post-test callbration.

\section{Convergence Wire Temperature Monitors}

Convergence wire extensometers (CWEs) are long-gauge-length, removable instruments capable of accurately measuring relative displacements across mined underground openings. Because the $0.635-\mathrm{mm}$-diam connecting wire used on this instrument changes length with changes in temperature, it was necessary to develop a technique capable of measuring the average temperature of stainless steel wires 2.9 to $8.0 \mathrm{~m}$ long.

The convergence wire temperature monitors (CWTs) operate on the same principal as RTDs. Two small metal clamps attached near the end points of the stainless steel wire are in turn attached to two pairs of lead wires, one of which provides a known pulsed current while the other measures the voltage drop across the wire. Thus, a four-wire resistance measurement is made. Knowing the temperature coefficient of resistance and an initial wire resistance at a known temperature, it is possible to calculate an average wire temperature. Sequential CWT measurements are used to calculate changes in temperature that in turn are used to calculate the thermal expansion of the wire.

\section{Temperature Coefficient of Resistance}

To use the four-wire measurement technique, it is necessary to know the relationship between changes in resistance and changes in temperature of the wire material. A search of the literature for available data revealed that the temperature coefficient of resistance varied widely among steel alloys from 0.0001 to $0.005 /{ }^{\circ} \mathrm{C}$.
Given this high variability, we developed a simple test fixture to determine the temperature vs resistance relationship for the 304 stainless steel wire used for the CWEs (Fig. 15). A $5.5-\mathrm{m}$ long section of the wire was wrapped in loops over two plastic spools mounted on opposite ends of a flat plate. The wire was arranged in a spiral so that the loops did not contact each other, and provision was made to dead-weight-load the wire. Thermistors were attached in three locations on the wire and the entire assembly was placed in a muffle oven where temperatures were cycled between 18 and $40^{\circ} \mathrm{C}$ with simultaneous thermistor and wire resistance readings at selected temperatures. The process was repeated for both the unloaded and dead-weight-loaded configurations. After normalizing the resistance readings with respect to wire length, the slope of the resulting line through the data was $480 \mathrm{~m} \cdot{ }^{\circ} \mathrm{C} / \Omega$.

To determine average wire temperat' ire, the following equation is applied:

$\mathrm{T}=\left[\mathrm{T}_{0}-\frac{\dot{\mathrm{T}} \mathbf{R}_{0}}{\mathrm{~L}}\right]+\frac{\dot{\mathrm{T}}}{\mathrm{L}} \mathbf{R}$,

where

$\mathrm{T}$ is the present wire temperature, ${ }^{\circ} \mathrm{C}$,

$T_{n}$ is the reference temperature at which $R_{0}$ is measured, ${ }^{\circ} \mathrm{C}$,

$\dot{T}$ is the slope of the temperature-resistance line, $480 \mathrm{~m} \cdot{ }^{\circ} \mathrm{C} / \Omega$,

$R_{0}$ is the reference resistance at temperature $T_{0}, \Omega$,

$R$ is the present wire resistance as determined by a four-wire measurement, $\Omega$, and

$\mathrm{L}$ is the wire length between the current/ voltage probes, $m$.

\section{Calibration}

The individual wires were calibrated in isothermal containers constructed of two overlapping cardboard boxes lined with low-density styrofoam blocks about $70 \mathrm{~mm}$ thick. The wires 


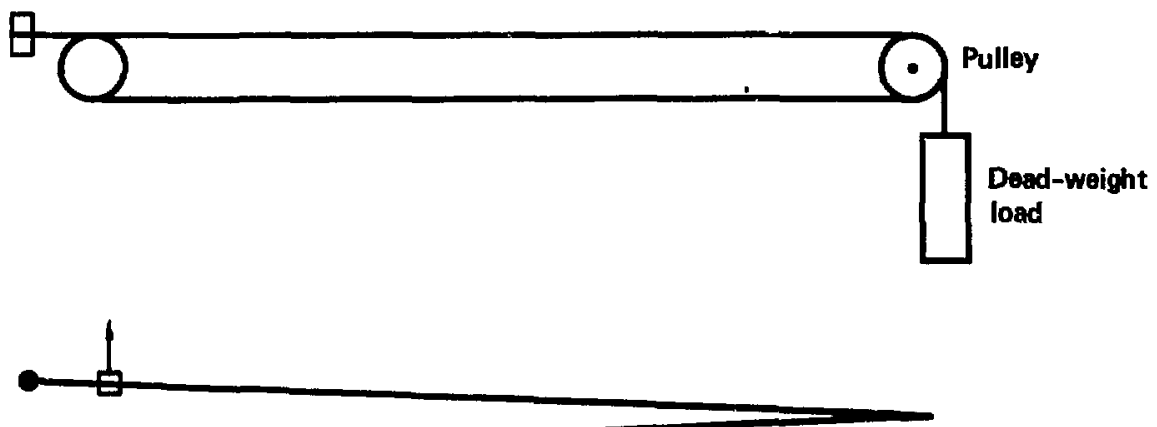

1. $20 \mathrm{ft}(6.1 \mathrm{~m})$ of $304 \mathrm{~B} \mathrm{SS}$ wire

2. Place clips at $18 \mathrm{ft}(5.5 \mathrm{~m})$ separation

3. Themistor monitors for temp ( 3 places)

4. Place coil unstressed in oven

5. Repeat with stressed configuration

0.025 in

$(0.635 \mathrm{~mm})$ diameter
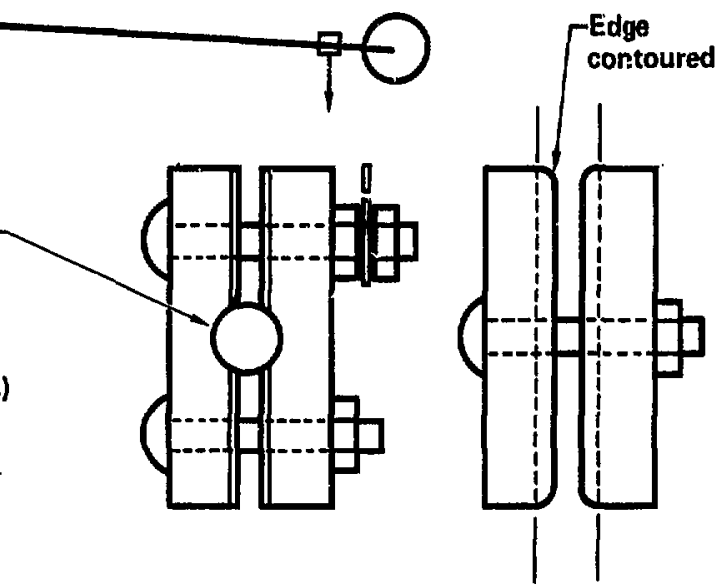

Figure 15. Sketch of calibration fixture for the convergence wire temperature monitor.

coiled naturally into circles about $0.2 \mathrm{~m}$ in diameter when removed from the CWE and the individual loops of each coil were insulated, using either plastic sheets or tubing, to prevent shorting during the calibration process. Two YSI Model 44014 thermistors were placed at diametrically opposite positions on the coil, and the insulated box was closed and sealed for about 12 hours. Once the temperature within the box became uniform and stable, the thermistors and CWT resistance were recorded. An equilibrium value of $R_{0}$ was thus obtained at a singie known temperature $T_{0}$.

Since the values of $T$ and $L$ in Eq. (10) may be assumed to be constants for a given wire (at least for the short duration of a calibration), determination of only the first term of the equation was required, and the single-temperature calibration procedure outlined above was adequate. This approach thus assumes the slope $\dot{T} / L$ to be constant and checks for changes in the offset cotstant (intercept), $\mathrm{T}_{0}-\mathrm{TR}_{0} / \mathrm{L}$. Table 9 provides the measured changes in offset constant that occurred between the pre-installation February 1982 calibration and the post-test February 1984 calibration. Because errors are a function of wire length, the CWTs are treated in three groups. Note that while the average errors are acceptably small, individual errors in some cases approached or exceeded $0.5^{\circ} \mathrm{C}$.

\section{Error Analysis}

Four potential sources were identified that together produce the calibration errors reported above: the coefficient $\dot{\mathrm{T}}$, wire length, thermistor 
Table 9. Measured errors resulting irom changes in offuet constant during the two-year period of deployment of convergence wire temperature monitors.

\begin{tabular}{|c|c|c|c|c|}
\hline \multirow{2}{*}{$\begin{array}{l}\text { Wire length } \\
\text { (m) }\end{array}$} & \multirow{2}{*}{$\begin{array}{l}\text { Number } \\
\text { callibrated }\end{array}$} & \multicolumn{3}{|c|}{ Errore $\left({ }^{\circ} \mathrm{C}\right)$} \\
\hline & & Mein & Std der & kange \\
\hline 2.9 to 3.5 & 18 & -0.101 & 0.354 & -0.814 to 0.429 \\
\hline 4.6 to 5.9 & 11 & -0.090 & 0.219 & -0.426 to 0.784 \\
\hline 8.0 & 1 & -0.248 & $\mathbf{N M F}^{\mathbf{n}}$ & $\mathbf{N M F}^{\mathbf{a}}$ \\
\hline
\end{tabular}

'No meaningful figure.

temperature reading, and the resistance reading The coefficient $t$ is first analyzed separately because it is itself a function of several sources of error:

$\dot{\mathrm{T}}=\frac{\mathrm{T}^{*} \mathrm{~L}^{*}}{\mathrm{R}^{*}}$

where

$\mathrm{T}^{*}$ is the calibration temperature, ${ }^{\circ} \mathrm{C}$,

$L^{*}$ is the length of the calibrated wire, $m$, ana $R^{*}$ is the calibration resistance, $\Omega$.

The sensitivity factors for $\mathrm{T}$ are calculated by differentiating Eq. (11) with respect to its three components

$$
\theta_{\mathrm{L}}=\frac{\mathrm{dT}}{\mathrm{dL}}=\frac{\mathrm{T}^{*}}{\mathrm{R}^{*}}
$$

for errors in wire length,

$$
\theta_{T}=\frac{d T}{d T}=\frac{L^{*}}{R^{*}}
$$

for errors in temperature measured by the thermistor,

$\boldsymbol{\theta}_{\mathrm{R}}=\frac{\mathrm{d} \dot{\mathrm{T}}}{\mathrm{dR}}=-\frac{\mathrm{T}^{*} \mathrm{~L}^{*}}{\mathrm{R}^{* \mathbf{2}}}$

For errors in wire resistance.

The maximum RSS uncertainty of the value of $\dot{T}$ is calculated to be $8.836 \times 10^{-2}{ }^{\circ} \mathrm{C} \cdot \mathrm{m} / \Omega$. Maximum individual sources of error were (a) wire length, $\pm 1.5 \mathrm{~mm},(b)$ temperature $\pm 0.2^{\circ} \mathrm{C}$, and $(c)$ resistance, $\pm \ldots \ldots$

Sensitivity factors for $\mathrm{T}$ may be calculated by cifferentiating Eq. (10) with respect to each of the four error sources. Ignoring the slope term for reasons outlined above, we calculate $\theta_{\dot{\tau}}=\frac{d T}{d T}=-\frac{R_{0}}{L}$,

for errors in the coefficient;

$\theta_{1}=\frac{d T}{d L}=\frac{T_{0}}{L^{2}}$,

for errors in the wire length;

$\boldsymbol{\theta}_{\mathrm{T}_{1}}=\frac{\mathrm{dT}}{\mathrm{dT}_{0}}=1$

for errors in temperature measured by the thermistor;

$\boldsymbol{\theta}_{\mathrm{R}_{3}}=\frac{\mathrm{dT}}{\mathrm{dR}_{\mathrm{q}}}=-\frac{\dot{\mathrm{T}}}{\mathrm{L}}$.

for errors in wire resistance.

The maximum uncertainty of the calibration is calculated for each of the three classes of CWTs by obtaining the product of the sensitivity factor and its associated maximum error. Maximum errors wore (a) coefficient determination, $\pm 8.84 \times$ $10^{-2}{ }^{\circ} \mathrm{C} \cdot \mathrm{m} / \Omega$; (b) length measurement, $\pm 1.5 \mathrm{~mm}$; (c) temperature measurement, $\pm 0.2^{\circ} \mathrm{C}$ (see the section entitled "Thermistors"); and (d) resistance measurement, $\pm 5 \mathrm{~m} \Omega$.

Table 10 presents the uncertainty for each source of error and the resulting composite uncertainty that was calculated as the RSS of the four uncertainties. These calculated errors agree favorably with those observed during calibrations (Table 9).

The error analysis may be extended to operation of the CWTs in the field where the slope term in Eq. (10) becomes operational. The sensitivity factors are now

$\Theta_{\dot{T}}^{\prime}=\frac{d T}{d T}=-\frac{R_{0}}{L}+\frac{R}{L}=\frac{R-R_{0}}{L} ，$

$\boldsymbol{\theta}_{\mathrm{L}}^{\prime}=\frac{\mathrm{dT}}{\mathrm{dL}}=-\frac{\dot{\mathrm{T}}}{\mathrm{L}^{2}}\left(\mathbf{R}-\mathbf{R}_{\mathrm{0}}\right)$,

$\Theta_{T_{0}}^{\prime}=\frac{d T}{d_{0}}=1$

$\theta_{\mathrm{R}}^{\prime}=\frac{\mathrm{dT}}{\mathrm{dR}}=\frac{\dot{\mathrm{T}}}{\mathrm{L}}$.

Note that the value of Eq. (18a) differs from Eq. (18) only in sign. This result occurs because $R$ 
Table 10. Calculated errors in offeet constant associated with calibration of convergence wire ters. perature monitors.

\begin{tabular}{cccccc}
\hline \multirow{2}{*}{$\begin{array}{c}\text { Wire length } \\
\text { (m) }\end{array}$} & Coefficient $\dot{\mathrm{T}}$ & $\begin{array}{c}\text { Length } \\
\text { measurement }\end{array}$ & $\begin{array}{c}\text { Thermitor } \\
\text { temperature }\end{array}$ & $\begin{array}{c}\text { Resistance } \\
\text { reading }\end{array}$ & RSS \\
\cline { 2 - 6 } & 0.900 & 0.520 & 0.200 & 0.824 & 1.015 \\
4.9 to 3.5 & 0.200 & 0.306 & 0.200 & 0.506 & 0.655 \\
B.0 5.9 & 0.200 & 0.203 & 0.200 & 0.354 & 0.496 \\
\hline
\end{tabular}

Table 11. Calculated total errors associated with field deployment of convergence wire temperature monitors.

\begin{tabular}{|c|c|c|c|c|c|}
\hline \multirow[b]{2}{*}{$\begin{array}{l}\text { Wire length } \\
\text { (m) }\end{array}$} & \multicolumn{5}{|c|}{ Source and magnilude of error $\left({ }^{\circ} \mathrm{C}\right)$} \\
\hline & Coefficient $T$ & $\begin{array}{c}\text { Length } \\
\text { medsurement }\end{array}$ & $\begin{array}{l}\text { Thernistor } \\
\text { temperature }\end{array}$ & $\begin{array}{l}\text { Resiniunce } \\
\text { reading }\end{array}$ & kss \\
\hline 2.9 to 3.5 & $0.0 \mathrm{~ns}$ & 0.011 & 0.200 & 0.824 & 0.48 \\
\hline 4.6105 .9 & 0,004 & 0.006 & 0.200 & 0.506 & 0.54 \\
\hline 8.0 & 0.004 & 0.004 & 0.200 & 0.354 & 0.407 \\
\hline
\end{tabular}

is not present during calibration and $R_{0}$ is present but is a constant (the derivative of which is zero) during field deployment of the instruments. Values of $R-R_{0}$ were calsulated using average values of $T / L$ over the temperature range of 18 to $40^{\circ} \mathrm{C}$ observed in the field. Table 11 presents the maximum uncertainty for each error source and for the RSS error. Note that the RSS errors during field deployment of the CWTs are less than the RSS errors associated with calibration because the errors associated with the coefficient $\dot{T}$ and wire length are partially self-compensating.

\section{Reliability}

The 32 CWT units deployed at the SFT-C functioned reliably throughout the monitoring period with one exception. CWT011 was located across a fault zone where the rock and clay gouge were very moist and pyrite was plentiful. These conditions produced a small battery that caused current to pass through the wire. As a result, variations in the apparent resistance of the wire made this CWT unusable. This observation indicates a need to insulate the CWE wire from the rock mass in applications where the rock is an insufficient dielectric medium or where ratural "batteries" may be present.

During calibration, one of the metal clamps used to connect electrical lead wires to the stainless steel wire siipped on CWEO11 and CWE0:31, resulting in calibration errors of several degrees. Calculated errors associated with replacing the slipped clamps range from about 0.2 to $0.5^{\circ} \mathrm{C}$, assuming that contact resistance renained unchanged or small.

\section{V. ntilation System Instrumentation}

It was necessary to control the ventilation of the underground space to maintain a safe, habitable working environment while not extracting so much thermal energy that the rock would not attain realistic temperatures. Pretest calculations (Montan and Patrick, 1981) indicated that without ventilation, air temperatures would reach about $60^{\circ} \mathrm{C}$ during the test. These calculations also showed that a modest air flow would limit air temperatures to about $40^{\circ} \mathrm{C}$ and remove about $13 \%$ of the total energy deposited during the test.

It was necessary to monitor the energy removal so that the ventilation model could be evaluated and so that the general heat transfer model could be modified as necessary to account for the loss of energy from the test environment. Instrumentation was deployed vo measure air temperature, dewpoint, and ventilation flowrate. 
During the spent-fuel storage phase of the test, all air flow occurred throigh a single exhaust port: the canister access shaft. Flow was regulated in the three drifts by means of bulkheads and louvers (Patrick and Mayr, 1981). Following spentfuel retrieval, an additional exhaust port was added to each heater drift to expedite cooling of the rock mass surrounding the facility. Ventilation system instrumentation was deployed for each of these phases of the test.

\section{Air Temperature}

Type $K$ thermocouples sheathed in Inconel 600 were positioned at the trifurcation of the heater drifts and canister drift, at the ventilationcontrol bulkheads at the far ends of the two heater drifts, at the heater drift midpoints, and at the far end of the canister drift where the canister access shaft intersects the roofline. This last location is where the ventllation air exits the facility. In addition, a thermocouple was located at the inlet of each of two exhaust tubes used to expedite cooling of the facility following spent-fuel retrieval.

Thermocouples measure the so-called dry bulb temperature of the airstream. Changes in temperature between the ventilation inlet and outlet points at a constant water content are thus used to calculate the sensible heat removed from the SFT-C.

Since these thermocouples were from the batch described previously in the section on Temperature Sensors, they are not described further here. The RSS uncertainty in temperatures in the 20 to $40^{\circ} \mathrm{C}$ range was previously established to be $\pm 0.12^{\circ} \mathrm{C}$ for the batch of thermocouples, but by using individual calibrations, maximum errors were limited to $\pm 0.005^{\circ} \mathrm{C}$.

\section{Dewpoint}

Dewpoint sensors were located at the ventilation inlet and outlet points to determine changes in water content of the ventilation airstream. These measurements are usad to calculate the enengy removed as a result of adding water to the airstream through vaporization. This component, together with the sensible heat component noted above, constitutes the total energy removed in the ventilation airstream.

Two Yellow Springs Instrument Co., Inc., (YSI) Model 9400 lithium chloride dewpoint cells were mated with Weather Measure Corp. Model H361-DPYA dewpoint sensor assemblies to pro- vide the necessary dewpoint messurements during the spent-fuel storage phase of the test. Two additional cells were added to obtain measurements at the two exhaust points addred during the cooling phase.

\section{Calibration}

Dewpoints ranged from 10 to $22^{\circ} \mathrm{C}$ during the test with differences between inlet and outlet dewpoints of about 1 to $2{ }^{\circ} \mathrm{C}$ (relative humidity was about $50 \%$ during the test).

The dewpoint cells were calibrated before and after the test to confirm their adherence to YSI-tabulated values. Calibrations were performed at 21 and $49^{\circ} \mathrm{C}$ pretest and at $21^{\circ} \mathrm{C}$ posttest. These calibrations were performed under contract at the Sandia Standards Laboratory, Albuquerque, New Mexico. Figures 16 through 19 show the excellent agreernent between calibration results and YSI-tabulated relationships between dewpoint cell resistance and dewpoint temperature.

\section{Error Analysis}

Comparisons between YSI and calibration resistance readings at dewpoint temperatures between 10 and $22^{\circ} \mathrm{C}$ show that typical errors in RTD resistance are 0.1 to $0.2 \%$ with two extreme errors of 0.4 and $0.9 \%$. Since RTD readings are a linear function of cell temperature in this range, the RTD errors may be expressed as dewpoint errors of about $2.2^{\circ} \mathrm{C} / 1 \%$ error in RTD reading. Because RTD errors were typically a few tenths of a percent as noted above, the resulting dewpoint errors are well within the YSI-quoted "maximum possible errors," which range from -1.75 to $+0.75^{\circ} \mathrm{C}$ at a dewpoint of $10^{\circ} \mathrm{C}$, to $-1.50^{\circ} \mathrm{C}$ to $+1.25^{\circ} \mathrm{C}$ at a dewpoint of $20^{\circ} \mathrm{C}$.

In the energy balance calculations, vapor pressure (rather than dewpoint temperature) is used directly. Vapor pressure $V_{p}$ and dewpoint cell resistance $R$ are related by the equation

$V_{p}=A_{0}+A_{1} R+A_{2} R^{2}+A_{3} R^{3}+A_{4} R^{4}$.

The sensitivity factor for errors in RTD resistance reading is found by differentiating Eq. (19) with respect to $R$, such that

$G_{R}=\frac{d V_{p}}{d R}=A_{1}+2 A_{2} R+3 A_{3} R^{2}+4 A_{4} R^{3}$.

Maximum uncertainty in vapor pressure due to errors in resistance readings is \pm 0.0187 Torr, 


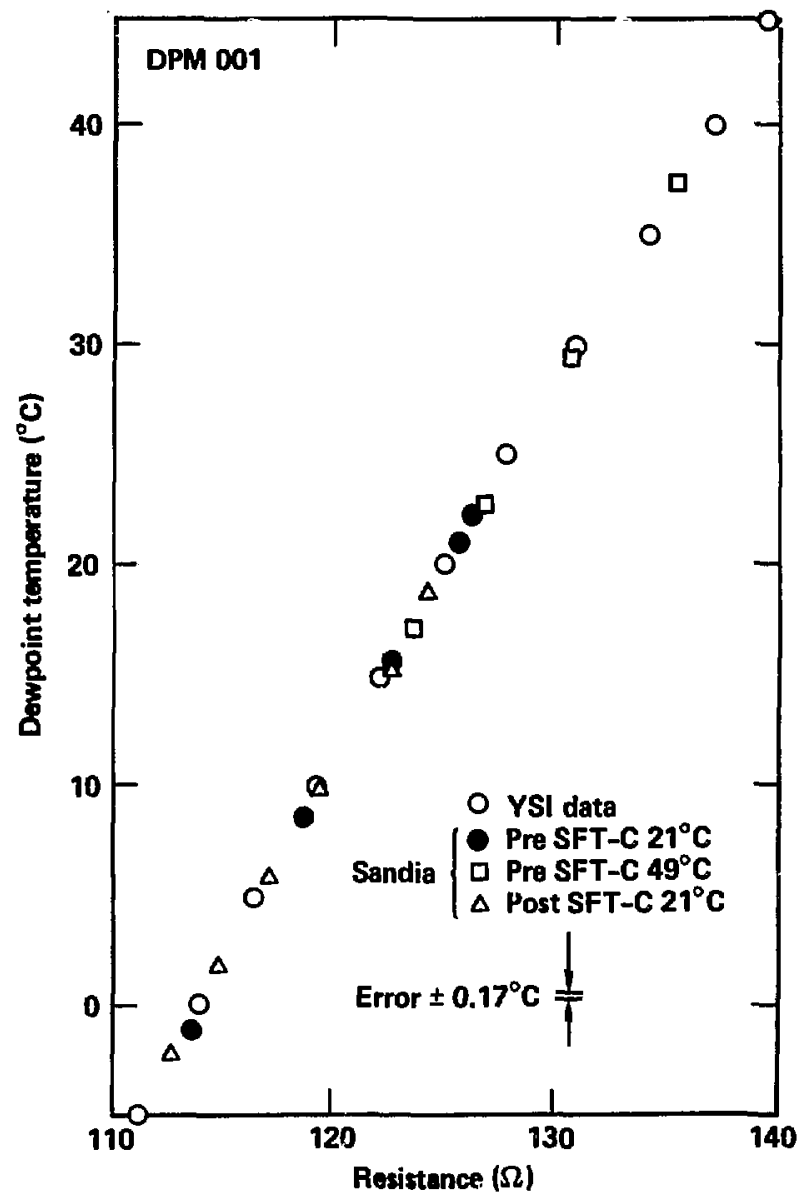

Figure 16. Comparien of dewpoint calibration data with YSItabulated data for dewpoint cell DPMO01.

based on an error in resistance of $0.011 \Omega$ (see the section on RTDs). Since the energy calculations are based on differences in vapor pressures, any systematic errors that may exist cancel.

\section{Reliability}

All four dewpoint cells functioned reliably throughout their deployment periods. Two of the cells were in use for about three years, while the other two were in service only for the 6-month cooling period following spent-fuel retrieval.

\section{Ventilation Flowrate}

An Engineering Measurements Company Model TMP turbine flowmeter was located in the surface duct-work of the ventilation system to measure air flow, In addition, a Model FTP812S3700-GJS-12 "Mini-Probe" flowmeter was installed in the duct-work of each heater drift following spent-fuel retrieval to monitor the augmented airflow. These units are referred to as "airflow monitors" and carry designations of the form AFMxxx.

\section{Calibration}

Calibrations were performed by REECo Industrial Hygiene Section personnel using a handheld pitot tube that was inserted through a port in the duct-work. Simultaneous readings of the pitot tube and flowmeter were obtained at 10 positions across both the horizontal and vertical diameters of the duct. Measurements were obtained at three 
Plare 17. Conperiven of dewpoint cellibrition dite with YSIibulated deta for dewpoint cell DPMO02.

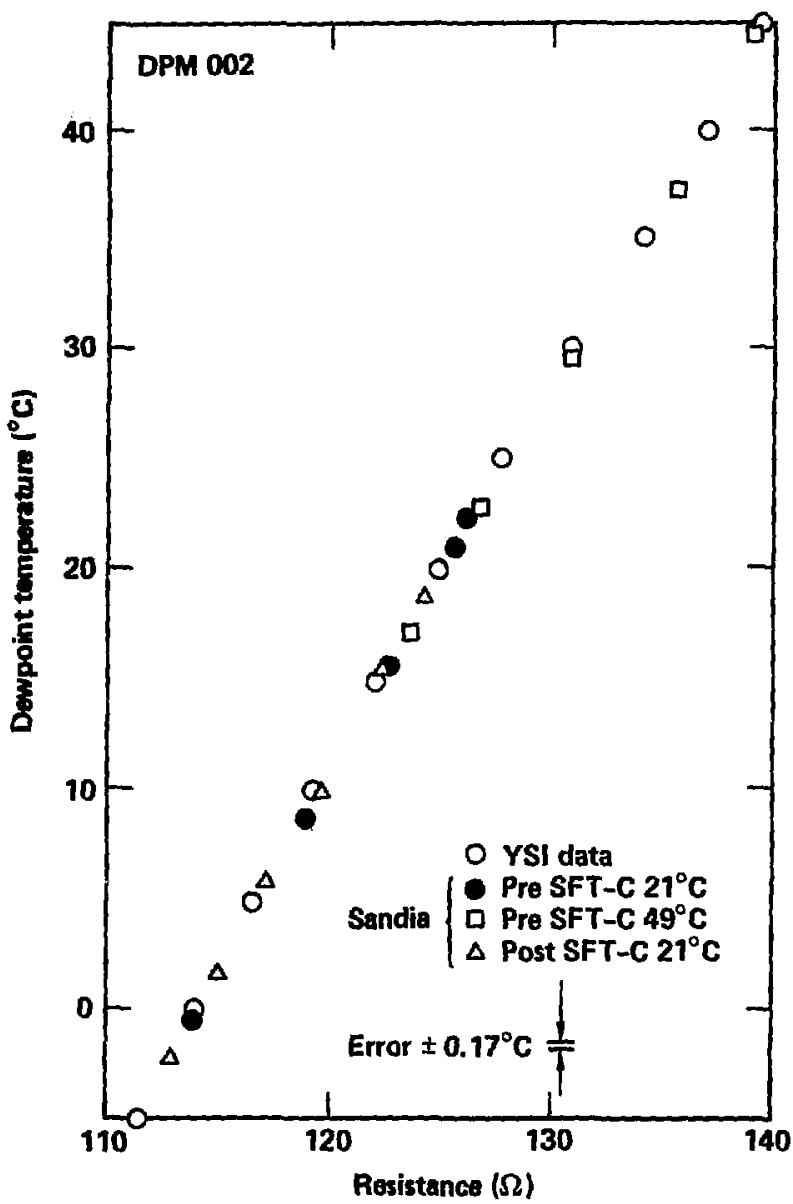

flowrates. The pitot tube measurements used a Magnehelic panel consisting of a barometer and Dwyer magnehelics with ranges of 0 to 2 in. $\mathrm{H}_{2} \mathrm{O}$, 0 to 5 in. $\mathrm{H}_{2} \mathrm{O}$, and $\mathrm{O}$ to 60 in. $\mathrm{H}_{2} \mathrm{O}$. The REECo Standards and Calibration Facility certified an accuracy $\pm 0.1 \%$ of reading for the magnehelics. However, the rather poor resolution of the magnehelics limited the actual accuracy to $\pm 3 \%$ for the main ventilation system (AFM201) and $\pm 5 \%$ for the augmented ventilation system (AFMOO2 and AFMOO3).

Average airflow velocities were used to compute volumetric flowrates of standard temperature and pressure air. The volumetric flowrate $Q$ was in turn related to the flowmeter output voltage using the equation

$\mathbf{Q}=\mathbf{A V}+\mathbf{B}$.

A comparison of the pre- and post-test calibrations indicates that substantial shifts occurred in the parameter B in Eq. (21). The resulting errors are $0.20 \mathrm{~m}^{3} / \mathrm{s}$ (17\%) for AFMO02 (north drift), 0.22 $\mathrm{m}^{3} / \mathrm{s}$ (18\%) for $\mathrm{AFMO03}$ (south drift), and 0.50 $\mathrm{m}^{3} / \mathrm{s}(18 \%)$ for AFM201. In all cases, the post-test measured flowrates are lower for a given voltage output. Conversely, the voltage output is higher for a given measured flowrate, which is the opposite of what occurs when a turbine fails because of 


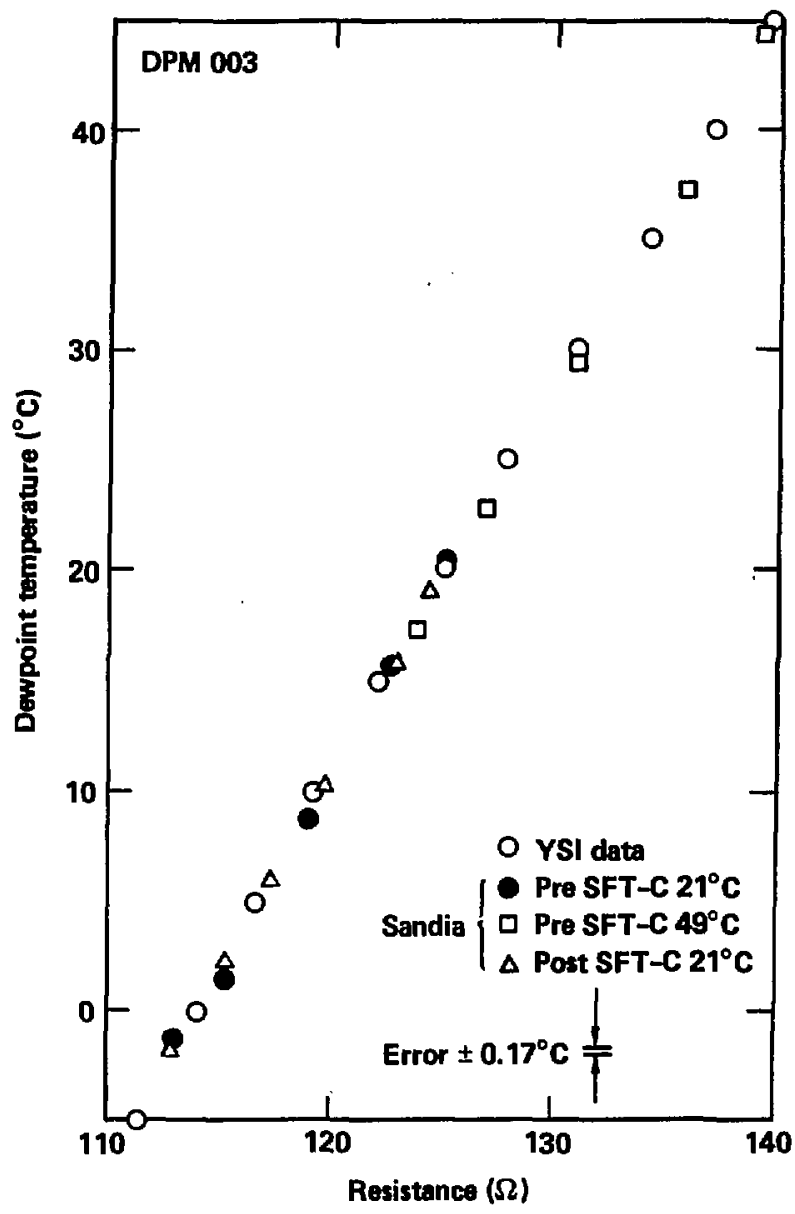

Figure 18. Comparion of dewpoint calibration data with YSItabulated data for dewpoint cell DPMO03.

increased friction in the bearings or because of dust accumulations on the turbine blades. Examination of the flowrate data recorded during the SFT- $C$ indicates no systematic increase in apparent flow with time. We suspect that this very consistent $(\sim 18 \%)$ error was introduced in calibration and is not present in the data acquired during the test.

\section{Reliability}

The three turbine flowmeters appear to have functioned reliably throughout the test period. The only question concerning reliability relates to the apparent $18 \%$ shift in readings discussed above. AFM201, which was in service for 3.5 years, experienced one curbine failure at about 4.5 YOC* (two years inte the test) and was replaced at that time. It also malfunctioned at about 4.72 YOC in August 1982 during the third exchange of spent-fuel assemblies. The turbine was cleaned, reinstalled, and functioned reliably through termination of the test.

- YOC is a time index based on the spent fuel age measured in "years out of core." It is used throughout the SFT-C data acquisition and reporting activities. The first spent-fuel assembly was emplaced on April 18, 1980, with an age of 2.412 YOC. 
Fizare 19. Comparioun of dewpoint colibriblion dete with YSItabulued data for dewpoint cell DPMDOL.

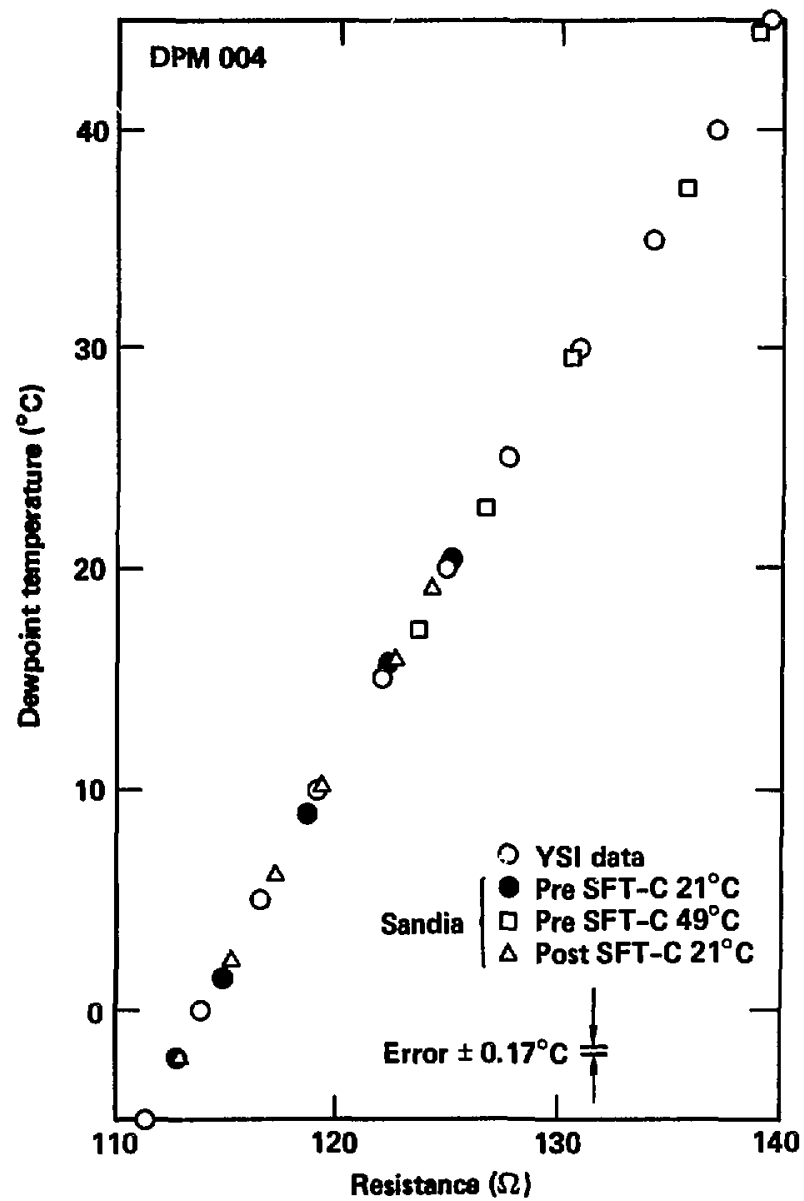

for errors in outlet temperature;

$\boldsymbol{\theta}_{\mathrm{T}_{\mathrm{i}}}=\frac{\mathrm{dP}_{\mathrm{s}}}{\mathrm{dT}_{\mathrm{i}}}=-\mathrm{V}$,

for errors in inlet temperature;

where $T_{0}$ and $T_{i}$ are outlet and inlet temperatures and $V$ is the volumetric flow rate. Differentiating Eq. (22) with respect to each parameter gives

$\boldsymbol{\theta}_{\mathrm{T}_{\mathrm{il}}}=\frac{\mathrm{dP}_{\mathrm{s}}}{\mathrm{dT}_{0}}=\mathrm{V}$. $\theta_{v}=\frac{d P_{s}}{d V}=\left(T_{0}-T_{i}\right)$,

for errors in volumetric flowrate.

The algorithm for determining the power removed as the latent heat of vaporization is 
$P_{L}=2.135\left(V_{P 2}-V_{P 1}\right) V$,

where $V_{P 2}$ and $V_{P 1}$ are the outlet and inlet vapor pressures and $V$ is the volumetric flowrate. Differentiating Eq. (26) with respect to each parameter gives

$\theta_{V_{\Gamma 2}}=\frac{d P_{L}}{d V_{P 2}}=2.135 \mathrm{~V}$,

for errors in the vapor pressure of the outlet air,

$\theta_{V_{p 1}}=\frac{d P_{L}}{d V_{P 1}}=-2.135 \mathrm{~V}$,

for errors in the vapor pressure of the inlet air,

$\theta_{V}=\frac{d P_{L}}{d V}=2.135\left(V_{P 2}-V_{P 1}\right)$, for errors in the volumetric flowrate.

Maximum errors in temperature were limited to $\pm 0.005^{\circ} \mathrm{C}$ by using individual thermocouple calibration data, and errors in vapor pressure were \pm 0.0187 Torr (see the section entitled "Dewpoint"). The manufacturer's specified error for flowrate of $\pm 0.1 \%$ was used because fundamental inaccuracies in the calibration system were so large (see the section entitled "Ventilation Flowrate") that the calibrations were of little value in establishing absolute relationships between flowrate and transducer output. Using Eqs, (23)(25) and Eqs. (27)-(29), we calculate a total uncertainty in energy removal rate of $\pm 0.19 \mathrm{~kW}$, or about $\pm 3.4 \%$ during the spent-fuel storage phase of the test. This uncertainty increased to $\pm 0.21 \mathrm{~kW}$, or about $\pm 3.7 \%$ during the cooling phase of the test when the auxiliary ventlation system was operating.

\section{Watt Transducers}

Watt transducers were selected and deployed to measure the quantity of electrical energy introduced to the rock mass and ventilation airstream during the SFT-C. Three primary sources of electrical heat were present: electrical simulators, auxiliary heaters, and areal lighting. An overall accuracy requirement of $2 \mathrm{~kW}$ for the system $-1.5 \mathrm{~kW}$ with lighting off-was determined to be adequate for the purposes of the SFT-C (Brough and Patrick, 1982).

The thermal output of the six electrical simulators was monitored and controlled on an individuai basis. Outputs ranged from about 1.6 to $0.6 \mathrm{~kW}$ per simulator. Loyola In:dustries BPACseries controllers (SCR-type) delivered power to the simulators. American Aerospace Controls, Inc., Model 413-25-230 watt transducers measured the power output of the controllers.

The power output of the 10 auxiliary heaters located in each of the side drifts ranged from 1.85 to $0.625 \mathrm{~kW}$ per heater. Since the heaters were grouped in two sets of three and one set of four in each drift, measured powers ranged from 7.40 to $1.88 \mathrm{~kW}$. Loyola SCRs and American Aerospace Controls, Inc., Model 413-100-115 watt transducers were used.

The power output of the areal lights was monitored with two ranges of transducers. Canister drift lighting was monitored with three American Aerospace Controls, Inc., Model 413-100-115 watt transducers, whereas the heater drift lighting was monitored with a total of four Model 413-25-
115 watt transducers. Electrical lights were connected directly to utility power with no intervening SCRs.

\section{Calibration}

Calibrations were performed to examine the accuracy and behavior of the transducers under realistic conditions. The relative complexity and need for precision precluded use of field calibrations so laboratory calibrations were performed. A calibration system was developed that used incandescent lights as electrical loads. Both pre- and post-test calibrations were conducted. Details of the calibration configuration are presented by Brough and Patrick (1982).

Means and standard deviations of errors measured during pre- and post-test calibrations are presented in Table $\mathbf{1 2}$ for transducers deployed with SCRs. Similar data are presented in Table 13 for transducers deployed in the continuous ac voltage mode. Error data are given both as ausolute watts and as a percentage of reading. A systematic change in transducer response is noted in all cases. Pretest errors were negative (measured power less than power calculated using manufacturer's sensitivity and offset values) in all but one case. On the other hand, post-test errors were positive in all but two cases, and even here the errm-s became more positive.

The observed systematic changes in transducer response are attributed nonspecifically to 
Table 1.2. Errors measured during pre- and post-test calibration of watt transducers with SCRcontrolled voltage.

\begin{tabular}{|c|c|c|c|c|c|}
\hline \multirow{2}{*}{$\begin{array}{l}\text { Inutrument } \\
\text { lice ive plate }\end{array}$} & \multirow{2}{*}{$\begin{array}{l}\text { Sexial } \\
\text { number }\end{array}$} & \multicolumn{2}{|c|}{$\begin{array}{l}\text { Freteat callib. mean } \\
\text { (old dev) e.rror }\end{array}$} & \multicolumn{2}{|c|}{$\begin{array}{l}\text { Post-test calib. mean } \\
\text { (std dev) error }\end{array}$} \\
\hline & & Watts & \% reading & Watts & 7 reading \\
\hline \multicolumn{6}{|c|}{ Auxiliary heater watt transducers } \\
\hline NHW001 & 121 & $-69.0(23.7)$ & $-1.3(0.3)$ & $137.4(50.5)$ & $3.2(0.3)$ \\
\hline NHWOO2 & 122 & $-53.5(37.1)$ & $-1.3(0.8)$ & $119.1(36.8)$ & $2.8(0.4)$ \\
\hline NHWOO3 & 123 & 18.3 (25.8) & $0.3(0.5)$ & $\rightarrow$ & - \\
\hline SHW001 & 124 & $-221.0(90.7)$ & $-3.9(0.5)$ & $66.6^{2}(17.1)$ & $1.6^{2}(0.4)$ \\
\hline SHW002 & 125 & $-43.3(6.5)$ & $-1.1(0.4)$ & $173.6(60.2)$ & $4.1(0.4)$ \\
\hline SHWOO3 & 126 & $-13.9(10.0)$ & $-0.4(0.3)$ & $26.7(12.7)$ & $0.7(0.4)$ \\
\hline Composite & $\mathbf{N} / \mathbf{A}$ & $-63.7(66.6)$ & $-1.3(1.4)$ & $105.6(63.5)$ & $2.5(1.2)$ \\
\hline \multicolumn{6}{|c|}{ Electrlcal simulator walt tranoducers } \\
\hline CHW021 & 136 & $-80.6(45.9)$ & $-3,8(1,4)$ & $20.9(6.0)$ & $3.6(0.9)$ \\
\hline CHWOAI & 137 & $-69.8(41.3)$ & $-3.2(1.0)$ & $14.8(4,6)$ & $2.8(1.0)$ \\
\hline CHWO61 & 138 & $-74.8(46.4)$ & $-3.4(1.1)$ & $13.5(5.3)$ & $2.2(0.9)$ \\
\hline CHW131 & 139 & $-63.8(37,8)$ & $-2.9(0.7)$ & $31.6(9.6)$ & $5.3(0.9)$ \\
\hline CHW151 & 140 & $-85.1(36.1)$ & $-4,0(1,3)$ & $16.9(6.9)$ & $2.4(1.0)$ \\
\hline CHW171 & 141 & $-83.0(33.1)$ & $-4.0(1.2)$ & $18.9(5.9)$ & $3.1(0.6)$ \\
\hline Componite & $N / A$ & $-76.2(38.9)$ & $-3.5(1.1)$ & $19.4(8.6)$ & $3.2(1.3)$ \\
\hline
\end{tabular}

"Apparently damaged in shipment. See discussion in "Reliabllity" section.

Table 13. Errors measured during pre- and post-test calibration of watt transducers with continuous alternating current.

\begin{tabular}{|c|c|c|c|c|c|}
\hline \multirow{2}{*}{$\begin{array}{l}\text { Instrument } \\
\text { license plate }\end{array}$} & \multirow{2}{*}{$\begin{array}{l}\text { Serital } \\
\text { nutnber }\end{array}$} & \multicolumn{2}{|c|}{$\begin{array}{l}\text { Pretest calib. mean } \\
\text { (atd dev) error }\end{array}$} & \multicolumn{2}{|c|}{$\begin{array}{l}\text { Post-test calib. mean } \\
\text { (std dev) error }\end{array}$} \\
\hline & & Watts & to reading & Watts & $\%$ reading \\
\hline \multicolumn{6}{|c|}{ Heater drift lighting watt irantucers } \\
\hline NLW001 & 131 & $-36.1(11.3)$ & $-2.7(0.7)$ & $8.5(5.4)$ & $0.7(0.5)$ \\
\hline NLWOO2 & 132 & $-33.8(9.9)$ & $-2.5(0.9)$ & $11.8(6.8)$ & $9.8(0.4)$ \\
\hline SLW001 & 133 & $-37.8(11.4)$ & $-2.8(0.4)$ & $20.0(10.5)$ & $1.4(0.3)$ \\
\hline SLW002 & 134 & $-38.2(11.2)$ & $-2.8(0.5)$ & $-9.3(4.7)$ & $-0.7(0.3)$ \\
\hline Composite & $\mathbf{N} / \mathbf{A}$ & $-36.5(10.5)$ & $-2.7(0.4)$ & $7.7(12.8)$ & $0.5(0.9)$ \\
\hline \multicolumn{6}{|c|}{ Canisler drift lighting watt traneducers } \\
\hline CLW001 & 127 & $-284.4(87.7)$ & $-7.0(0.8)$ & $-66.1(31.9)$ & $-1.8(0.9)$ \\
\hline CLWO02 & 128 & $-86.7(35.4)$ & $-2.2(0.6)$ & - & - \\
\hline crwons & 129 & $-83.4(19.9)$ & $-2.1(0.5)$ & - & - \\
\hline Composite & $\mathbf{N} / \mathbf{A}$ & $-151.5(109.0)$ & $-3.7(2.4)$ & $-66.1(31.9)$ & $-1.8(0.9)$ \\
\hline
\end{tabular}

'Apparently damaged in shipment. See discussion in "Rellability" section. 
component aging. The same measurement system, calibration standards, and procedures were used in both calibrations so there is little likelihood that a different error source was introduced at this point. Furthermore, it is clear that the offset, while systematic in design, varies quite widely in terms of both absolute power and percentage of reading. We are confident that these differences in pre- and post-test errors represent actual changes in transducer responses.

\section{Error Analysis}

Changes such as those identifled above present a real challenge in determining how to utilize calibration results in the data conversion algorithms. This observation may also suggest a need to perform additional periodic calibrations or to obtain additional information on the aging of these transducers.

In the absence of such information, we performed an error analysis using the calibration results directly, ignoring the lighting transducers since the contribution of input energy from lighting was only $4.8 \%$ of the total (Patrick et al., 1984). Tire approach is based on the calibration data presented above with the power calculated from the manufacturer's specification taken as the "true" value. This analysis indicates that at the start of the SFT-C, $1.3 \%$ less energy than planned was being deposited by the auxiliary heaters and 3.5\% less energy than planned was being deposited by the electrical simulators. By the end of the test, 2.5 and $3.2 \%$ more energy than planned was being deposited, respectively, from these two heat sources. Since there was a period when the average error was negative and then positive, it follows that the cumulative error was less than either of these extremes.

\section{Reliability}

With one exception, the watt transducers deployed on the six electrical simulators functioned reliably throughout the 2.8-yr heating phase of the SFT-C. The SCR for the CEH17 simulator failed and was out of service for 12 days between 2.83 and 2.86 YOC. Examination of the individual plots of power output shows no other periods of erratic behavior. The sensitivity of the partial duty cycle controllers to variations in line voltage became excessive as the power level was reduced below about $1 \mathrm{~kW}$ (Patrick et al., 1982). A set of process controllers with power-sensing feedback was installed at about 5.0 YOC to reduce the variability in output power. A markedly more stable power output resulted (Fig, 20).

Several component malfunctions were observed in the auxiliary heater control system. The performance of each system is noted in Table 14. Figure 21 shows the failure mode for the heater controller. The power level fluctuates, fairly repeatedly, between the setpoint and some higher power level that is less than the full power of the controller. Note that the problems were identified with the controller, not with the watt transducers themselves. Auxiliary heater power levels were set too low on February 19, 1982; beginning on March 1, 1982 they were adjusted upward in power to balance out the period of low power input. In addition, one watt transducer was apparently damaged in shipment so a valid post-test calibration was not obtained (Table 12).

Individual data records indicate that the canister-drift and heater-drift-lighting watt transducers functioned reliably throughout the measurement period. As noted in Table 13, two of the seven were apparently damaged in shipment, which precluded obtaining a valid post-test calibration. 


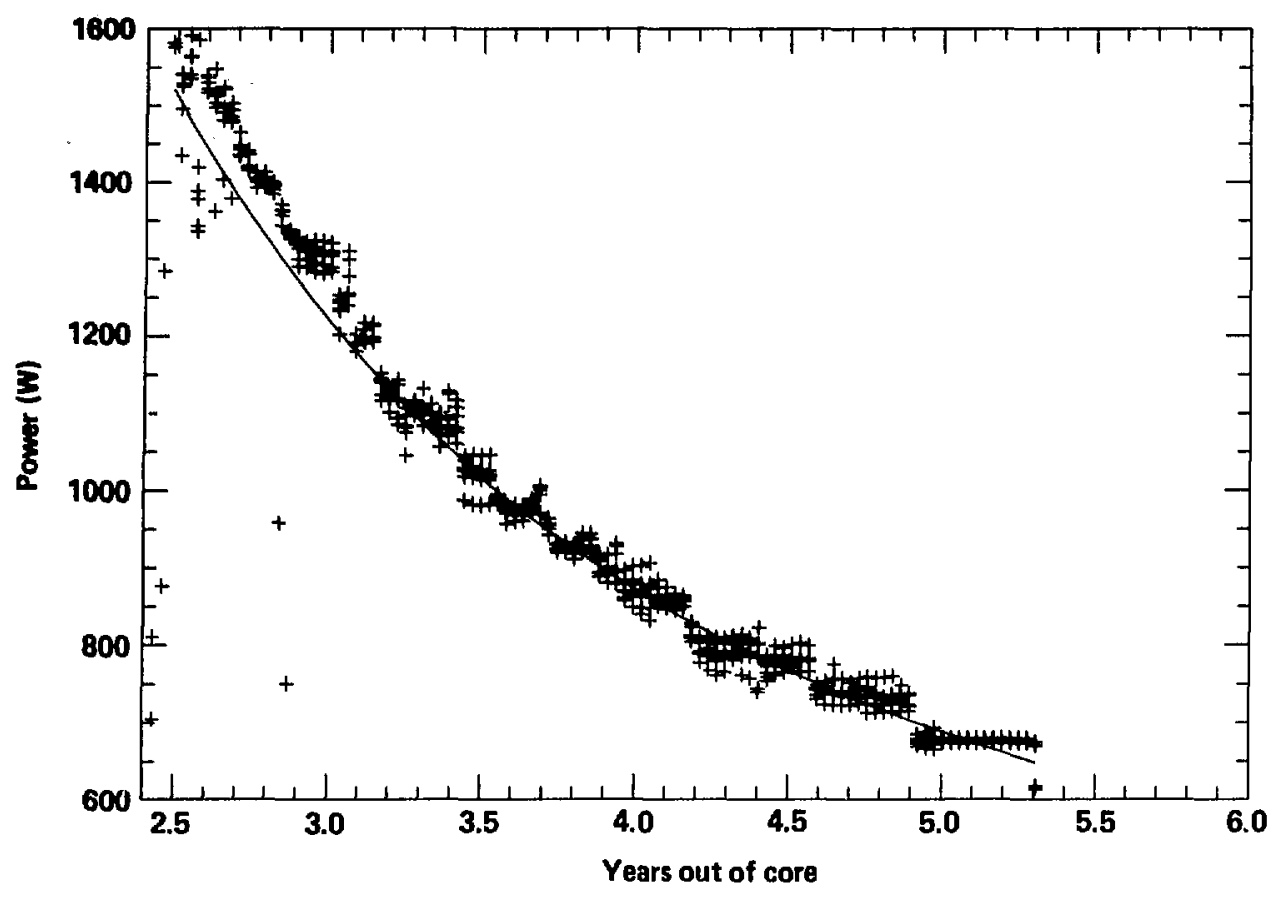

Figure 20. Electrical simulator power history showing effect of loop controller addition at 5.0 YOC.

Table 14. Performance history of the auxiliary heater controller systems.

\begin{tabular}{llr}
\hline $\begin{array}{c}\text { Associated } \\
\text { wall transducer }\end{array}$ & \multicolumn{1}{c}{ Mode of failure } & Period of failure \\
\hline NHW001 & & None \\
NHW002 & Erratic controller output, changed controller & $10 / 22 / 81-10 / 30 / 81$ \\
& Erratic controller output, changed controller & $11 / 11 / 81-11 / 19 / 81$ \\
& Erratic controller output, changed controller & $1 / 23 / 82-2 / 9 / 82$ \\
NHW003 & Erratic controller output, checked connections, some loose & $2 / 21 / 82-3 / 2 / 82$ \\
& Erratic controller output, changed controller & $3 / 11 / 82-3 / 25 / 82$ \\
SHW001 & Erratic controller output, changed controller, also & \\
SHW002 & Changed watt transducer $11 / 8 / 82$ with no improvement & $10 / 7 / 82-11 / 10 / 82$ \\
SHW003 & & $3 / 8 / 82-3 / 25 / 82$ \\
\hline
\end{tabular}




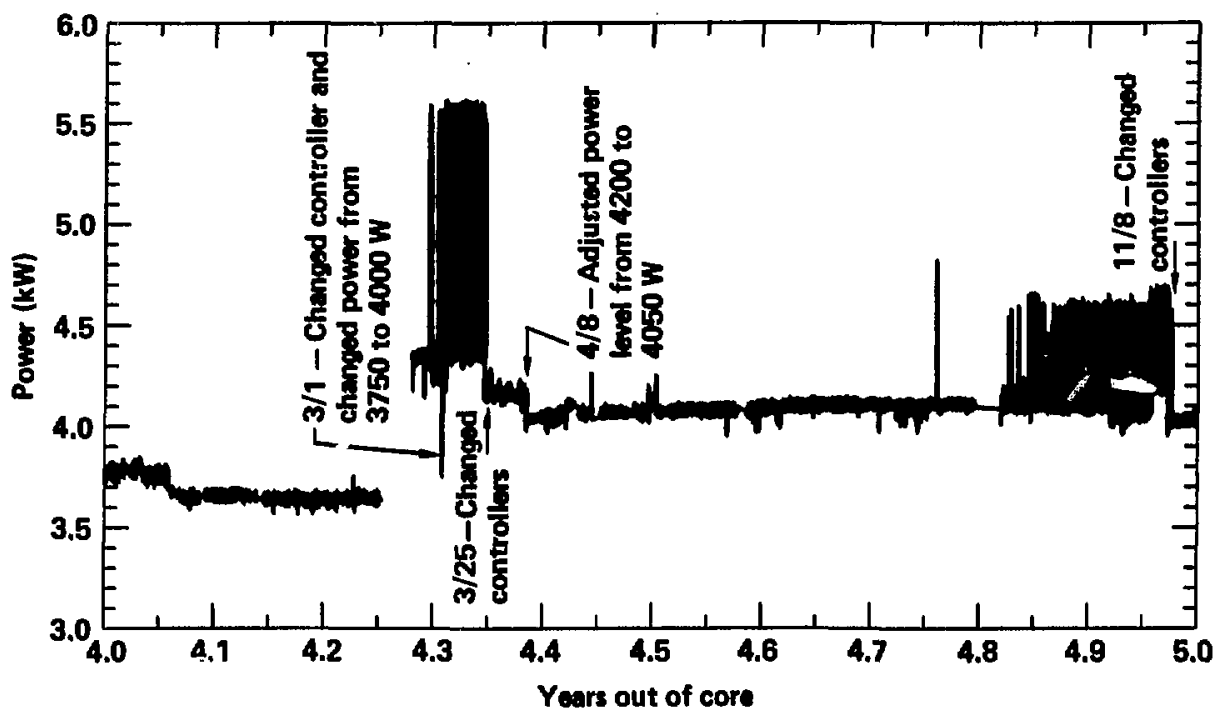

Figure 21. Guard heater power history for north heater drift group showing effect of controller malfunctions.

\section{Stressmeters}

Vibrating-wire stressmeters were deployed at the SFT $-C$ to measure stress changes that occurred as a result of heating the rock mass. Three IRAD Gage Co. Model VBS-1HR (hard rock) stressmeters were used in the pillars during the Mine-by experiment (Wilder and Patrick, 1981). During the heated phase of testing, 18 Model VBS-1HT[HR] (high-temperature hard rock) stressmeters were used in the pillars and at positions $1.2 \mathrm{~m}$ radially outward from the spent-fuel assemblies (Brough and Patrick, 1982) (Figs. 22 and 23). The principal differences in the latter units were the use of Teflon-sheathed electrical wire and higher temperature potting and O-ring seals.

Three steps were taken to reduce the likelihood of corrosion of the stressmeters during the heated phase. These actions were taken based on observed corrosion of the three stressmeters deploye: for the Mine-by experiment (Carlson et al., 1980). First, the stressmeter bodies and platens were plated before assembly with a 0.127 . mm-thick electroless nickel containing 7 to $10 \%$ phosphorus. Second, the stressmeters were coated with a 0.167-mm-thick film of Pyrolene-N. Third, following installation, the borehole void was filled with inert high-density foam.
Twelve stressmeters were deployed in two sets of three in each of two $38 \mathrm{-mm}$-diam horizontal boreholes in the north pillar of the SFT $-C$. Vertical, 60-degree clockwise and 60-degree counterclockwise orientations were used in each set of three to form a rosette with $150-\mathrm{mm}$ spacings between gauges (Carlson et al., 1980). Two sets were positioned near the center of the pillar and two sets were located within $1 \mathrm{~m}$ of the canister drift rib. In addition, six stressmeters were deployed in two rosettes in vertical boreholes adjacent to canister emplacement boreholes $\mathrm{CEH} 03$ and $\mathrm{CEH} 09$. Details concerning the positioning and installation of all stressmeters are reported by Abey and Washington (1980). A single Type $\mathrm{K}$ thermocouple was positioned with each set of three stressmeters to provide temperature data to compensate for the effects of thermal expansion.

The initial set of 18 stressmeters failed in service and were replaced with units featuring a new seal design (Patrick et al., 1981). Stainless steel end-caps were electron-beam welded in place to hermetically seal the center cavity of the stressmeters, which houses the vibrating wire. Details concerning the positioning and installation of the replacement units are provided in Patrick et al. (1982 and 1983) and Patrick et al. (1981). 
Reconditioned Mine-by extensometer array. Circles indicate approximate anchor locations for upper extensometer

-๑) Thermal phase extensometer installed versically

-ono- Vibrating-wire stressmeters showing approximate gauge locetion. Not reintalled for thermal phase monitoring

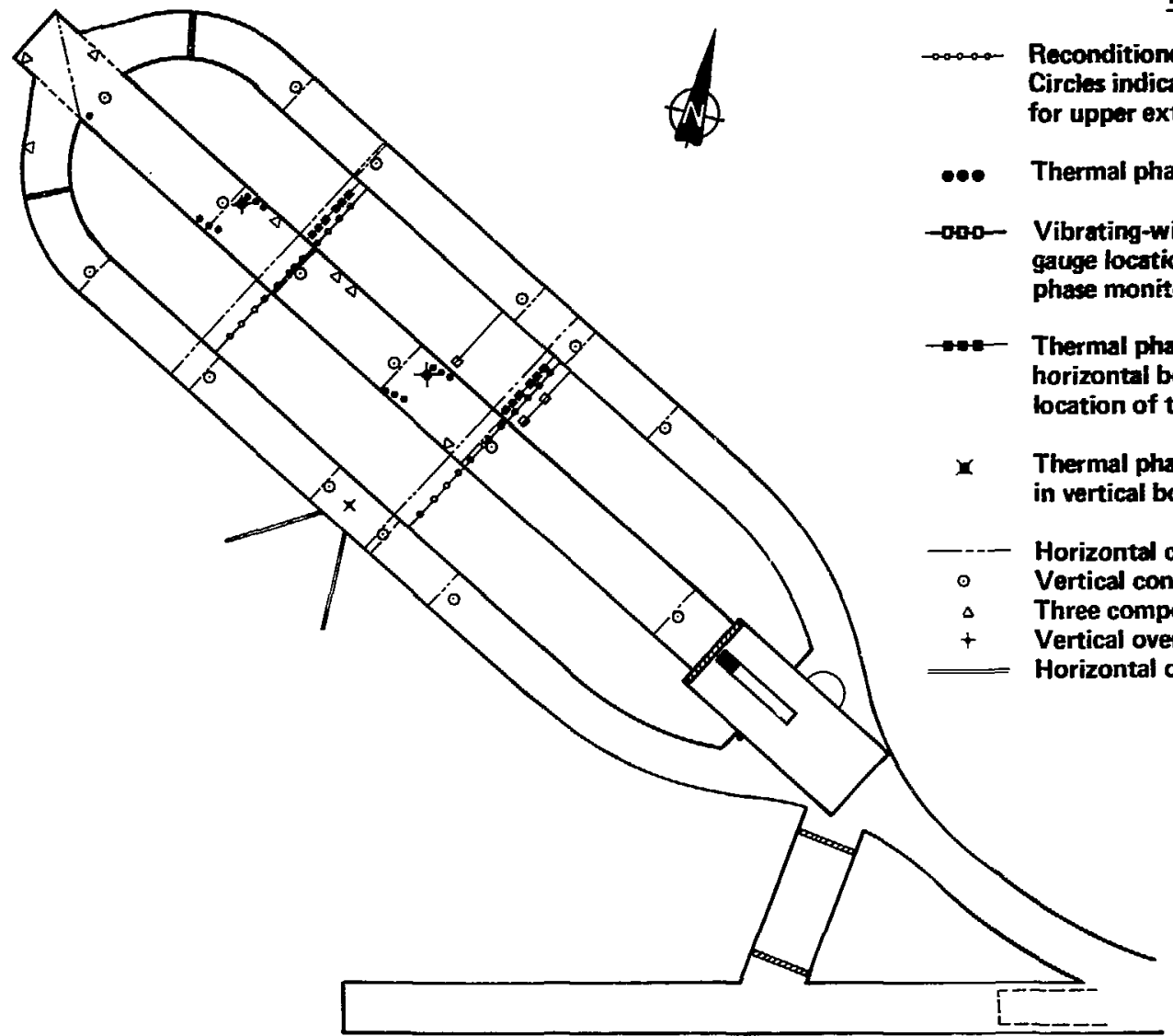

Figure 22. Location of thermal phase instrumentation. 


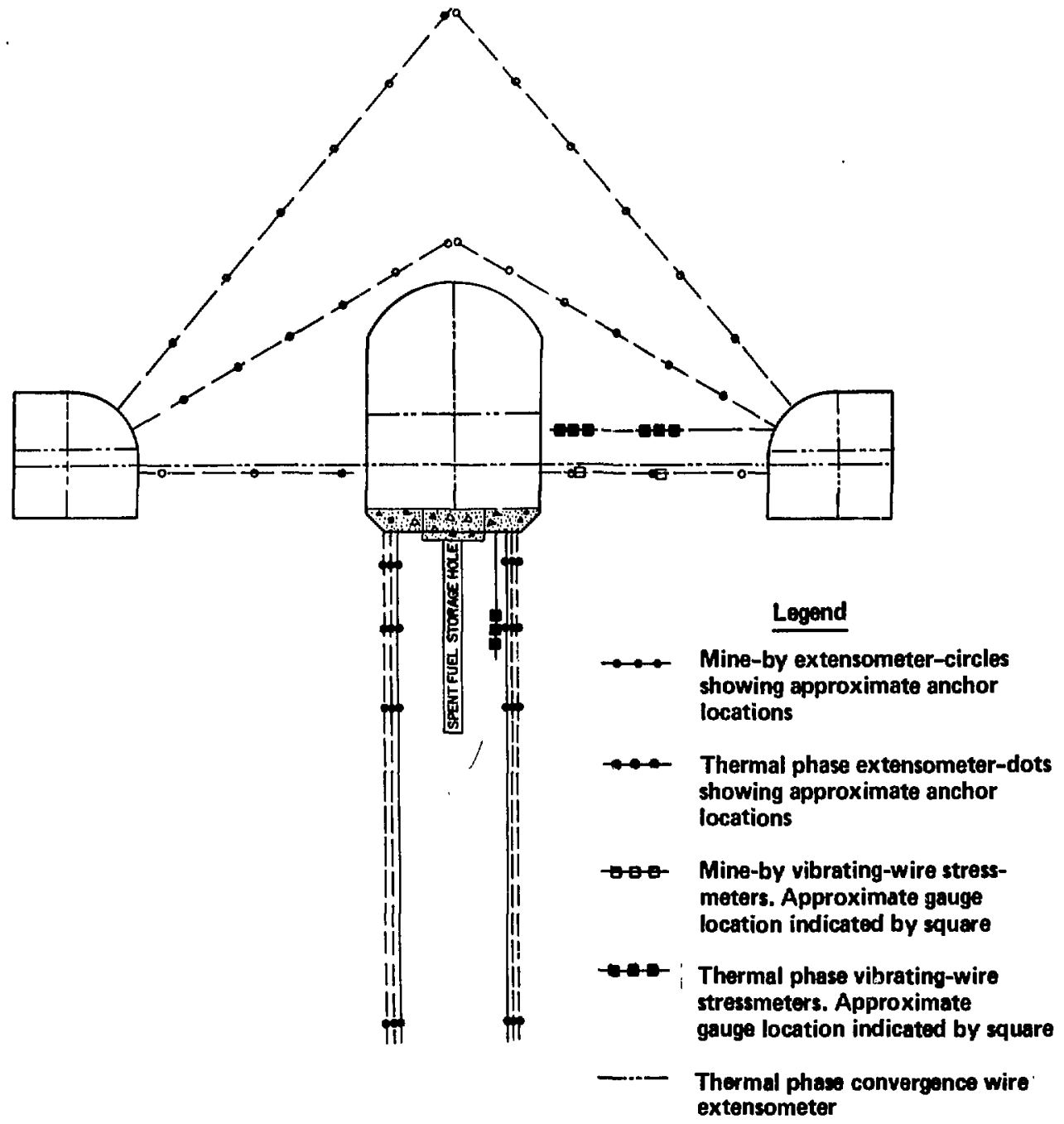

Note: lines dashed when borehole is out of the plane of the cross-section

Figure 23. Cross section showing thermal-phase and Mine-by instrumentation arrays. 


\section{Calibration}

Three special investigations were conducted on the calibration characteristics of the IRAD vibrating-wire stressmeters. An in-house study by Abey and Washington (1980) focused on techniques to reliably install a stressmeter in such a way that its calibration coefficient was known. Depending on borehole conditions, the initial preload decreased varying amounts when the installation tool was released. This study found that the calibration coefficient was directly related to the preload on the stressmeter.

IRAD Gage, Inc., was contracted to perform a second, broader series of laboratory calibration studies that focused on the behavior of the vibrating-wire stressmeter in Climax granite at elevated temperatures (Dutta et al., 1981). A test program was developed to study nine important factors that influence stressmeter response: test block size, stressmeter stiffness, gauge reproducibility and hysteresis, gauge prelnad, initial stress field, platen geometry, platen orientation, elevated temperature, and rock anisotropy. Many of these tests were cortucted under uniaxial, biaxial, and triaxial Ioading conditions. In addition to imploving our basic understanding of the stressmeter response to a variety of test conditions, the results of these studies were used to develop the algorithm for data reduction and interpretation. These results are summarized below.

1. Blocks of aluminum, Barre granite, and lucite were used in this study to examine the effect of sample size. While sample width was constant at $250 \mathrm{~mm}$, the height-to-width ratio was varied from 1.0 to 1.5 or 2.0 . Tor the three materials tested, the influence of sample size on stressmeter sensitivity was $7.3,3.1$, and $1.1 \%$, respectively.

2. Stressmeter stiffness studies revealed that the LLNL gauge, which was electroless-nickel plated, had a stiffness of $1.29 \times 10^{7} \pm 1 \% \mathrm{~N} / \mathrm{cm}$, whereas the standard VBS-1HT had a slightly lower stiffness of $1.24 \times 10^{7} \pm 3 \% \mathrm{~N} / \mathrm{cm}$.

3. Gauge reproducibility was investigated under two conditions: single setting with multiple-load cycles and multiple setting with a single-load cycle. For all materials tested, a zero shift was noted between the first and second cycles. This zero shift (expressed as a percentage of the maximum stress change in the wire) is 18.3, 17.5, and $7.06 \%$ for Climax granite, Barre granite, and aluminum, respectively. It appears that this zero shift is a result of the stressmeter "bedding in" on the first cycle since, for later cycles, the shift is almost nonexis'ent.
4. Gauge preload effects were observed at low preload values, but the sensitivity of the gauge is nearly constant for preloads of $\mathbf{1 7 5}$ units or more.

5. The influence of initial stress field on gauge response was determined to be negligible.

6. Tests in lucite and aluminum indicated that the hard rock (HK) platen results in markedly smaller (in fact, negligible) variations in the sensitivity factor as a function of stress than when soft rock and modified soft rock (SR and MSR) platens are used.

7. Theory shows that the ratio of gauge sensitivity to loading parallel to the wire compared with loading perpendirular to the wire should be -3.00 . However, test results indicated that the actual ratio varies from -2.84 to -3.28 , depending on stress level.

8. The influence of teinperature is probably the most critical aspect of gauge response as it relates to the SFT- $C$. Changes in temperature were found to simply cause an offset in stressmeter reading by a factor $1.55 \Delta t$. For the range of temperatures experienced at the SFT $-\mathrm{C}$, changes in stressmeter sensitivity with increasing temperature are negligible.

9. Tests in three slabs of Climax granite revealed that fairly significant anisotropy exists (11 to $27 \%$ ) for different stressmeter orientations. This may be the result of preferential orientation of healed geologic fractures and feldspar phenocrysts in the rock slabs.

The first two calibration studies made it clear that the response of a stressmeter was a unique function of the local rock conditions and installation process. Since the stressmeters have no provision for in situ calibration, we developed an experimental approach to retrieve the gauges while they were still encased in a core of rock for subsequent laboratory calibration (Mao, 1984).

Each rosette of three stressmeters was retrieved by overcoring with a nominal 0.25 -m-diam diamond-impregnated bit. Only 6 of the 18 stressmeters were successfully retrieved because of problems associated with the geological structure and the drilling technique. Once the largediameter core was received at the laboratory, it was overcored with a nominal 0.15 -m-diam bit to obtain concentricity with the $38-\mathrm{mm}$ borehole containing the stressmeters.

The retrieved stressmeters, still encased in the section of rock in which they were installed, were calibrated under uniform biaxial compression. Mao (1984) shows that the sensitivity factor for a particular stressmeter installation may vary widely from the nominal value obtained during 
conventional laboratory calibration. The importance of accurately knowing the sensitivity factor is discussed below.

\section{Error Analysis}

The basic equation for determining changes in stress is

$$
S=1.7842 \times 10^{14} \mathrm{~A}\left[\frac{1}{\left(\mathrm{~T}_{1}^{\prime}\right)^{2}}-\frac{1}{\left(\mathrm{~T}_{2}\right)^{2}}\right] \text {, }
$$

where

$S=$ is the stress change in pascals,

$\mathrm{T}_{1}^{\prime}=\mathrm{T}_{1}+1.55 \Delta \mathrm{t}$, where $\mathrm{T}_{1}$ is the initial stressmeter reading and $\Delta t$ is the change in temperature that occurred between the readings $T_{1}$ and $T_{2}$,

$T_{2}=$ the current gauge reading,

$A=$ assumed to be a constant.

Note that the values of $T_{j}$ are obtained from the IRAD MB- 6 readout box (or its equivalent) and are equal to $10^{7} / \mathrm{f}$, where $f$ is the frequency of the vibrating wire. Based on the early studies by Abey and Washington (1980), the following values were used in our data conversion algorithm:

- $A=1.6$ for gauges with a stable preioad.

- $\mathrm{A}=1.8$ for gauges showing a 5 to $10 \%$ decrease in preload.

- $\mathrm{A}=\mathbf{2 . 0}$ for gauges showing a yrcater than $10 \%$ decreased in preload.

The study by Mao (1984) indicates that variations in $A$, which are caused by unique gauge-rock interactions, are the most significant source of error in the stressmeters. Gauge-to-gauge variations have been shown to be small (when the gauge is test $\mathrm{t}$ independent of th: rock) and gauge sensitivity and stability are excellent (0.1 to $1.0 \%)$ (Patrick et al., 1982).

Error sensitivity factors are determined by differentiating Eq. (30) with respect to temperature and the gauge factor $A$, such that

$$
\begin{aligned}
& \Theta_{1}=\frac{d S}{d t}=-5.531 \times 10^{14} \frac{A}{\left(T_{1}^{\prime}\right)^{3}}, \\
& \theta_{A}=\frac{d S}{d A}=1.7842 \times 10^{14}\left[\frac{1}{\left(T_{1}^{\prime}\right)^{2}}-\frac{1}{\left(T_{2}\right)^{2}}\right] .
\end{aligned}
$$

Evaluating Eq. (31) for errors in temperature readings of $0.14^{\circ} \mathrm{C}$, as developed in the section on thermocouples, we calculate an error of 0.019 $\mathrm{MPa}, q$ trivial quantity compared with anticipated
Table 15. Errors introduced by differences between assumea and measured calibration constants for six vibrating-wire stressmeters.

\begin{tabular}{cccc}
\hline $\begin{array}{c}\text { Instrument } \\
\text { Iicense plate }\end{array}$ & $\begin{array}{c}\text { Assumed } \\
\text { "A" value" }\end{array}$ & $\begin{array}{c}\text { Measured } \\
\text { "A" value }\end{array}$ & $\begin{array}{c}\text { Percentage } \\
\text { error }\end{array}$ \\
\hline NSG231 & 1.6 & 0.99 & +38 \\
232 & 1.6 & 1.30 & +19 \\
223 & 1.8 & 2.85 & -58 \\
& & & -51 \\
NSG244 & 1.6 & 2.42 & -46 \\
245 & 1.6 & 2.34 & -39 \\
246 & 1.8 & 2.51 & \\
\hline
\end{tabular}

- Baced on data from Patrick, Carlion, and Rector (1901).

b Based on dala from Mao (1984).

magnitudes of stress changes on the order of several MPa. Likewise, Eq. ( 52 ) may be evaluated using differences between the assumed $A$ values and those reported by Mao (1:384). Táble 15 shows the observed range of differences in $A$ values and the resultirig errc's in calculated stress changes.

This analysis highlights the need to obtain reliable post-test calibrations. ine stressmeters while they are still encased in titu same volume of rock as in the field.

\section{Reliability}

The original set of vibrating-wize stressmeters began failing a few months after their installation in March 1980 with the onset of failure marked by an erratic output signal (Fig. 24). The earliest failures were noted in the CSG-series instruments, which experienced the thermal pulse that accompanied spent fuel emplacement much sooner than the NSG-series instruments (Table 16). Thermal time constants for these positions are 12.5 and 240 days and the mean times to failure are 114 and 352 days, respectively.

Although we have defined failure here in terms of erratic gauge beharior, it is quite possible that the stressmeter data were incorrect by some amount for an unknown time period before the onset of erratic behavior. Direct inspection of the wires determined the failures to be caused by rusting of the vibrating wires (Patrick et al., 1981). The erratic output signal was apparently generated when rust particles on the wire critically damped the vibrations. Before the critical damping, however, the wire was increasing in mass due to the rust (Patrick et al., 1981). This mass loading would tend to decrease the vibrational frequency 

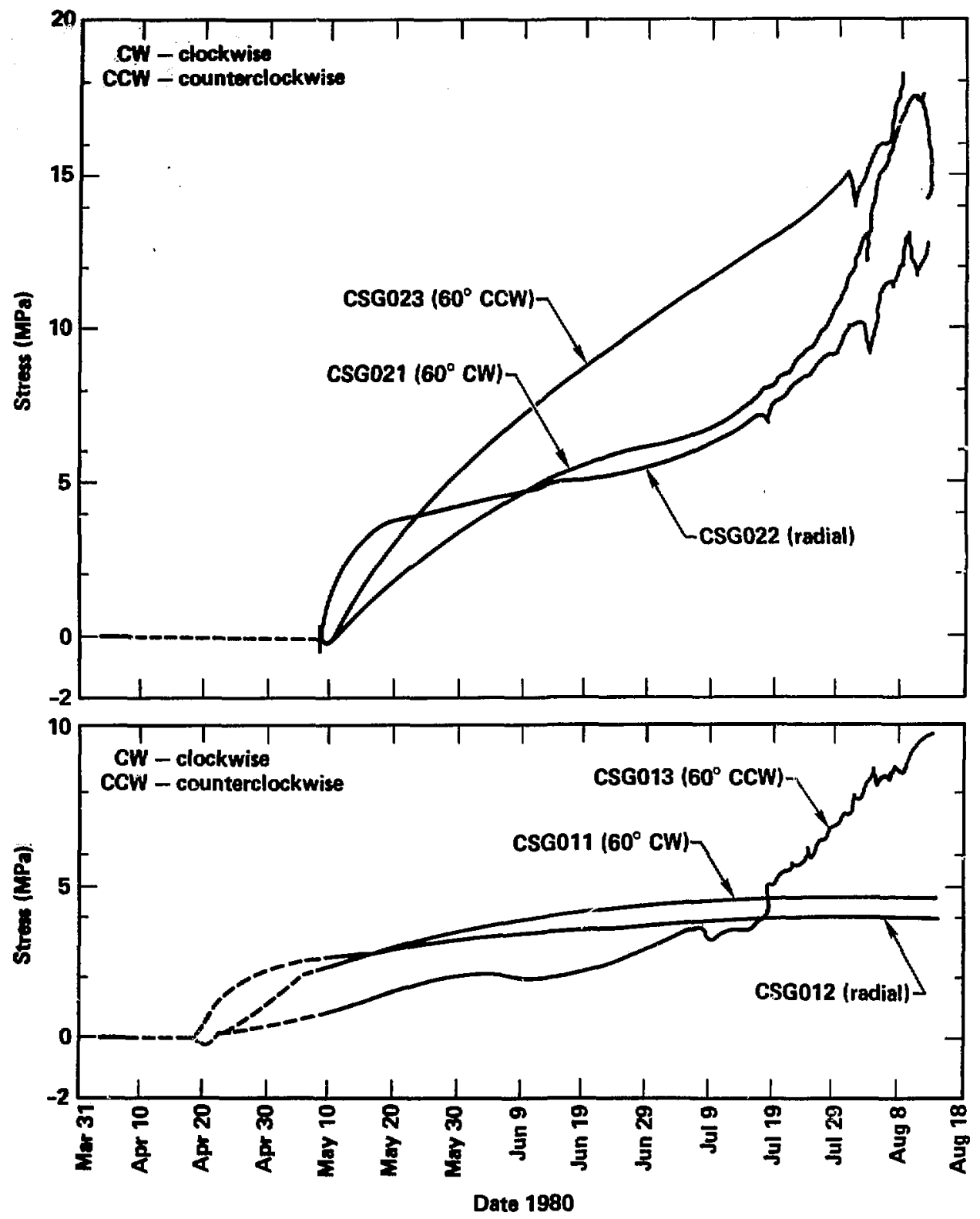

Figure 24. Data from selected vibrating:wire atreameters showing signatures of normal and falling unita. 
of the wire, which would be interpreted as an increase in rock ress. Since an actual increase in

Table 16. Time-to-failure data for vibratingwire stressmeters.

\begin{tabular}{|c|c|c|c|}
\hline $\begin{array}{l}\text { Instrument } \\
\text { license plate }\end{array}$ & $\begin{array}{l}\text { Serial } \\
\text { number }\end{array}$ & $\begin{array}{c}\text { Failure } \\
\text { date (YOC) }\end{array}$ & $\begin{array}{l}\text { Time to } \\
\text { failure (dayo) }\end{array}$ \\
\hline CSG011 & 07 & 2.86 & 161 \\
\hline 012 & Q15 & 2.84 & 153 \\
\hline 013 & 05 & 2.63 & 77 \\
\hline CSG021 & $\mathbf{Q 1}$ & 2.70 & 102 \\
\hline 022 & Q27 & 2.66 & 88 \\
\hline 023 & Q4 & 2.70 & 102 \\
\hline NSG031 & $\mathbf{Q}$ & 3.72 & 476 \\
\hline 032 & Q13 & 3.72 & 477 \\
\hline 033 & Q18 & 3.27 & 310 \\
\hline NSG034 & Q17 & $\$ .50$ & 760 \\
\hline 035 & Q22 & 3.52 & 402 \\
\hline 036 & Q26 & 3.27 & 310 \\
\hline NSG041 & 011 & 3.20 & 285 \\
\hline 042 & 020 & 3.14 & 264 \\
\hline 043 & 03 & 3.05 & 230 \\
\hline NSGO44 & 012 & 3.29 & $\mathbf{3 1 8}$ \\
\hline 045 & 023 & 3.13 & 260 \\
\hline 046 & 024 & 2.80 & 139 \\
\hline
\end{tabular}

- "Failure" is based on the onset of erralic data. The data received prior to "failure" may or may not be reliable. stress was anticipated based on rock response calculations, it is impossible to discem what portion of the observed gauge response is due to actual stress change in the rock and what is due to mass loading of the wire.

Urider independent funding, IRAD subsequently designed and tested a hermetically sealed version of the gauge. In the new version, sealing is accomplished by thin, stainless-steel cups welded to the gauge body around the perimeter of the hole at the ends of the gauge (Fig. 25). Since the welding is done by electron beam, the interior of the gauge is a hard vacuum, thereby eliminating any moisture entry during assembly.

Nine of these new gauges were installed at the SFT-C on June 16 and 17, 1981, and the remaining nine were installed on Ottober 15-27, 1982. With the assistance of a borescospe, the location and orientation of each gauge was precisely selected to avoid rough spots, fractures, and residual foam on the wall contact areas. Locations and initial readings of the replacement gauges are provided by Patrick et al. (1981) and Patrick et al. (1983).

With two exceptions, the 18 replacement stressmeters functioned reliably. Stressmeter number INSG242 occasionally returned erratic output signals for about 3.5 months following its installation in October 1982, and NSG243 exhibited similar behavior throughout its 1-year deployment period. Most readings were reliable for both gauges. The cause of the erratic readings was not determined.

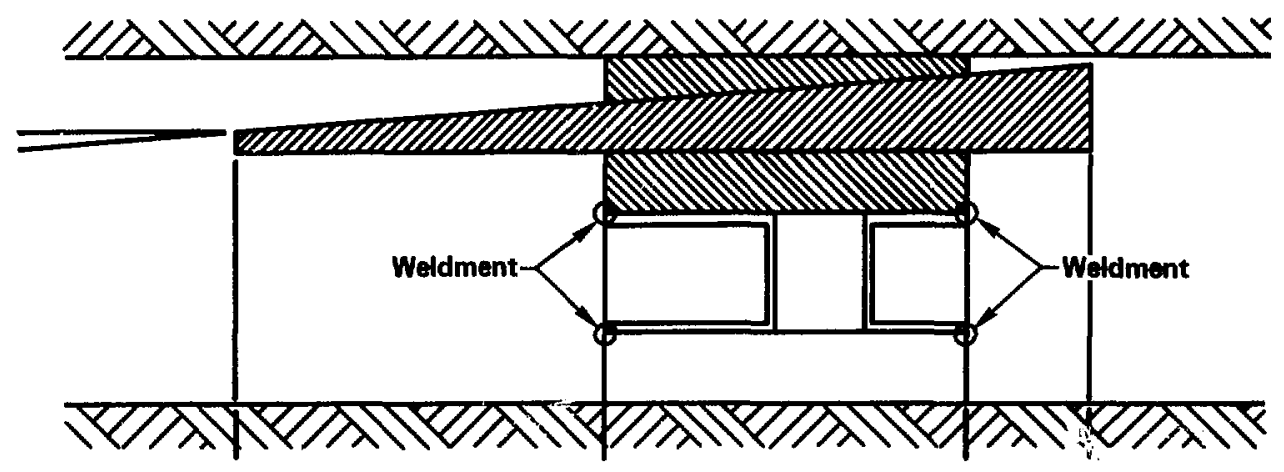

Figure 25. Use of thin stainless cups in the new-deaign vibrating-wire stressmeters. 


\section{Rod Extensometers}

Commercially available multiple-point borchole extensometers (MPBX) were used as the principal instrument to measure relative displacements within the rock mass at the SFT $-C$. Two series of extensometers were deployed, both of which were manufactured by Terrametrics Co., Golden, Colorado.

The Mine-by instrument (MBI) series consisted of four sets of three- and six-anchor units that were installed from the north and south heater drifts of the SFT-C (Figs. 22 and 23) and were originally used to measure relative displacements that took place as the canister drift was excavated (Wilder and Patrick, 1980 and Heuze et al., 1981). The MBI-series extensometers were hydraulically anchored in 76-mm-diam (NX)* boreholes using a standard burst tube and check valve irflation system. Only the collar stabilizer tube was grouted; the rest of the borehole remained open. The connecting rods were carbon steel and were enclosed as a group in a siliconerubber-sheathed flexible metal conduit. Following the Mine-by experiment, the head assemblies were refurbished, the associated linear potentiometers were recalibrated, and the MBI-series extensometers were returned to service for the heated phase of the SFT $-C$.

During the heated phase, the MBI-series extensometers were augmented by a second series that was grouped in four sets to measure nearfield thermal effects in the canister storage drift. These units are called the GxE-series, where the " $x$ " is $A, B, C$, or D depending on which set is being described (Figs. 22 and 23). The GAE and GDE units each comprise one four-anchor MPBX, whereas the GBE and GCE units each comprise two subsets of three four-anchor MPBXs located on either side of the drift centerline. The GXEseries extensometers were also hydraulically anchored but used a nitrogen-over-hydraulic-oilpressure maintenance system to ensure adequate initial inflation and subsequent pressures during the heated phase of the test (Brough and Patrick, 1982). These units were grouted along their entire length using a grout formulated to expand slightly as it cured. To allow for differential expansion and shear between extensometer components, grout, and rock, a ring of closed-cell foam was attached about $0.3 \mathrm{~m}$ above and below each hydraulic anchor. Because temperatures would reach 60 to

\footnotetext{
- NX is a standard borehole size, nominally $76 \mathrm{~mm}$ (3 in.).
}

$65^{\circ} \mathrm{C}$, Superinvar connecting rods were used on the GxE-series extensometers. The connecting rods were ericlosed as a group in a siliconerubber-sheathed flexible metal conduit.

For their initial deployments, both the MBIand GxE-series extensometer transducers were Bourns Model 5184 rectilinear potentiometers. The refurbished $\mathrm{MBl}$ units also used these transducers. The potentiometer shafts were attached to the extensometer connecting rods with threaded fittings and lock nuts.

The GxE-series extensometers experienced severe transducer failures shortly after deployment for the heated phase (Patrick et al, 1981). As a resuli, four types of transducers were installed to evaluate how each type performed. Three extensometers were equipped with each type for a total of 12 of each transducer type. The transducers used in this evaluation were the Bourns Model 5184 rectilinear potentiometer, Vernitron Model 113 rectilinear potentiometer, Schaevitz Model 250 HCD LVDT, and Kaman Sciences Model KD2310-6U electromagnetic proximeter. With the exception of the proximeter, which is a noncontacting device, the transducers were coupled to the connecting rods through a springloaded ball resting on a machined flat surface. Each set of four transducers of each type was subjected to one of three environments: sealed head assembly connected to sealed borehole; head assembly continuously flushed with a small flow of dry nitrogen; and head assembly ventilated of potentially harmful vapors with a slight vacuum.

\section{Calibrations}

\section{Laboratory Callbrations}

All transducers were laboratory-calibrated before installation to establish that the individual transducer was operating within specifications. Posi-test laboratory calibrations were used to establish changes in transducer sensitivity, linearity, and hysteresis characteristics. Because there was no means to reliably establish a "mechanical zero" for the transducer, from which one could determine the theoretical electrical zero position, changes in the offset constant of the transducer could not be determined.

Significant changes occurred in the sensitivity of each type of transducer, with the performance of the electromagnetic proximeters clearly being 
poorer than that of the potentiometers and the LVDTs. The errors in displacement readings generated by these changes in sensitivity are shown in the top half of Table 17. These errors were calculated for an assumed displacement of $5 \mathrm{~mm}$, somewhat larger than anticipated from calculations of rock mass response and thermal expansion of the rods. This approach is conservative for two reasons. First, it focuses the error analysis on the range of interest and does not smooth out the errors in this range by including data from the entire range of the transducer (a common problem with error analyses that are expressed as a percentage of full-scale output). Second, we have observed that this approach tends to highlight the detrimental effects of nonlinearities in the range of interest.

The distribution of errors resulting from changes in transducer sensitivity is shown in histogram form in Fig. 26. Note that the distribution is fairly symmetric at about zero, and about $80 \%$ of all errors fall within a $\pm 50-\mu \mathrm{m}$ range. Errors of this magnitude are a relatively small contribution to the total system errors for the extensometers, as discussed below in "Error Analysis."

Although it is easy to understand how drift in the reiatively complex electronics of the LVDTs and proximeters could produce the observed changes in sensitivity, we did not foresee such changes in the linear potentiometers. A plausible mechanism for such changes is an increase or decrease in resistance near either end of the resistive element. A debonding or flaking of the resistive material near either terminal would increase the resistance over that segment of the potentiometer, thus decreasing the sensitivity over the remainder of the potentiometer. If this occurred outside the calibration range, the potentiometer would remain linear, as we observed in most cases. On the other hand, introducing a parallel resistance near a terminal would have the opposite effect of increasing the sensitivity over the remainder of the potentiometer. A conductive oxide film or accumulation of chemical residue and moisture could

Table 17. Summary of laboratory and in situ calibration errors for borehole rod extensometers.

\begin{tabular}{|c|c|c|c|c|c|c|}
\hline \multirow[b]{2}{*}{ Transducer } & \multirow[b]{2}{*}{ Calibration } & \multirow[b]{2}{*}{ Number } & \multicolumn{4}{|c|}{ Magnitude of error $(\mu \mathrm{m})^{\lambda}$} \\
\hline & & & Mean & Std dev & Kang & \\
\hline potenitiometers & Laboratory & 58 & -3.8 & 67.4 & -281.2 to & +348.1 \\
\hline G×E-series, & & & & & & \\
\hline potentiometers & Laboratory & 29 & $-\mathbf{3 0 . 8}$ & 104.3 & -539.6 to & +115.4 \\
\hline GxE-series, & & & & & & \\
\hline LVDTs & Laboratory & 12 & -22.8 & 59.7 & -207.2 to & +13.9 \\
\hline $\begin{array}{l}\text { GxE-series, } \\
\text { proximelers }\end{array}$ & Laboratory & 12 & +190.8 & 308.1 & -398.0 to & +586.9 \\
\hline $\begin{array}{l}\text { MBI-series, } \\
\text { potentiometers }\end{array}$ & in situ & 59 & -222.5 & 603.7 & -3440.3 to & +29.4 \\
\hline $\begin{array}{l}\text { GxE-series, } \\
\text { potentiometers }\end{array}$ & ins situ & 29 & -105.9 & 168.0 & -938.6 to & +45.1 \\
\hline $\begin{array}{l}\text { GxE-series, } \\
\text { LVDTs }\end{array}$ & in situ & 11 & -94.1 & 31.0 & -136.3 to & -45.5 \\
\hline $\begin{array}{l}\text { GxE-series, } \\
\text { proximeters }\end{array}$ & in situ & 11 & -746.8 & 895.2 & -2651.2 to & 580.9 \\
\hline
\end{tabular}

\footnotetext{
- Errors result from differences between pre- and post-test sensitivilies. A positive sign indicates that the post-teat trans-
} ducer sensitivity was greater than the pretest value. 
Figure 26. Distribution of errors measured in laboratory calibration of GxE- and MBIseries extensometer transducera. Errore result from changet in traneclucer sensitivity between pre- and post-test calibrations.

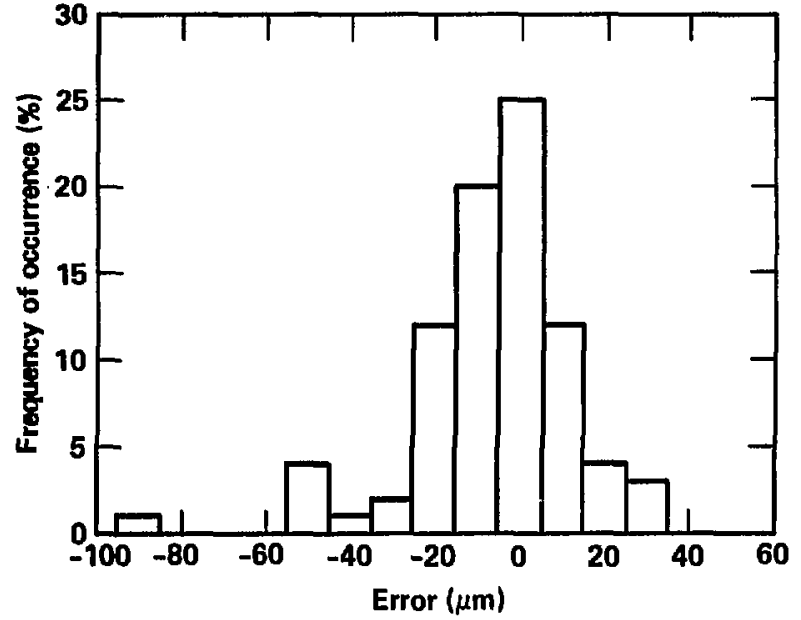

produce this effect. Both of these mechanisms are consistent with our observations concerning failure of linear potentiometers, as discussed below in "Reliability."

\section{In Situ Calibrations}

Because MPBXs are relatively complex mechanical systems, we also performed field calibrations. The manufacturer's recommended procedure was followed for all pretest field calibrations of $\mathrm{MBI}$ - and GxE-series units. This procedure calls for displacing the head assembly relative to the anchors by means of machined steel blocks. To perform this calibration, the head assembly is displaced upward relative to the collar stabilizer tube by means of three bolts. Three calibration blocks are then positioned 120 degrees apart and the head assembly is lowered onto the appropriate steps of the blocks. Thus, whether the gross displacements are increasing or decreasing, the head assembly is always moved down relative to the collar stabilizer tube before each calibratior reading is obtained. These calibrations were performed in 1-mm steps over a range of $5 \mathrm{~mm}$ for the potentiometers, and in $0.5-\mathrm{mm}$ steps over a range of $4 \mathrm{~mm}$ for the electromagnetic proximeters and the LVDTs (Brough and Patrick, 1982; and Patrick et al., 1981).

A new device was developed to facilitate field calibration of borehole rod extensometers. Based on a concept developed by researchers at the Lawrence Berkeley National Laboratory for studies at the Stripa Mine in Sweden (DuBois et al.,
1981), our calibrator incorporates several improvements, including a motor drive, microprocessor control, and independent transducers that provide reference data for the calibrations. The calibrator both automates the calibration process and circumvents the need for lowering the head assembly onto step blocks. Automation is achieved through an HP85B microprocessor, interfaced to the central DAS, which actuates a stepping motor to drive a gear train and screw jacks to raise or lower the extensometer head assembly (Fig. 27). At appropriate displacements, the motor stops and voltage readings are obtained for the extensometer transducers and the three LVDTs on the microadjuster. Note that the three LVDTs, rather than step blocks, constitute the "standard" against which the extensometer transducers are calibrated. Hysteresis and stick-slip behavior are more readily studied with the system's truly bidirectional calibration capability.

Two types of error analyses were performed using the field calibration data. First, an end-point (terminal-point) analysis was used to determine the range of errors that occurred during the preand post-test calibrations. Second, pre- and posttest calibration results were examined to detect changes in transducer sensitivity that would introduce errors in displacement readings.

The end-point analysis is a convenient technique for examining the extreme errors that occurred over the range of the field calibration. Note that this calibration range corresponds to the range of actual displacements recorded in the field 


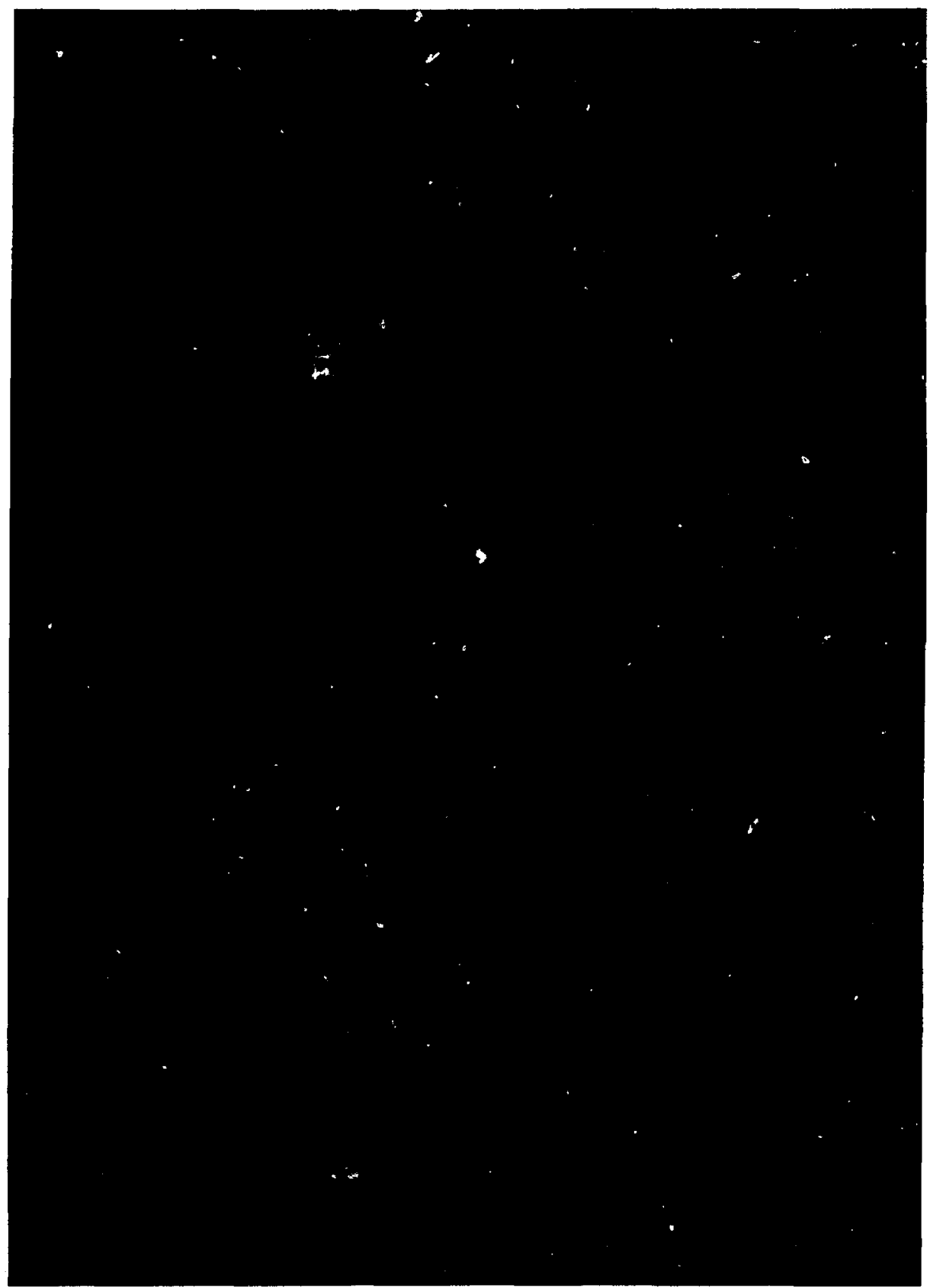

Figure 27. Photograph of the microprocessor-controlled "microadjuster" calibration device. 
rather than the full range of the transducer. While the laboratory calibrations measure only transducer errors, errors measured in the field calibrations propagate as a result of nonlinearities and hysteresis in the entire extensometer system. We distinguish between nonlinearity and hysteresis by defining the former as deviation from a straight line for either the ascending or descending portion of the calibration cycle. On the other hand, hysteresis is the offset in apparent displacement observed between the ascending and descending segments of the calibration. Table 18 summarizes the pertinent end-point error data for each transducer and extensometer type as well as for the entire set of instruments. While all transducers performed quite well in the calibrations, it is clear that the LVDTs exhibited less variability than the potentiometers during both the pre- and post-test calibrations. It is equally clear that the electromagnetic proximeters are more variable from unit to unit and also have a larger mean error. The distributions of the pre- and post-test calibration errors show a tight grouping near the zero point and are rather flat but symmetric beyond $\pm 5 \mu \mathrm{m}$ (Fig. 28). Only subtle changes are evident between the pre- and post-test distributions of errors. About $74 \%$ of the pretest errors and $75 \%$ of the post-test errors fall within a \pm 50 $\mu \mathrm{m}$ window.

As was the case for laboratory calibrations, it is not possible to determine changes in the offset constant because there is no way to establish a zero value for the transducers. However, the errors in displacement readings generated by changes in transducer sensitivity can be determined. Once again, these errors are evaluated from changes in slope over a range of $5 \mathrm{~mm}$. The measured changes in extensometer sensitivities and the errors associated with those changes are dramatic (Table 17, lower half). The distribution of field calibration errors arising from changes in transducer sensitivity is shown in Fig. 29. After removing six outliers, the mean errors caused by sensitivity changes are reduced to $\mathbf{- 1 1 0 . 9 ,}-\mathbf{7 6 . 1}$, -94.1 , and $-305.1 \mu \mathrm{m}$, respectively. The errors are observed to cluster about the first three of these means, giving the frequency histogram a bimodal shape with a central plateau (Fig. 29). This is different from the results obtairied in the laboratory where the errors resulting from changes in sensitivity are normally distributed about a mean value near zero (Fig. 26).

It appears, then, that the errors associated with changes in extensometer sensitivity observed in the field calibrations are not solely the result of changes in transducer sensitivity. Nor are they the result of a difference in the errors generated during the pre- and post-test calibrations, since these error distributions are nearly identical (Fig. 28). We hypothesize two plausible sources of the observed changes in sensitivity. First, rust on the extensometer connecting rods may have prevented them from moving freely through the collar stabilizer tube and head assembly during the

Table 18. Summary of pre- and post-test in situ calibration errors for borehole rod extensometers.

\begin{tabular}{|c|c|c|c|c|c|}
\hline \multirow[b]{2}{*}{ Transducer } & \multirow[b]{2}{*}{ Calibration } & \multirow[b]{2}{*}{ Number' } & \multicolumn{3}{|c|}{ Magnitude of error $(\mu \mathrm{m})^{b}$} \\
\hline & & & Mean & Std dev & Range \\
\hline \multirow[t]{2}{*}{ MBl-deries potentiometers } & Pretest & 120 & 9.5 & 60.6 & -173.1 to +234.0 \\
\hline & Post-test & 116 & -5.6 & 55.3 & -261.0 to +186.4 \\
\hline \multirow[t]{2}{*}{ GxE-series polentiometert } & Pretest & 180 & 1.4 & 51.8 & -212.4 to +170.2 \\
\hline & Post-tent & 58 & -8.6 & 36.3 & $-136.060+97.3$ \\
\hline \multirow[t]{2}{*}{ GxE-series LVDT: } & Pretest & 24 & 1.2 & 17.3 & -31.2 to +32.1 \\
\hline & Post-test & 22 & -3.6 & 7.6 & -18.3 to +6.8 \\
\hline \multirow[t]{2}{*}{ GxE-series proximeters } & Pretest & 24 & $\mathbf{3 1 . 2}$ & 51.4 & -65.6 to +130.2 \\
\hline & Post-test & 20 & 176.9 & 309.0 & $-226.610+1072.8$ \\
\hline \multirow[t]{2}{*}{ All inatruments } & Pretest & 348 & 6.2 & 53.9 & -212.4 to +234.0 \\
\hline & Post-test & 216 & 10.7 & 115.2 & $-226.610+1072.8$ \\
\hline
\end{tabular}

"The "number" in twice the actual number of transducers because a two-sided error band is used.

'Enors result from the characteristics of the transducer and extensometer as a system. Data represent extreme errors calculated from an end-point error analysis. 

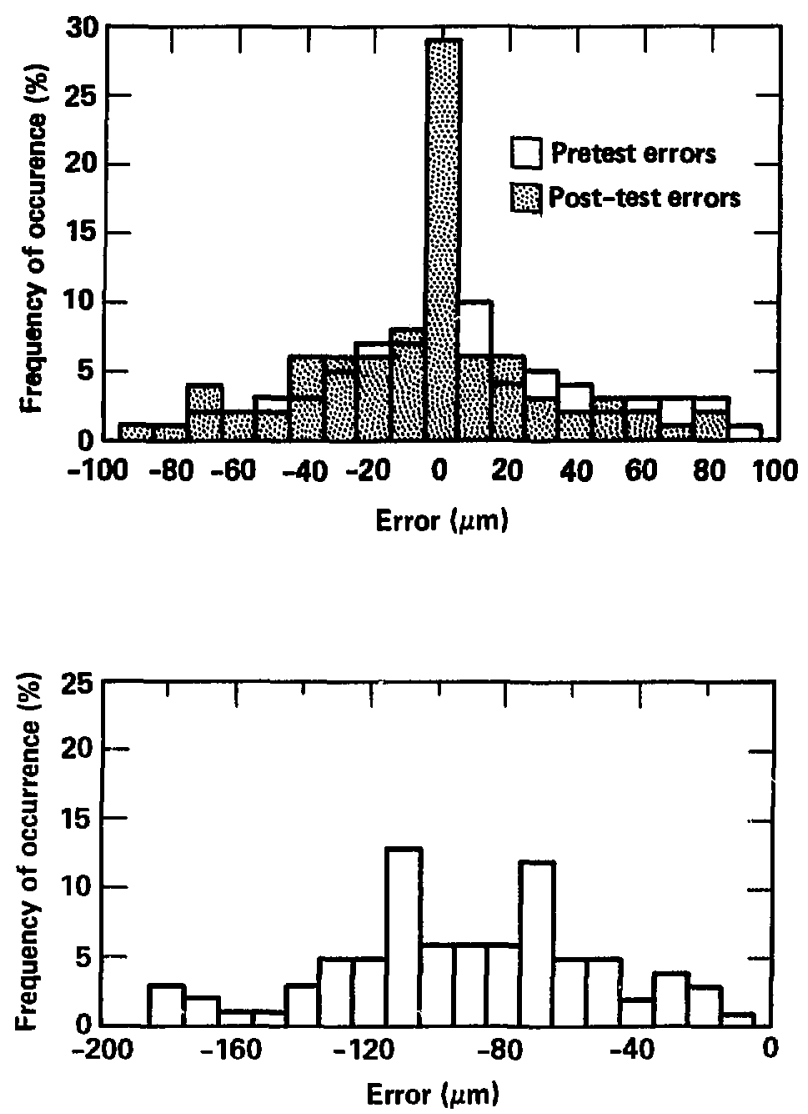

Figure 28. Distribution of errors measured in pre- and post-test field calibrations of borehole extensometer transducers. Data represent extreme errors calculated from an endpoint error analysis.
Figure 29. Distribution of errors measured in field calibrations of GxE- and MBI-series borehole extensometers. Errors result from changes in transducer sensitivity between preand post-test calibrations. post-test calibration. The net result would be a smaller transducer output for a given (apparent) displacement. The transducer would appear to decrease in sensitivity, as was observed (Table 17). The potential for this problem was recognized and all extensometers were exercised over the range of the calibration before any data were acquired. However, minor problems may still have occurred. Second, the differences in extensometer sensitivity may be an accurate reflection of the differences between the two calibration procedures. No explicit cause of such differences has been identified to date, however.

It is also important to realize that the two sources of errors discussed above are not completely independent of each other. Since the first represents errors propagated in a single calibration, it is a component of the second that measures average changes that occurred in the time interval between the pre- and post-test calibrations. Therefore, the two errors should not be root-sum-square added. On the other hand, the former errors, which are based on all calibration positions, are not a strict subset of the latter, which are based only on the two endpoints.

\section{Error Analysis}

Three types of transducers, each with different operating characteristics, were deployed on borehole rod extensometers: potentiometers, LVDTs, and electromagnetic proximeters. Connecting rods were fabricated from Superinvar for near-field GxE-series units, or carbon steel for MBI-series units. These variations were present in four combinations. An error analysis for each type is presented below. 


\section{GxE-series with Potentiometers}

Seven sources of error were identified for the rod extensometers where rectilinear potentiometers were used: the calibration coefficient, excitation and signal voltages, the coefficient of thermal expansion, rod length, and initial and current rod temperatures. The calibration coefficient is determined to be

$K=\frac{E}{S} \cdot D^{*}$.

where

$D^{*}$ is the displacement recorded at calibration, $m$,

E is the excitation, $V$,

$\mathrm{S}$ is the recorded signal, $\mathrm{V}$.

Sensitivity factors are calculated by differentiating Eq. (33), such that

$\boldsymbol{\theta}_{\mathrm{E}}=\frac{\mathrm{dK}}{\mathrm{dE}}=\frac{\mathrm{D}^{*}}{\mathrm{~S}}$,

for errors in excitation voltage;

$\boldsymbol{\theta}_{\mathrm{S}}=\frac{\mathrm{dK}}{\mathrm{dS}}=-\frac{\mathrm{D}^{*} \mathrm{E}}{\mathrm{S}^{2}}$,

for errors in signal voltage;

$\theta_{\mathrm{D}}=\frac{\mathrm{dK}}{\mathrm{dD}}=\frac{E}{\mathrm{~S}}$,

for errors in displacement. Maximum individual errors over an operational range of $5 \mathrm{~mm}$ are (a) signal, $7.48 \times 10^{-5} \mathrm{~V}$, (b) excitation, $5.3 \times 10^{-4} \mathrm{~V}$, and $(c)$ displacement, $2.54 \times 10^{-6} \mathrm{~m}$. The maximum RSS uncertainty in the value of $K$ is calculated to be $1.28 \times 10^{-5} \mathrm{~V} \cdot \mathrm{m} / \mathrm{V}$.

In field use, displacements are calculated using the equation

$\mathrm{D}=\mathrm{K} \cdot \frac{\mathrm{S}}{\mathrm{E}}+\alpha \mathrm{\alpha}\left(\mathrm{T}-\mathrm{T}_{0}\right)$,

where

$$
\begin{aligned}
\mathrm{L}= & \text { the rod length, } \mathrm{m} ; \\
\alpha= & \text { the coefficient of thermal expansion, } \\
& \mathrm{m} / \mathrm{m} \cdot{ }^{\circ} \mathrm{C} \text {. In this case, } \alpha=\mathrm{aT}+\mathrm{b} \\
& (\text { Patrick et al., 1983), where } \mathrm{a}= \\
& 0.33 \times 10^{-8} /{ }^{\circ} \mathrm{C}^{2} \text {, and } \mathrm{b}=-54.95 \\
& \times 10^{-8} /{ }^{\circ} \mathrm{C} \\
\mathrm{T}-\mathrm{T}_{0}= & \text { the change in temperature since in- } \\
& \text { stallation, }{ }^{\circ} \mathrm{C} \text {. }
\end{aligned}
$$

Differentiating Eq. (37) we obtain the following seven sensitivity factors:

$\boldsymbol{\theta}_{\mathrm{K}}=\frac{\mathrm{dD}}{\mathrm{dK}}=\frac{\mathrm{S}}{\mathrm{E}}$,

sor errors in calibration coefficient;

$\theta_{\mathrm{E}}=\frac{\mathrm{dD}}{\mathrm{dE}}=\frac{-\mathrm{KS}}{\mathrm{E}^{2}}$.

for errors in excitation voltages;

$\boldsymbol{\theta}_{\mathrm{s}}=\frac{\mathrm{dD}}{\mathrm{dS}}=\frac{\mathrm{K}}{\mathrm{E}}$,

for eriors in signal voltages;

$\boldsymbol{\theta}_{\alpha}=\frac{\mathrm{dD}}{\mathrm{d} \boldsymbol{\alpha}}=\mathrm{L}\left(\mathrm{T}-\mathrm{T}_{0}\right)$,

for errors in cueffirient of thermal expansion;

$\boldsymbol{\theta}_{\mathrm{t} .}=\frac{\mathrm{dD}}{\mathrm{dL}}=\boldsymbol{\alpha}\left(\mathrm{T}-\mathrm{T}_{0}\right)$

for errors in rod length;

$\boldsymbol{\theta}_{\mathrm{T}}=\frac{\mathrm{dD}}{\mathrm{dT}}=\left(2 \mathrm{aT}+\mathrm{b}-\mathrm{aT} \mathrm{T}_{0}\right) \mathrm{L}$,

for errors in current rod temperature;

$\boldsymbol{\theta}_{\mathrm{T}_{\mathrm{l}}}=\frac{\mathrm{dD}}{\mathrm{dT}_{\mathrm{0}}}=-(\mathrm{aT}+\mathrm{b}) \mathrm{L}$.

for errors in initial rod temperature.

\section{GxE-series with LVDTs}

Seven error sources were also identified for these units. Because a dc-to-dc converter that is insensitive to input voltage was used on the LVDTs, excitation was not a source of error in normal operation, as it was with potentiometers. However, the LVDTs had a temperature sensitivity that introduced errors of not more than $4.8 \times$ $10^{-6} \mathrm{~m} /{ }^{\circ} \mathrm{C}$. The LVDT calibration coefficient is determined to be

$K=\frac{D^{*}}{S}$.

Sensitivity factors are calculated by differentiating Eq. (45). 
$\theta_{S}=\frac{d K}{d S}=\frac{-D^{*}}{S^{2}}$

for errors in signal voltage;

$\theta_{\mathrm{D}}=\frac{\mathrm{dK}}{\mathrm{dD}}=\frac{1}{\mathrm{~S}}$,

for errors in displacement. Maximuın individual errors over an operational range of $\pm 2.5 \mathrm{~mm}$ are (a) signal, $2 \times 10^{-4} \mathrm{~V}$, and (b) displacement, 2.54 $\times 10^{-6} \mathrm{~m}$. The maximum RSS uncertainty in the value of $K$ is calculated to be $6.36 \times 10^{-7} \mathrm{~m} / \mathrm{V}$.

In field use, displacements are calculated using the equation

$D=K S+\alpha L\left(T-T_{0}\right)$.

Differentiating Eq. (48), we obtain

$\boldsymbol{\theta}_{\mathrm{S}}=\frac{\mathrm{dD}}{\mathrm{dS}}=\mathrm{K}$,

for errors in signal voltage;

$\theta_{\mathrm{K}}=\frac{\mathrm{dD}}{\mathrm{dK}}=\mathrm{S}$,

for errors in calibration coefficient. Note that $\theta_{\mathrm{E}}$ $=0$ for LVDTs, and all other $\theta$ values are as expressed in Eqs. (41) through (44) above.

\section{GxE-series with Proximeters}

The error sources for electromagnetic proximeters are the same as for LVDTs. The temperature sensitivity of these units introduces errors of not more than $2.4 \times 10^{-6} \mathrm{~m} /{ }^{\circ} \mathrm{C}$. Maximum individual errors during calibration over a $\pm 2.5-\mathrm{mm}$ range are (a) signal, $1.55 \times 10^{-4} \mathrm{~V}$ and (b) displacement, $2.54 \times 10^{-6} \mathrm{~m}$. The maximum RSS uncertainty in the value of $K$ is calculated to be $1.02 \times 10^{-6} \mathrm{~m} / \mathrm{V}$.

In field use, displacements are calculated using an equation of the form of Eq. (48). Sensitivity factors are as indicated by Eqs. (41) through (44), (49) and (50).

\section{MBI-series with Potentiometers}

Calibration errors associated with MBI-series units are the same in form and magnitude as for GxE-series extensometers.

In field use, displacements are calculated using an equation of the form of Eq. (37). Thus, the sensitivity factors $\theta_{K}, \theta_{k}, \theta_{S}, \theta \alpha_{s}$ and $\theta_{1}$ can be applied as given in Eqs. (38) through (42). Because $\alpha$ is essentially constant over the range of temperatures of interest here $\left(18\right.$ to $\left.35^{\circ} \mathrm{C}\right), \theta_{\mathrm{T}}$ and $\boldsymbol{\theta}_{\mathrm{T}_{0}}$ take on a simpler form:

$$
\Theta_{\mathrm{T}}=\frac{\mathrm{dD}}{\mathrm{dT}}=\alpha \mathrm{L} \text {. }
$$

for errors in current rod temperature;

$\boldsymbol{\theta}_{\mathrm{T}_{\mathrm{i}}}=\frac{\mathrm{dD}}{\mathrm{dT}_{0}}=-\mathrm{aL}$,

for errors in initial rod temperature.

\section{Calculation of Errors}

The unit values for the various sources of error are tabulated in Table 19. Those values are used in conjunction with the sensi. ary factors derived above to calculate the errors in displacement readings.

Table 20 displays maximum calculated errors for each of the four combinations of transducers and rod materials, and for three typical rod lengths for each of these four combinations. The effects of time-varying temperatures directly and indirectly introduce the most significant errors. Our relatively poor knowledge of and the high variability in the coefficient of thermal expansion of the rod materials introduces errors for all four combinations. Where carbon steel rods were used, significant errors are also generated as a result of the scheme used to approximate rod temperatures. In addition, the thermal sensitivity of LVDTs and proximeters is a major contributor to the total error. Note that the "calibration coefficient" errors shown in this table do not include the errors associated with changes in transducer sensitivity recorded during field calibrations (see the "Calibrations" section) but, rather, are the values calculated from Eq. (38) or (50).

\section{Reliability}

Three classes of problems were identified with the borehole rod extensometers: (1) transducers on the $G \times E$ series units deployed in the canister storage drift failed during use; (2) the GxE Superinvar connecting rods experienced stresscorrosion fracturing; (3) the stability of some of the MBI-series extensometer anchors was determined to be inadequate or marginally adequate. These units were inflated with the burst-line technique. In addition, a variety of minor miscellaneous problems occurred during the test period. These problems are summarized below. 
Table 19. Unit erron from various cources for borehole rod extensometers.

\begin{tabular}{|c|c|c|c|c|c|c|c|}
\hline \multirow[b]{2}{*}{$\begin{array}{c}\text { Extencometer } \\
\text { type }\end{array}$} & \multicolumn{7}{|c|}{ Error source and magnitude } \\
\hline & Cal. coeff. & $\begin{array}{c}\text { Excit: } \\
\left(\times 10^{-6} v\right)\end{array}$ & $\begin{array}{c}\text { Signal } \\
\left(\times 10^{-5} \mathrm{~V}\right)\end{array}$ & $\begin{array}{l}\text { Initial } \\
\text { temp } \\
\left({ }^{\circ} \mathrm{C} \cdot \mathrm{m}\right)\end{array}$ & $\begin{array}{l}\text { Current } \\
\text { lemp" } \\
\left({ }^{\circ} \mathrm{C} \cdot \mathrm{m}\right)\end{array}$ & $\begin{array}{c}\text { Coeff } \\
\exp .^{b, c} \\
\left(\times 10^{-7} / \circ C\right)\end{array}$ & $\begin{array}{c}\text { Length } \\
\left(\times 10^{-3} \mathrm{~m}\right)\end{array}$ \\
\hline GxE Bourns & $1.26 \times 10^{-3} \mathrm{~V} \cdot \mathrm{m} / \mathrm{V}$ & 5.30 & 7.48 & 3.0 & 3.0 & 3.0 & 3.05 \\
\hline GxE Vernitec & $1.28 \times 10^{-3} \mathrm{~V} \cdot \mathrm{m} / \mathrm{V}$ & $\mathbf{5 . 3 0}$ & 7.48 & 3.0 & 3.0 & 3.0 & 3.05 \\
\hline GxE LVDT & $6.36 \times 10^{-7} \mathrm{~m} / \mathrm{V}$ & - & 20.0 & 3.0 & $\mathbf{3 . 0}$ & 3.0 & 3.05 \\
\hline GxE Prox. & $1.02 \times 10^{-6} \mathrm{~m} / \mathrm{V}$ & - & 15.5 & 3.0 & 3.0 & 3.0 & 3.05 \\
\hline $\begin{array}{l}\text { GxE original } \\
\text { Bourn: }\end{array}$ & $1.28 \times 10^{-5} \mathrm{~V} \cdot \mathrm{m} / \mathrm{V}$ & 5.30 & 7.48 & 3.0 & 3.0 & 3.0 & 3.05 \\
\hline MBI Dourn: & $1.28 \times 10^{-5} \mathrm{~V} \cdot \mathrm{m} / \mathrm{V}$ & $\mathbf{5 . 3 0}$ & 7.48 & $\mathbf{3 . 0}$ & 3.0 & 5.85 & 3.05 \\
\hline
\end{tabular}

$" 3,0^{\circ} \mathrm{C} \cdot \mathrm{m}$ is maximum error introduced by trapezoldal approximation of the temperature diatribulion. Total temperature error is the RSS of $\left[3.0 /(\right.$ rod length) $]$ and $0.17^{\circ} \mathrm{C}$, the error in thermocouple readings.

${ }^{b}$ for $\mathrm{GxE}=\mathrm{aT}+\mathrm{b}$, where $=0.33 \times 10^{-0} /{ }^{\circ} \mathrm{C}^{2}$ and $\mathrm{b}=-54.95 \times 10^{\mathrm{s}} /{ }^{\circ} \mathrm{C}$; error oblained from LLNL measurements (Pattick et al, 1993).

$c$ e for MDI $=11.7 \times 10^{-6} /{ }^{\circ} \mathrm{C}$; error ascumed as $\pm 5 \%\left(5.85 \times 10^{-7} /{ }^{\circ} \mathrm{C}\right)$.

Table 20. Calculated maximum errors for borehole rod extensometers.

\begin{tabular}{|c|c|c|c|c|c|c|c|c|}
\hline \multirow{2}{*}{$\begin{array}{l}\text { Exiensometer series, } \\
\text { traneducer type, and } \\
\text { rod length (m) }\end{array}$} & & \multicolumn{7}{|c|}{ Error source and magnitude $(\mu \mathrm{m})$} \\
\hline & & $\begin{array}{l}\text { Calfb. } \\
\text { coeff. }\end{array}$ & $\begin{array}{l}\text { Excit. and } \\
\text { signal }\end{array}$ & $\begin{array}{l}\text { Component } \\
\text { temp. }\end{array}$ & $\begin{array}{l}\text { Coeff. of } \\
\text { expansion }\end{array}$ & $\begin{array}{l}\text { Temp. coeff. } \\
\text { of transducer }\end{array}$ & $\begin{array}{l}\text { Component } \\
\text { length }\end{array}$ & RSS \\
\hline \multirow[t]{3}{*}{ GxE, potentiometer, } & 2 & 1.3 & 0.02 & 1.9 & 13.2 & $\mathbf{0}$ & 0.03 & 13.4 \\
\hline & $\mathbf{5}$ & 1.3 & 0.02 & 1.9 & 33.0 & $\mathbf{0}$ & 0.03 & 33.1 \\
\hline & 13.5 & 1.3 & 0.02 & 1.9 & 89.1 & $\mathbf{0}$ & 0.03 & 89.1 \\
\hline \multirow[t]{3}{*}{ GXE, LVDT, } & 2 & 2.5 & 0.01 & 1.9 & 13.2 & 106 & 0.03 & 107.3 \\
\hline & 5 & 2.5 & $0.0 \mathrm{i}$ & 1.9 & 33.0 & 106 & 0.03 & 111.5 \\
\hline & 13.5 & 2.5 & 0.01 & 1.9 & 89.1 & 106 & 0.03 & 138.8 \\
\hline \multirow[t]{3}{*}{ GxE, proximeter, } & 2 & 2.6 & 0.02 & 1.5 & 13.2 & 53 & 0.03 & 54.7 \\
\hline & $\mathbf{5}$ & 2.6 & 0.02 & 1.9 & 33.0 & 53 & 0.03 & 62.5 \\
\hline & 13.5 & 2.6 & 0.02 & 1.9 & 89.1 & 53 & 0.03 & 103.7 \\
\hline \multirow[t]{3}{*}{ MBI, polentiometer, } & 1 & 1.3 & 0.02 & 24.8 & 9.9 & 0 & 0.78 & 26.8 \\
\hline & 5 & 1.3 & 0.02 & 24.8 & 49.7 & 0 & 0.78 & 55.6 \\
\hline & 15 & 1.3 & 0.02 & 24.8 & 149.2 & 0 & 0.78 & 151.3 \\
\hline
\end{tabular}

\section{Transducer Failures}

Several episodes of failures of GxE-series transducers took place. Each is discussed in chronological order.

Initial deployment. This series of transducens is designated by instrument license plates of the form GxE-0yz where " $x$ " is A, B, C, or D (as described previously), the leading " 0 " of the numeric code indicates the original set of transducers, " $y$ " is the borehole number (1 through 6), and " $z$ " is the anchor number (1 through 4).

The onset of failures was observed when computer-recorded readings of relative displace- ment at one extensometer (GCE023) began to be significant in laie-August 1980 , about four months following spent furl emplacement. The recorded displacements caused no concern since they were "reasonable" by at least three criteria. First, they were in the correct direction for early-time displacements since they reflected relative compression between the anchor point and the head assembly, as well as thermal expansion and upward motion of the rock near the anchor. Second, they were in the range of expected displacements. Third, they were following a familiar S-shaped response curve. 
Early in September 1980, routine monitoring showed other units (GCE014, GBE013, GCE033, and GCE063) responding in similar fashion. Apparent displacements became large enough (over $5 \mathrm{~mm}$ ) to cause concern, and a field inspection of these units took place. Although the data acquisition system was recording voltages that indicated displacements of several millimetres, this inspection revealed that the potentiometer shaft had not moved relative to the potentiometer body. Thus, these voltage measurements at the instrument head revealed that the problem was located there and not in the DAS hardware or software. A further set of voltage and confirming resistance measurements indicated that the resistance of the potentiometers was changing in a nonlinear manner with time.

A series of field and laboratory tests undertaken at that point indicatod the possibility of chemical vapor action on the potentiometer resistive element. Details of these evaluations were reported by Patrick et al. (1981). Pased on this assessment, the head assembly covers were removed to vent such vapors.

The principal means of detecting malfunctions of the linear potentiometers were checks for changes in total resistance and erratic voltage readings as a function of time. Total resistance was outside the manufacturer's specification of $5 \mathrm{k} \Omega \pm 10 \%$ for 23 of the 56 transducers (Patrick et al., 1981). Inspection of the recorded data provides additional information. Figure $\mathbf{3 0}$ displays typical output voltages as a function of time for two transducers located within the same head assembly. Several features of these plots are worth noting. First, the output voltage of GCE051 shows a definite break in trend at 2.8 YOC, followed by a period of erratic behavior between 2.9 and 3.0 YOC ( 0.5 to 0.6 years into the test). This behavior is distinctly absent for GCE052, which is located in the same head assembly. Second, the erratic behavior is confirmed by measurements of total resistance, At 3.0 YOC, unit GCE051 was out of specification with respect to total resistance but GCE052 was not. Third, beginning at about $\mathbf{3 . 0}$ YOC, there is a definite recovery in GCE051 and a slight upturn in the GCE052 output voltage. This change is associated with removing the O-ringsealed head assembly cover. Fourth, these displacements (up to the break in trend) agree in form and magnitude with anticipated values.

The break in trend exhibited by GCE051 is c but not ubiquitous, for the GxE0yz transducers. This indicates that transducer failure is an "event" rather than a "process." If Ne could

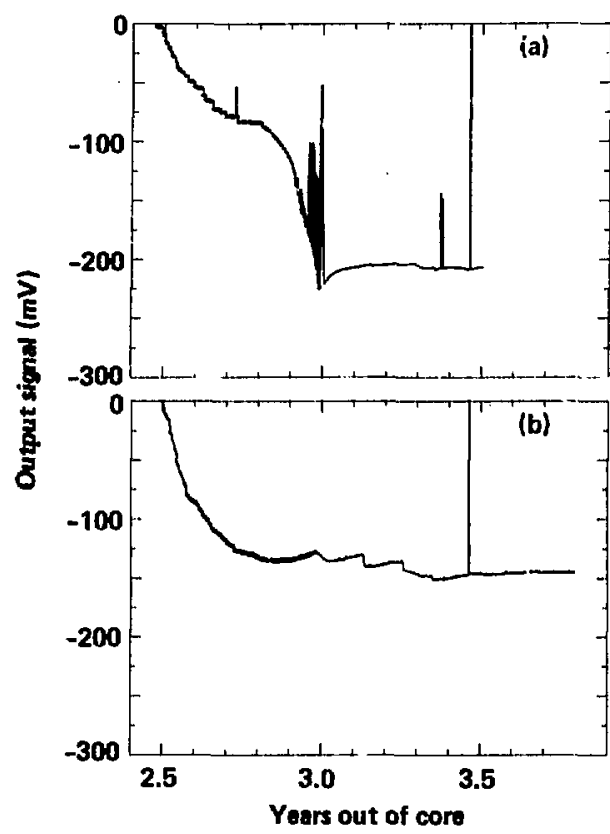

Figure 30. Voltage signatures for two typical Bourns linear potentiometers. (a) Unit GCE051 displays both an erratic output voltage and total resistance out of specification. (b) Unit GCE052 displays a smooth output signal and is still within specification with respect in total resistance.

establish that the break in trend could be used as a failure indicator, we would be confident in accepting data collected before the break. This is particularly tempting because the data agree in form and magnitude with our expectations. However, there is no known mechanism to support the hypothesis that failure is an "event" rather than a "process." Therefore, we have used the oreak in trend or erratic signal as indicators of the latest date at which acceptable data may have been acquired, and conditionally accepted data up to that time. Table 21 displays the perinent time periods for all GxEOyz units. The mean and standard deviation of time to failure using this criterion are 223 and 259 days, respectively.

We considered seven failure hypotheses in evaluating these failures (Patrick et al., 1981):

1. The failed units were from a bad batch.

2. The cause of failure was introduced in .e calibration laboratory. 
3. Electrical damage was caused by overpowering the units.

4. Dithering produced excessive wear to the resistive element. the units.

5. Shock-loading by explosives damaged

6. Higher downhole temperatures caused the sealing agents to cure, producing chemical vapors that damaged the resistive elements.

7. Hygroscopy of the resistive element produced the observed hanges in resistance.

The evaluation of the observed failures included field resistance measurements, gas sampling, hygroscopy studies at low pressure and elevated temperature, nicroscopic textural inspections, and chemical interaction tests. These evaluations are documented in Patrick et al. (1981). Although these investigations led us to eliminate several possible causes of failure, we have not found a totally satisf ctory answer to the problem to date. Hypothesis 6 remains the most plausible. As noted above, venting the potentiometers by removing the head assembly cover appeared to curtail and possibly re-erse the observed degradation.

Replacement Bourns Potentiometers. Following the laboratory and field evaluations noted above, replacement Bourns potentiometers were procured and calibrated at the EG\&G-Atlas facility. About two weeks later, before fielding, a sample of the replacement units was checked for total resistance and found to be out of specification. In all, 21 of the 64 replacement urits (33\%) failed. Testing showed that these transducers remained linear, contrary to the nonlinear mode of failure observed in the units deployed in the field. Sir.ie none of these transducers were fielded, their failures resulted in no direct loss of data.

Deplioyment for transducer evaluation. We decided to revise our original decision to install only "off-the-shelf" instrumentation (Brough and Patrick, 1982) to correct the problem of the failed potentiometers. A period of instrument evaluation was planned for the remaining life of the SFT- $C$. We based our changed philosuphy on three facts. First, since the cause of the potentiometer failures had not been definitively established, it seemed prudent to install several transducer types to minimize further loss of data if the failure mode was peculiar to one transducer type. Second, installation of several types would allow us to evaluate the relative performance of the selected transducers. Third, judicious choice of alternative transducers would not degrade the quality

Table 21. Failure ciates for Bourns linear potentiometers deploysd on borehole extensometers in the spent-fuel canister storage drift.

\begin{tabular}{|c|c|c|c|c|c|}
\hline $\begin{array}{l}\text { License } \\
\text { plate }\end{array}$ & $\begin{array}{l}\text { Failure date } \\
\text { (YOC) }\end{array}$ & $\begin{array}{c}\text { License } \\
\text { plate }\end{array}$ & $\begin{array}{c}\text { Failure date } \\
\text { (YOC) }\end{array}$ & $\begin{array}{c}\text { License } \\
\text { plate }\end{array}$ & $\begin{array}{l}\text { Failure date } \\
\text { (YOC) }\end{array}$ \\
\hline GAE011 & 4.3B & GBE051 & 2.68 & GCEOSI & -2 \\
\hline 012 & 4.38 & 052 & 2.72 & 0,2 & - \\
\hline 013 & 4.38 & 053 & 3.24 & 043 & -2 \\
\hline 014 & 4.38 & 054 & 2.69 & 044 & 2.76 \\
\hline GBE011 & -" & GBE061 & 2.60 & GCE05: & 2.82 \\
\hline 012 & - & 062 & 3.21 & 052 & 2.79 \\
\hline 013 & 2.75 & 063 & - & 053 & 2.79 \\
\hline 014 & 2.82 & 064 & 2.98 & 054 & - \\
\hline GBE021 & 2.64 & GCE011 & 2.92 & GCE06: & - \\
\hline 022 & 2.70 & 012 & 2.89 & 062 & - \\
\hline 023 & 2.62 & 013 & 2.67 & 063 & 2.77 \\
\hline 024 & 2.76 & 014 & 2.65 & 064 & 2.60 \\
\hline GBE031 & 2.60 & GCE021 & -" & GDE011 & 5.68 \\
\hline 032 & 2.65 & 022 & 2.73 & 012 & 4.85 \\
\hline 033 & 2.78 & 023 & 2.70 & 013 & - \\
\hline 034 & 2.65 & 024 & 2.77 & 014 & - \\
\hline GBEOS1 & 2.63 & GCE031 & 2.66 & - & - \\
\hline $0 \leq 2$ & 2.71 & 032 & 2.73 & - & - \\
\hline 043 & -2 & 033 & 2.69 & - & - \\
\hline o44 & 2.66 & 034 & 2.77 & - & - \\
\hline
\end{tabular}

a Not observed before removal at 3.84 YOC. 
of acquired data and might even improve the quality.

These three considerations led us to select four transducers to replace the $48 \mathrm{GBE}$ - and GCEseries units, where all failures had occurred to date. The leading digit of the numeric code was changed to " 2 " to denote the second series of transducers. Each group of three extensometers received one type of transducer. Schaevitz Model 250HCD linear variable differential transformess (LVDTs) were installed in GBE21x, GBE22x, and GBE23x; Bourns Model 5184 rectilinear potentiometers were reinstalled in GBE24x, GBE25x, and GBE26x; Kaman Model KD-2310-6U electromagnetic proximeters were installed in GCE21x, GCE22x, and GCE23x; and Vernitron Model 113 rectilinear potentiometers were installed in GCE24x, GCE25x, and GCE26x. The characteristics of the selected transducers are summarized by Patrick et al. (1981). Although each of the three alternates compares favorably in several ways with the original Boums potentiometers, both the LVDTs and proximeters are temperaturesensitive, as discussed previously in "Error Analysis."

We had observed in previous installations that the potentiometer shafts were eccentric with respect to the rods to which they were coupled. This condition introduces side loading, which causes the shaft and body of the potentiometers to bind and is responsible for some of the "stickslip" type motion observed in the rod extensometers. During replacement operations, a modification was introduced to circumvent this problem. All screw couplings of potentiometer and LVDT shafts to rods were replaced by spring-loading the shaft against a flat, smooth, stainless-steel fitting attached to the rod. A stainless-steel sphere screwed onto the shaft provided a point contact against the stainless-steel, machined flat surface attached to the rod. This modification was implemented on both potentiometer types and on the LVDT. The proximeter is a noncontacting device that uses a $19-\mathrm{mm}$-diam $\times 6.4-\mathrm{mm}$-thick aluminum target attached to the rod. These modifications are believed to have enthanced the quality of the acquired data.

Another modification was to subject each of the head assemblies associated with the Bourns, Vernitron, Schaevitz, and Kaman transducers to three different environments. To produce the three test environments, the head assemblies were sither (1) sealed with an O-ring on the cover of the head assembly; (2) sealed and flushed with dry nitrogen; or (3) sealed and ventilated of potentially harmful vapors using a small vacuum.

As an added precaution, all Vishay precision bridge completion resistors associated with linear potentiometers were replaced with hermetically sealed units. This change was implemented in response to two observed resistor failures (Patrick et al., 1981).

Before installation, all transducers were laboratory-calibrated, and all refurbished rod extensometers were calibiated in situ in accordance with the established procedures described above in "Casibration." Because of the shorter range of the Kaman and Schaevitz curs: Jucers, these units were calibrated in $0.5-\mathrm{mm}$ steps over a range of $4.0 \mathrm{~mm}$ rather than in $1.0-\mathrm{mm}$ steps over a range of $5.0 \mathrm{~mm}$.

A few months after the second deplcyment, the Vernitron linear potentiometers began to fail. Two failure modes were exhibited. Whereas most units showed a slight rise in signal as a function of time followed by a precipitous fali (Fig. 31), the

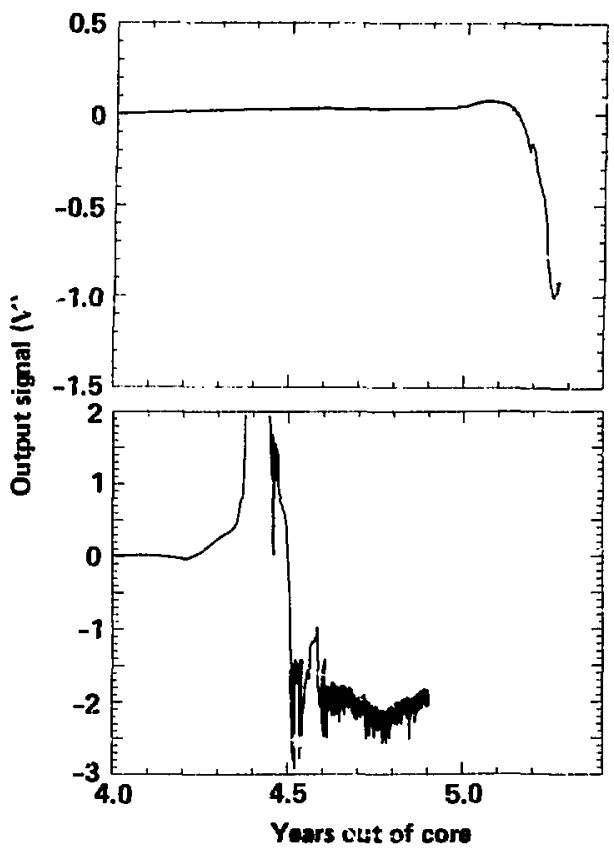

Figure 31. Failure signature of Vernitron linear poteritiometers. 
Tabse 22. Failure dates for Vernitroxi linear polentiometere deployed a borehole' extencometers in the epent-fuel canibter storage drift.

\begin{tabular}{rcc}
\hline Lceme plate & Indallation (YOC) & Failure (YOC) \\
\hline GCE241 & 3.95 & 4.46 \\
242 & 3.55 & 4.46 \\
243 & 3.55 & 4.46 \\
244 & 3.95 & 4.47 \\
GCE251 & 3.95 & 4.95 \\
252 & 3.95 & 5.01 \\
253 & 3.95 & 4.97 \\
244 & 3.95 & 5.06 \\
GCE261 & 3.95 & 4.12 \\
262 & 3.95 & 4.02 \\
263 & 3.95 & 4.14 \\
264 & 3.95 & $4 i$ \\
\hline
\end{tabular}

others showed an abrupt rise, typtcally to full scale positive voltage, followed by a precipitous fall to a voltage of -2 to $-4 \mathrm{~V}$. For the latter cases, the signal was generally erratic. Table 22 displays the interval during which data from these transducers are conditionally acceptable. The mean and standard deviations of time to failure are 210 and 141 days, respectively. As with the original failures, we cannot be certain that data are reliable before the break in trend, wh:ih was used as the failure criterion.

Failure analysis for these units was more limited than for the first sequence of failures. Optical and electron microscopy revealed that the resistive elements were severely fractured. In general, these fractures were transverse to the length of the resistive element and appeared to originate on the outer edge of the element and propagate inward. Fracturing was most intense opposite the shaft end of the potentiometer and decreased to none near the center (wiper) location.

Following failure of the Vernitron potentiometers, they were replaced with Bourns potentiomefers. The leading digit of the numeric code was changed to 4 to denote this series of transducers.

\section{Rod and inchorage Integrity Tests}

Both the MBI- and GxE-series borehole extensometers used hydraulic bladder anchors that consist of sections of flattened copper tube that have been welded along the ends and formed around a cylindrical mandrel. To ensure that the anchors were properly fabricated, leak tests were performed before installation. A connecting rod is attached to the mandrei to provide a reference for displacement measurements. In the case of the MBI units, the anchors had an integral check valve that was used in conjunction with a hydraulic burst-line to inflate the anchors and, presumably, maintain anchor pressure following the bursting of the inflation line. These units were not 1.. grouted in place. The initial inflation pressure was provided to the GxE anchors through highpressure Bundiweld tubing, and the pressure was maintained with a nitrogen-over-hydraulic system (Brough and Patrick, 1982). As previnisly noted, these units were full-column-grouted.

Anchor pressures. Schrauf and Board (1979) reported problems associated with inflating the MBI anchors. The MBI-105 and -106 anchors could not be installed to the planned depth because of "... pinching (jamming) of the hydraulic lines...." In addition, they report that the hydraulic lines burst prematurely for the MBI11z, MBI12z, and MBI13z units (a total of 15 anchors). The hydraulic lines typically burst at $\sim 1000$ psi (6.9 MPa), but the line associated with MB1136 burst at $\sim 500$ psi $(3.4 \mathrm{MPa})$. The effect of inadequate inflation pressures is discussed below.

As noted above, the near-field (GxE-series) rod extensometers used a nitrogen-over-hydrac: lic fluid sys'em in an effort to maintain stable anchor pressure. At approximately 1-ınonth intervals, the pressure of each anchor was checked for conformance to a 1750- \pm 50 -psi (12.1- $\pm 0.3-\mathrm{MPa})$ critericn. Nitrogen was added or vented to adjust the observed pressure to the acceptable rarige. Both pressure decreases and increases were observed. Pressure decreases may be due to system leaks, continued deformation of the anchor in the borehole, or differential expansion of the borehole relative to the anchor. Pressure increases are generally thought to be due to thermal expansion of the hydraulic fluid and differential contraction of the borehole relative to the anchor.

Although all GxE unit anchors were successfully inflated to the 1750-psi (12.1-MPa) anchoring pressure, 27 of the $56(48 \%)$ exhibited pressure losses as the test progressed. Table 23 documents the first occurrence of these leakages and the typical pressure recorded at the time of pressure adjustment (monthly). These represent irreparable leaks that occurred in the downhole components of the extensometer. Nearly $80 \%$ of the leaks occurred during the first year of the test when significant heating of the rock mass was in progress (Fig. 32). As discussed below, there is no evidence that these pressure losses adversely effected data quality. This is attributed to the fact that all anchors were subjected to proper inflation pressures for a minimum of two months before leaks occurred. 
Table 23. Loss-of-pressure record for GxEseriea borehole rod extensometer anchors that used a nitrogen-over-hydraulic inflation and pressure-maintenance system.

\begin{tabular}{|c|c|c|c|}
\hline $\begin{array}{l}\text { Instrument } \\
\text { Iicence }\end{array}$ & $\begin{array}{l}\text { First occurrerce } \\
\text { of leakage }\end{array}$ & $\begin{array}{r}\text { Typ } \\
\text { pressure [ }\end{array}$ & $\begin{array}{l}\text { pical } \\
\text { [pai (MPa)] }\end{array}$ \\
\hline GAE011 & $7 / 60$ & 0 & (0) \\
\hline 012 & $10 / 80$ & 200 & (1,4) \\
\hline 013 & $7 / 80$ & 0 & (0) \\
\hline 014 & $7 / 60$ & 500 & $(3.4)$ \\
\hline GBE013 & $12 / 81$ & 0 & (0) \\
\hline 021 & $10 / 80$ & 1425 & $(9,8)$ \\
\hline 023 & $4 / 60$ & 0 & (0) \\
\hline 031 & $6 / 80$ & 700 & $(4,8)$ \\
\hline 034 & $10 / 60$ & 1100 & $(7,6)$ \\
\hline 044 & $12 / 81$ & 1200 & $(8.3)$ \\
\hline 053 & $2 / 81$ & 650 & $(4.5)$ \\
\hline 054 & $12 / 80$ & 1050 & $(7.2)$ \\
\hline 061 & $6 / 80$ & 200 & $(1.4)$ \\
\hline GCE012 & $4 / 60$ & 250 & (1.7) \\
\hline 013 & $4 / 80$ & 0 & (0) \\
\hline 021 & $10 / 80$ & 1610 & (11.1) \\
\hline 022 & $7 / 80$ & $\mathbf{5 5 0}$ & $(3.8)$ \\
\hline 023 & $10 / 60$ & 1100 & $(7.6)$ \\
\hline 032 & $12 / 82$ & 1600 & (11.0) \\
\hline 033 & $6 / 80$ & 0 & (0) \\
\hline 034 & $10 / 80$ & 0 & (0) \\
\hline 052 & $3 / 82$ & 1250 & (B.6) \\
\hline 054 & $2 / 82$ & 950 & $(6.6)$ \\
\hline 061 & $6 / 00$ & 200 & (1.4) \\
\hline 063 & $6 / 80$ & 1050 & $(7.2)$ \\
\hline 064 & 4,83 & 0 & (0) \\
\hline GDE014 & $6 / 80$ & 475 & $(3,3)$ \\
\hline
\end{tabular}

'First leakage below 1650 poi (11.4 MPa). Date is month and year of presure check when leakage was observed.

In situ teats of anchor integrity. A positive-displacement hydraulic system was designed, fabricated, and deployed to pull-test each individual rod of the MBI- and GxE-series extensometers after the post-test calibrations were completed (Fig. 33). These pull-test results were used to confirm that the anchors were stable during the SFT-C. To provide an a rerage displacement value at each load increment, ihree linear potentiometers were positioned at 120-degree azimuthal orientations at a common radial distance from the rod axis. The reference for the potentiometers was attached directly to the individual rod, so slip of the coupling, which was being pulled by the hydraulic ram, would not be measured. Load was measured by a calibrated load cell located between the hollow hydraulic ram and the reaction plate of the test fixture. Each rod and anchor assembly was subjected to four cycles of loading and unloading. The test plan required a minimum load of $300 \mathrm{lb}(1.3 \mathrm{kN})$ [ $\sim 6100 \mathrm{psi}(42.1$ $\mathrm{MPa}$ ) rod stress], but most tests on GxE-series extensometers were conducted to $900 \mathrm{lb}(4.0 \mathrm{kN})$ to examine anchor and rod integrity at higher loads.

Anchor slip was interpreted by comparing the measured stiffness of the system $K_{a}$ with the calculated rod stiffness $K$. Because of uncertainties in material properties, we established a criterion that $K_{\mathrm{n}}$ be within $10 \%$ of $K$. The value of $K_{\mathrm{p}}$ was obtained graphically as the slope of the load vs displacement plot at the nominal rod tension of $100 \mathrm{lb}(0.4 \mathrm{kN})$ for the first loading of the rod and anchor system. The value of $K$ was calculated as $K=E A / L$, where $E$ is the Young's modulus of the rod, $A$ is the rod cross-sectional area, and $L$ is the rod length. Nominal values of $E$ and $A$ and measured values of $L$ were used in these calculations,

Table 24 shows the values of $K_{k}$ and $K$ as well as the ratio $K_{a} / K$ for the $M B I$-series extensometers, The ratio of $\mathrm{K}_{\mathrm{a}} / \mathrm{K}$ is near unity for most anchors, and load-vs-displacement curves are linear (Fig. 34), indicating that the anchors are stable under the nominal force exerted on the rods during the active phases of testing at the SFT-C. Furthermore, the load at which the anchors slipped (as noted by a change in slope of the load-vsdisplacement curve) is typically several times the nominal force. Only units MBI-103, -105, -113, -135 , and -136 exhibited nonlinear behavior at loads less than $100 \mathrm{lb}(0.4 \mathrm{kN})$. An example is provided in Fig. 35. Even these displayed linear behavior (but low stiffness) near $100 \mathrm{lb}(04 . \mathrm{kN})$. In addition, units MBI-022, -036, -131, and -132 showed anchor slip at loads less than $200 \mathrm{lb}(0.9$ $\mathrm{kN}$ ), twice the nominal load. We judge that these nine anchors were stable during the heated phase of the SFT $-C$, but may have slipped during the excavation phase (Mine-by) when they were subjected to high explosive shocks.

Similar data for the $\mathrm{GxE}$-series extensometers are shown in Table 25. Most ratios of $K_{a} / K$ are near unity, and the load-vs-displacement curves are linear (Fig. 36). Note that the longest rod of each set exhibited nonlinear behavior in most cases (Fig. 37). In general, the nonlinear behavior resulted in a lower value of $K_{2}$. We believe that nonlinear behavior at low loads is caused by the rods being straightened from their relaxed position. In the relaxed position, the 13.2-m-long rods, which are oriented vertically downward, flex 


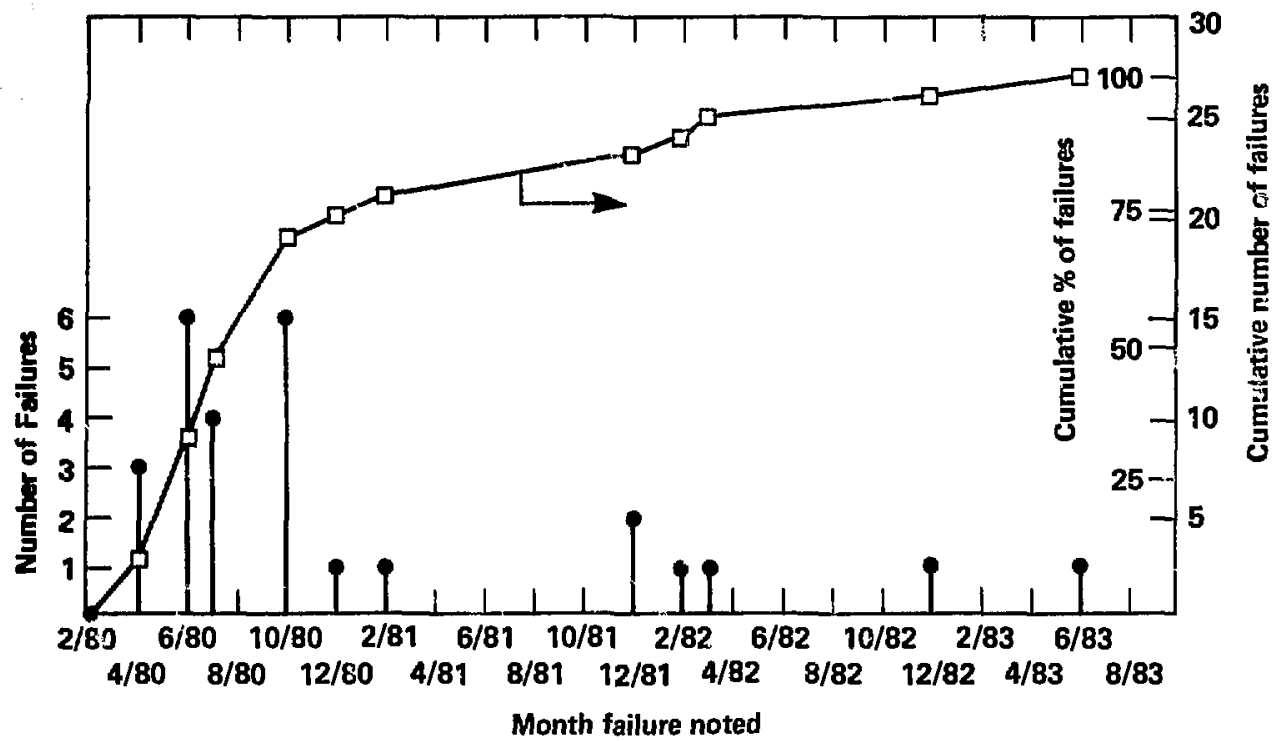

Figure 32. History of pressure loss for GxE-series rod extensometers that had pressure maintenance systems.

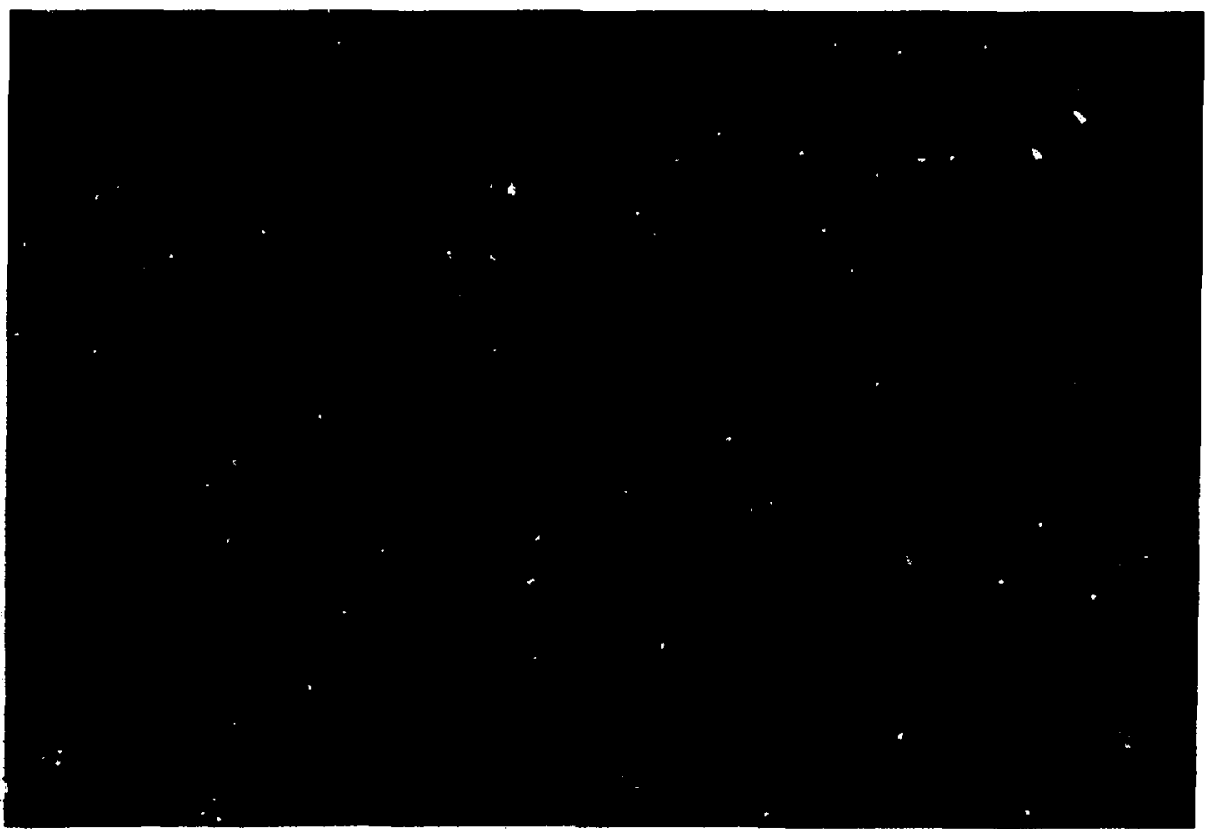

Figure 33. Photograph of the borehole extensometer rod- and anchorage-integrity tester. 
Table 24. Comparison of measured and calculated rod stiffness of the MBI-series extensometers as a measure of anchor stability.

\begin{tabular}{|c|c|c|c|c|}
\hline $\begin{array}{l}\text { Instrument } \\
\text { license }\end{array}$ & $\begin{array}{c}\mathrm{K}_{\mathrm{a}} \\
{\left[10^{3} \mathrm{lb} / \mathrm{in}(\mathrm{MN} / \mathrm{m})\right]^{\mathrm{a}}}\end{array}$ & $\stackrel{\mathrm{K}}{\left[10^{3} \mathrm{lb} / \mathrm{tn}(\mathrm{MN} / \mathrm{m})\right]^{\mathrm{b}}}$ & $\mathrm{K}_{2} / \mathrm{K}$ & $\begin{array}{l}\text { Commentse } \\
\text { [lb (kN)] }\end{array}$ \\
\hline MBI 011 & $20.99(3.68)$ & $20.72(3.63)$ & 1.01 & - \\
\hline 012 & $8.49(1.49)$ & $9.08(1.59)$ & 0.94 & $560(2.5)$ \\
\hline 013 & $6.67(1.17)$ & $6.36(1.11)$ & 1.05 & $520(2.3)$ \\
\hline MBI 021 & $19.93(3.49)$ & $19.98(3.50)$ & 1.00 & - \\
\hline 022 & $9.50(1.66)$ & $9.26(1.6 .2)$ & 1.03 & $160(0.7)$ \\
\hline 023 & $6.28(1.10)$ & $5.95(1.04)$ & 1.06 & 720 (3.2) \\
\hline 024 & $4.74(0.83)$ & $4.46(0.78)$ & 1.06 & $750(3.3)$ \\
\hline 025 & $4.09(0.72)$ & $3.96(0.69)$ & 1.03 & $580(2,6)$ \\
\hline 026 & $3.62(0.63)$ & $3.42(0.60)$ & 1.06 & $570(2.5)$ \\
\hline MBI 031 & $18.33(3.21)$ & $18.29(3.20)$ & 1.00 & - \\
\hline 032 & $7.33(1.26)$ & $7.34(1.29)$ & 1.00 & - \\
\hline 033 & $1.73(0.83)$ & $4.59(0.80)$ & 1.03 & $740(3.3)$ \\
\hline 034 & $3.87(0.68)$ & $3.59(0.63)$ & 1.08 & $920(4.1)$ \\
\hline 035 & $3.12(0.55)$ & $2.96(0.52)$ & 1.05 & $690(3.1)$ \\
\hline 036 & $2.59(0.45)$ & $2.56(0.45)$ & 1.01 & $190(0.8)$ \\
\hline MBI 041 & $20.83(3.65)$ & $20.28(3.55)$ & 1.03 & - \\
\hline 042 & $8.87(1.55)$ & $9.85(1.72)$ & 0.90 & $770(3.4)$ \\
\hline 043 & $6.89(1.21)$ & $6.76(1.18)$ & 1.02 & - \\
\hline MBI 051 & $20.68(3.62)$ & $20.88(3.66)$ & 0.99 & - \\
\hline 052 & $10.13(1.77)$ & $9.72(1.70)$ & 1.04 & - \\
\hline 053 & $6.64(1.16)$ & $6.45(1.13)$ & 1.03 & $400(1.8)$ \\
\hline 054 & $5.21(0.91)$ & $5.10(0.89)$ & 1.02 & $390(1.7)$ \\
\hline 055 & $4.30(0.75)$ & $4.13(0.72)$ & 1.04 & $510(2.3)$ \\
\hline 056 & $3.51(0.61)$ & $3.49(0.61)$ & 1.01 & $290(1.3)$ \\
\hline MBI 061 & $21.83(3.82)$ & $19.57(3.43)$ & 1.12 & - \\
\hline 062 & $7.39(1.29)$ & $6.58(1.15)$ & 1.12 & $630(2.8)$ \\
\hline 063 & $4.69(0.82)$ & $4.61(0.81)$ & 1.02 & $260(1.2)$ \\
\hline 064 & $3.68(0.64)$ & $3.48(0.61)$ & 1.06 & $490(2.2)$ \\
\hline 065 & $2.99(0.52)$ & $2.95(0.52)$ & 1.01 & $610(2.7)$ \\
\hline 066 & $2.56(0.45)$ & $2.54(0.44)$ & 1.01 & $550(2.4)$ \\
\hline MBI 081 & $16.27(2.85)$ & $15.72(2.75)$ & 1.03 & - \\
\hline 082 & B.65 (1.51) & $9.02(1.58)$ & 0.96 & - \\
\hline 083 & $6.67(1.17)$ & $6.46(1.13)$ & 1.03 & $610(2.7)$ \\
\hline MBI 091 & $20.68(3.62)$ & $19.30(3.38)$ & 1.07 & - \\
\hline 092 & $9.65(1.69)$ & $9.75(1.71)$ & 0.99 & $390(1.7)$ \\
\hline 093 & $6.77(1.19)$ & $6.69(1.17)$ & 1.01 & $550(2,4)$ \\
\hline 094 & $5.19(0.91)$ & $4.98(0.87)$ & 1.04 & $270(1.2)$ \\
\hline 095 & $4.24(0.74)$ & $4.01(0.70)$ & 1.06 & $590(2.6)$ \\
\hline 096 & $3.90(0.67)$ & $3.49(0.61)$ & 1.09 & $660(2.9)$ \\
\hline
\end{tabular}


Table 24. (Centinued)

\begin{tabular}{|c|c|c|c|c|}
\hline $\begin{array}{l}\text { Inotrument } \\
\text { licenes }\end{array}$ & {$\left[10^{3} \mathrm{lb} / \mathrm{in}(\mathrm{MN} / \mathrm{m})\right]^{\mu}$} & {$\left[10^{3} \mathrm{lb} / \mathrm{in}(\mathrm{MN} / \mathrm{m})\right]^{\mathrm{b}}$} & $\mathbf{K}_{2} / \mathbf{K}$ & $\begin{array}{l}\text { Comments } \\
\text { [lb (kN)] }\end{array}$ \\
\hline MBI 101 & $19.64(3.44)$ & $19.03(3.33)$ & 1.03 & - \\
\hline 102 & $8.30(1.45)$ & $7.73(1.35)$ & 1.07 & $\rightarrow$ \\
\hline 103 & $0.81(0.14)$ & $4.56(0.80)$ & 0.18 & $20,120(0.09,0.5)$ \\
\hline 104 & $3.87(0.68)$ & $3.65(0.64)$ & 1.06 & - \\
\hline 105 & $0.71(0.12)$ & $2.97(0.52)$ & 0.24 & $10,190(0.04,0.8)$ \\
\hline 106 & $2.71(0.47)$ & $2.60(0.46)$ & 1.04 & $320(1.4)$ \\
\hline MBI 111 & $17,86(3.13)$ & $16.75(2.93)$ & 1.07 & - \\
\hline 112 & $9.24(1.62)$ & $9.17(1.61)$ & 1.01 & - \\
\hline 113 & $6.96(1.22)$ & $6.86(1.20)$ & 1.01 & $35,190(0.2,0.8)$ \\
\hline MBI 121 & $19.71(3.45)$ & $19.70(3.45)$ & 1.00 & - \\
\hline 122 & $8.13(1.42)$ & $8.69(1.52)$ & 0.94 & $570(2.5)$ \\
\hline 123 & $6.16(1.08)$ & $6.32(1.11)$ & 0.97 & $230(1.0)$ \\
\hline 124 & $5.24(0.92)$ & $4.97(0.87)$ & 1.05 & $520(2.3)$ \\
\hline 125 & $4.17(0.73)$ & $4.13(0.72)$ & 1.01 & $400(1.8)$ \\
\hline 126 & $3.38(0.59)$ & $3.70(0.65)$ & 0.91 & $300(1.3)$ \\
\hline MBI 131 & $12.93(2.26)$ & $19.84(3.47)$ & 0.65 & $150(0.7)$ \\
\hline 132 & $7.20(1.26)$ & $7.50(1.31)$ & 0.96 & $130(0.6)$ \\
\hline 133 & $3.99(0.70)$ & $4.57(0.80)$ & 0.87 & $390(1.7)$ \\
\hline 134 & $3.74(0.65)$ & $3.71(0.65)$ & 1.01 & $290(1.3)$ \\
\hline 135 & $2.76(0.48)$ & $3.00(0.53)$ & 0.92 & $100,210(0.4,0.9)$ \\
\hline 136 & $2.99(0.52)$ & $2.66(0.47)$ & 1.12 & $50,450(0.2,2.0)$ \\
\hline
\end{tabular}

' Stiffness of the extensometer system at the nominal rod tension of $1001 \mathrm{~b}(0.4 \mathrm{kN})$. Determined as the slope of the load-vsdisplacement curve.

${ }^{b}$ Calculated stiffness of the extensometer system, $K=$ EA/L. Where $E=28.5 \times 10^{6} \mathrm{psi}(197 \mathrm{GPa})$, rod $0.25 \mathrm{in}$. (6.35 mm) in diameter, length varies.

' Rod load at which an anchor slipped was noted by a change in slope of the load-vs-displacement curve. Where two loads are given, they delineate the linear portion of the curve.

(buckle) elastically under their own weight of about $3.5 \mathrm{~kg}$. In addition, during assembly of the extensometers, the rods were noted to have a permanent curvature that was introduced in manufacturing and shipping the rods. This curvature was straightened as the load on the rods increased, producing a linear curve at higher loads (Fig. 37). Since the nominal $100-\mathrm{lb}$ rod tension was essentially constant with time, this behavior does not adversely affect data quality.

As previously discussed, we were unable to maintain anchor pressure on 27 of the GXE-series extensometers (Table 23). Of those, only GAE011, GBE044, and GDE014 have $K_{a} / K$ ratios which are less than 0.90 , that is they have a measured stiffness at least $10 \%$ less than the calculated stiffness. Furthermore, GCE041, GCE043, and GDE013 have $K_{a} / K$ ratios less than 0.90 , yet anchor pressures were maintained throughout the test. Neither the nonlinearities in the load-vsdisplacement curves nor the occurrence of $K_{a} / K$ less than unity are believed to have adversely affected the test data.

In situ test of rod integrity. The Superinvar connecting rods of the GxE-series borehole extensometers began failing about three years into the test, shortly before the heated phase of the test concluded. Seven rods failed in service as noted in Table 26. The rod and anchorage integrity tester was used to determine which rods were approaching failure by subjecting them to load. Three additional rods failed during testing, bringing the total to 10 of the $56(18 \%)$ Superinvar rods deployed on the test. The failure loads indicate that the rod cross sections at failure were about $15 \%$ of the nominal value.

Rod failure analysis. Metallographic sections of the rod failure surfaces revealed classic 

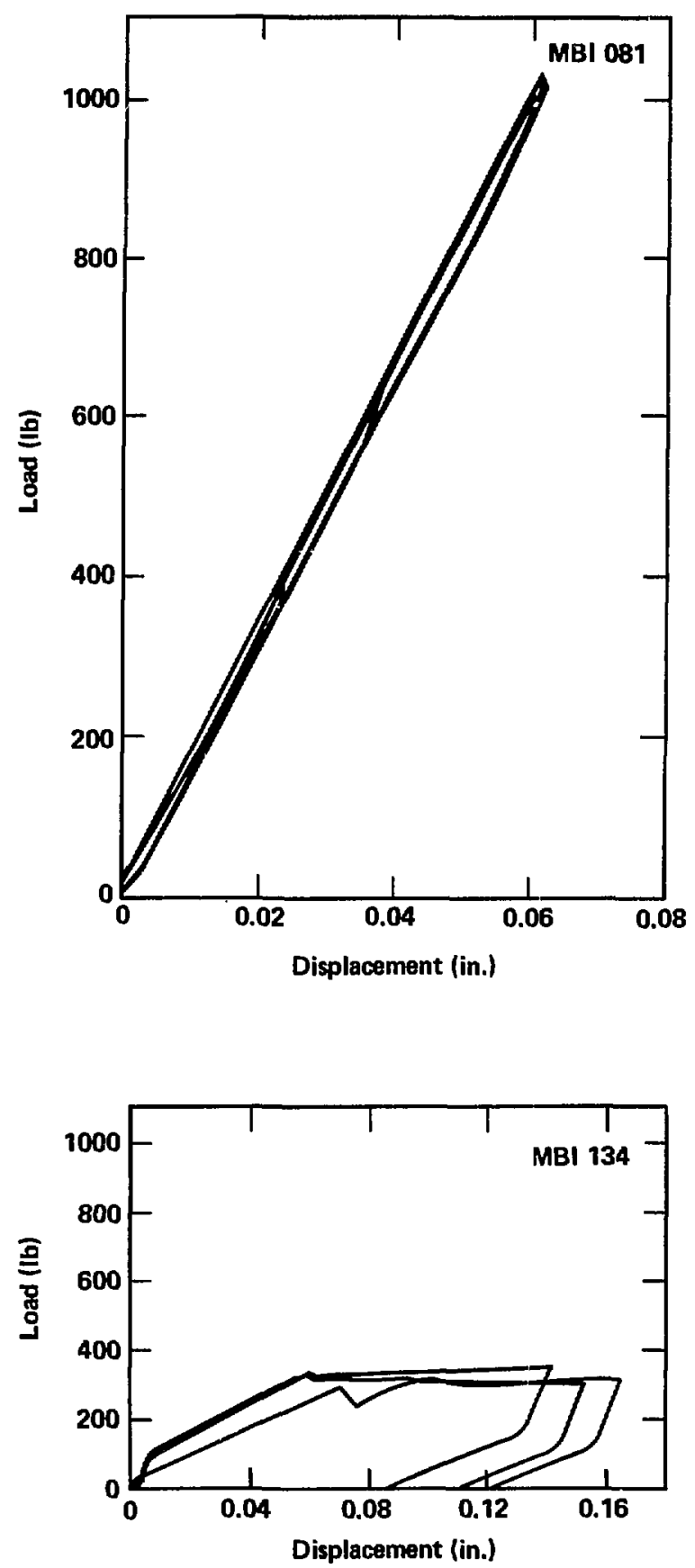

Figure 34. Typical example of linear load vs displacement response of an MBI-series extensometer.
Figure 35. Typical example of load vs displacement response of an MBI-series extensometer where anchor slip was encountered. 
Table 25. Comparicon of measured and calculated rod stiffness of the GxE-series extensometers as a meawure of anchor stabllity.

\begin{tabular}{|c|c|c|c|c|}
\hline $\begin{array}{l}\text { Instrument } \\
\text { license }\end{array}$ & $\begin{array}{c}K_{2} \\
{\left[10^{3} \mathrm{lb} / \mathrm{in}(\mathrm{MN} / \mathrm{m})\right\}^{\mathrm{e}}}\end{array}$ & $\underset{\left[10^{3} \mathrm{lb} / \mathrm{in}(\mathrm{MN} / \mathrm{m})\right]^{\mathrm{b}}}{\mathrm{K}}$ & $K, / K$ & Comments \\
\hline GAE 011 & $10.46(1.83)$ & $11.89(2.08)$ & 0.88 & \\
\hline 012 & $6.55(1.15)$ & $6.91(1.21)$ & 0.95 & \\
\hline 013 & $4.74(0.83)$ & $4.84(0.85)$ & 0.98 & \\
\hline 014 & $1.73(0.30)$ & $1.86(0.33)$ & 0.93 & Nonlinear \\
\hline GBE 011 & $12.41(2.17)$ & $12.13(2.12)$ & 1.02 & \\
\hline 012 & $6.90(1.22)$ & $6.97(1.22)$ & 1.00 & \\
\hline 013 & $4.85(0.05)$ & $4.85(0.85)$ & 1.00 & \\
\hline 014 & $1.02(0.32)$ & $1.86(0.33)$ & 0.98 & \\
\hline GBE 021 & $11.04(2.07)$ & $11,93(2,09)$ & 0.99 & \\
\hline 022 & $7.14(1,25)$ & $6.89(1.21)$ & 1.04 & \\
\hline 023 & $4.50(0.79)$ & $4.83(0.85)$ & 0.93 & \\
\hline 024 & $1.64(0.29)$ & $1.83(0.32)$ & 0.90 & \\
\hline GBE 031 & $12.10(2.12)$ & $12.07(2.11)$ & 1.00 & \\
\hline 032 & $7.23(1.27)$ & $6.89(1.21)$ & 1.05 & \\
\hline 033 & $4.87(0.85)$ & $4.83(0.85)$ & 1.01 & \\
\hline 034 & $\mathbf{N} / \mathbf{A}$ & $1.83(0.32)$ & $\mathbf{N} / \mathbf{A}$ & Rod broken \\
\hline GBE 041 & $12.10(2.12)$ & $12.00(2.10)$ & 1.01 & \\
\hline 042 & $6.72(1.18)$ & $6.89(1.21)$ & 0.98 & \\
\hline 043 & $4.66(0.82)$ & $4.83(0.85)$ & 0.96 & \\
\hline 0.4 & $1.39(0.24)$ & $1.91(0.33)$ & 0.73 & Nonlinear \\
\hline GBE 051 & $12.53(2.19)$ & $12.06(2.11)$ & 1.04 & \\
\hline 052 & $7.06(1.24)$ & $6.95(1.22)$ & 1.02 & \\
\hline 053 & $4.76(0.83)$ & $4.86(0.85)$ & 0.98 & \\
\hline 054 & $1.78(0.31)$ & $1.88(0.33)$ & 0,95 & Nonlinear \\
\hline GBE 061 & $12.23(2.14)$ & $12.11(2.12)$ & 1.01 & \\
\hline 062 & $6.81(1.19)$ & 6.94 (1.22) & 0.98 & $\begin{array}{l}\text { Rod failed } \\
\text { in testing }\end{array}$ \\
\hline 063 & $4.64(0.81)$ & $4.86(0.85)$ & 0.95 & \\
\hline 064 & $1.79(0.31)$ & $1.86(0.33)$ & 0.96 & Nonlinear \\
\hline GCE 011 & $12.56(2.20)$ & $12.44(2.18)$ & 1,01 & \\
\hline 012 & $7.13(1.25)$ & $7.05(1.23)$ & 1.01 & \\
\hline 013 & $4.98(0.87)$ & $4.93(0.86)$ & 1.01 & \\
\hline 014 & $1.81(0.32)$ & $1.83(0.32)$ & 0.99 & Nonlinear \\
\hline GCE 021 & $\mathbf{N} / \mathbf{A}$ & 12.41 (2.17) & $\mathbf{N} / \mathbf{A}$ & Rod broken \\
\hline 022 & $7.22(1.26)$ & $6.86(1.20)$ & 1.05 & \\
\hline 023 & N/A & $4.83(0.85)$ & N/A & Rod broken \\
\hline 024 & $1.80(0.32)$ & $1.82(0.32)$ & 0.99 & Nonlinear \\
\hline GCE 031 & $10.42(1.82)$ & $11.35(1.99)$ & 0.92 & Nonlinear \\
\hline 032 & $7.00(1.23)$ & $6.92(1.21)$ & 1.01 & \\
\hline 033 & $5.00(0.88)$ & $4.84(0.85)$ & 1.03 & \\
\hline 034 & $1.71(0.30)$ & $1.82(0.32)$ & 0.94 & Nonlinear \\
\hline
\end{tabular}


Table 25. (Continued)

\begin{tabular}{|c|c|c|c|c|}
\hline $\begin{array}{l}\text { Instrument } \\
\text { license }\end{array}$ & {$\left[10^{3} \mathrm{lb} / \mathrm{in}(\mathrm{MN} / \mathrm{m})\right]^{\mathrm{a}}$} & {$\left[10^{3} \mathrm{lb} / \mathrm{in}(\mathrm{MN} / \mathrm{m})\right]^{\mathrm{b}}$} & $K_{\mathbf{a}} / K$ & Comments \\
\hline GCE 041 & $9.36(1.64)$ & $12.02(2.11)$ & 0.78 & $\begin{array}{l}\text { Rod failed in } \\
\text { testing }\end{array}$ \\
\hline 042 & $\mathbf{N} / \mathbf{A}$ & $7.25(1.27)$ & $\mathbf{N} / \mathbf{A}$ & Rod broken \\
\hline 043 & $4.07(0.71)$ & $4.85(0.85)$ & 0.84 & Nonlinear \\
\hline 044 & $1.74(0.30)$ & $1.82(0.32)$ & 0.96 & Nonlinear \\
\hline GCE 051 & $\mathbf{N} / \mathbf{A}$ & $12.06(2.11)$ & $\mathbf{N} / \mathbf{A}$ & Rod broken \\
\hline 052 & $\mathbf{N} / \mathbf{A}$ & $6.90(1.21)$ & $\mathbf{N} / \mathbf{A}$ & Rod broken \\
\hline 053 & $4.83(0.85)$ & $4.79(0.8 \cdot 1)$ & 1.01 & Nonlinear \\
\hline 054 & $1.85(0.32)$ & $1.82(0.32)$ & 1.02 & Nonlinear \\
\hline GCE 061 & $12.82(2.25)$ & $12.26(2.15)$ & 1.05 & \\
\hline 062 & $\mathbf{N} / \boldsymbol{A}$ & $6.96(1.22)$ & $\mathbf{N} / \mathbf{A}$ & Rod broken \\
\hline 063 & $1.46(0.78)$ & $4.88(0.85)$ & 0.91 & Nonlinear \\
\hline 064 & $1.83(0.32)$ & $1.83(0.32)$ & 1.00 & Nonlinear \\
\hline GDE 011 & $12.50(2.19)$ & $12.20(2,14)$ & 1.02 & \\
\hline 012 & $6.27(1.10)$ & $6.95(1.22)$ & 0.90 & Nonlinear \\
\hline 013 & $3.44(0.60)$ & $4.87(0.85)$ & 0.71 & Very nonlinear \\
\hline 014 & $1.12(0.20)$ & $1.80(0.32)$ & 0.62 & Very nonlinear \\
\hline
\end{tabular}

a Stiffness of the extensometer system at the nominal rod tension of $100 \mathrm{lb}(0.4 \mathrm{kN})$. Determined as the slope of the load-vsdisplacement curve.

${ }^{b}$ Calculated stiffness of the extensometer system, $K=E A / L$. Where $E=19.8 \times 10^{6}$ psi $(136 \mathrm{GPa})$, rod $=0.25 \mathrm{in} .(6.35 \mathrm{~mm})$ in diameter, length varies.

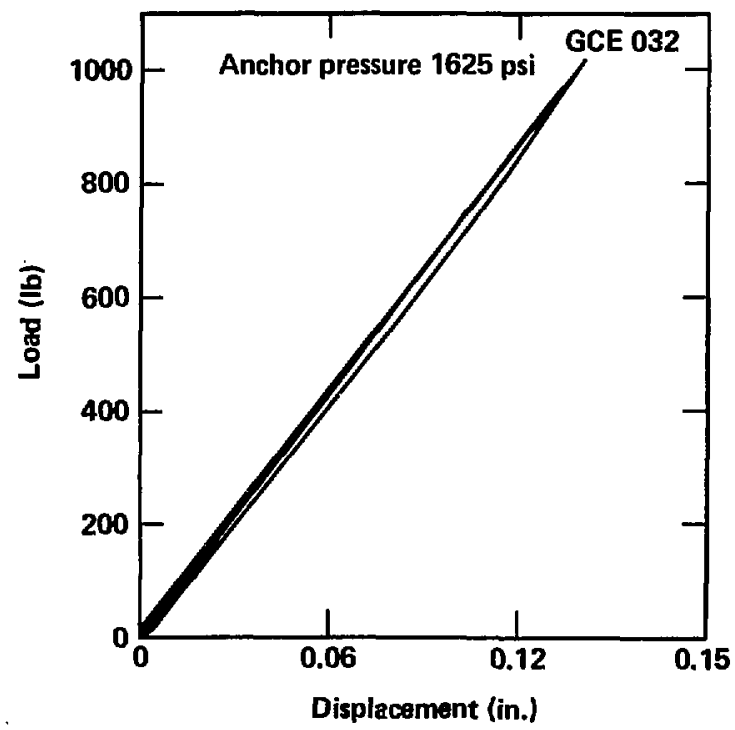

Figure 36. Typical example of linear load displacement response of a GxE-series extensometer. 
Figure 37. Typical example of nonlinear load displacement response. Nonlinearity is due to straightening a rod that had permanent curvature.

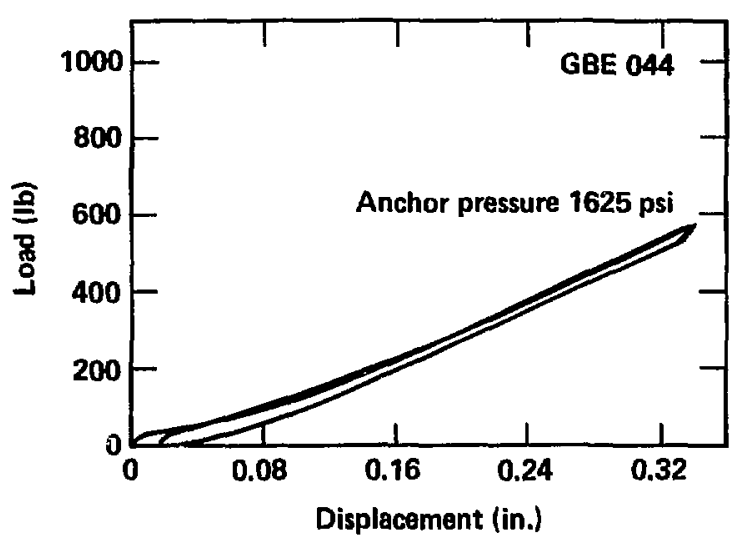

instrumentation. We conducted two series of experiments using virgin Superinvar obtained from the same lot as was used in the field instrumentation. Although we evaluated a variety of couplings and specimen surface preparations, all specimens had in common exposure to Climax groundwater and a temperature of $50^{\circ} \mathrm{C}$ (Patrick et al., 1983).

Failures were observed in the first series of tests, where coupling to either copper or copper and carbon steel was present, but the observed fracture morphology indicated ductile fracture rather than stress corrosion cracking, as was observed in the field. The second test series was accelerated by adding $94 \mathrm{~g} / \mathrm{L} \mathrm{CuCl}_{2}-2 \mathrm{H}_{2} \mathrm{O}$. Corrosion progressed rapidly and two failures occurred. The surface morphology of these specimens included both transgranular and intergranular fracture, and thus was similar to the fractures observed in the field. In addition, pitting of the rod surface was evident as a result of the chloride ion.

The classic corrosion cracking curve of Copson (1959)-Fig. 38-indicates that Superinvar ( $31.5 \%$ nickel content) is a poor choice of material to use where chloride ion is present, as is the case for typical granite groundwaters. There is obviously a trade-off between the exceilent thermal expansion properties of the Superinvar and its relatively poor corrosion behavior.

\section{Miscellaneous Problems}

A variety of relatively minor problems arose and were corrected during the SFT-C. Since each of these adversely affected the data for several 
days, they are enumerated here to assist analysts in interpreting the measurements.

Two of the $2.5-\mathrm{k} \Omega$ bridge completion resistors used in the potentiometer circuit (Brough and Patrick, 1982) failed. The precision resistors were replaced on September 16, 1980, for GCE03z, and October 14, 1980, for GBE03z. In addition, electrical shorts were observed at various times during the test. These resulted when the resistive element of the potentiometer became "dirty," typically with an oxidation film or a speck of metallic or other resistive debris. Such problems were corrected by cleaning and lubricating units GBE26x (February 5, 1982); GBE011 (July 1, 1982); GAE014 (December 8, 1982); and GBE263 (September 8, 1983).

Two MBl-series rectilinear potentiometers malfunctioned during the test. First, MBI081 became nonlinear while maintaining total resistance within specifications (5.4 kR). It was replaced and renamed MBI084 on October 28, 1980. Second, MBI063 displayed erratic output. After several attempts to correct the problem by cleaning and lubricating the potentiometer, it was removed from service for repair on November 10, 1982. Details concerning these and other problems are documented in SFT $-\mathrm{C}$ project records.

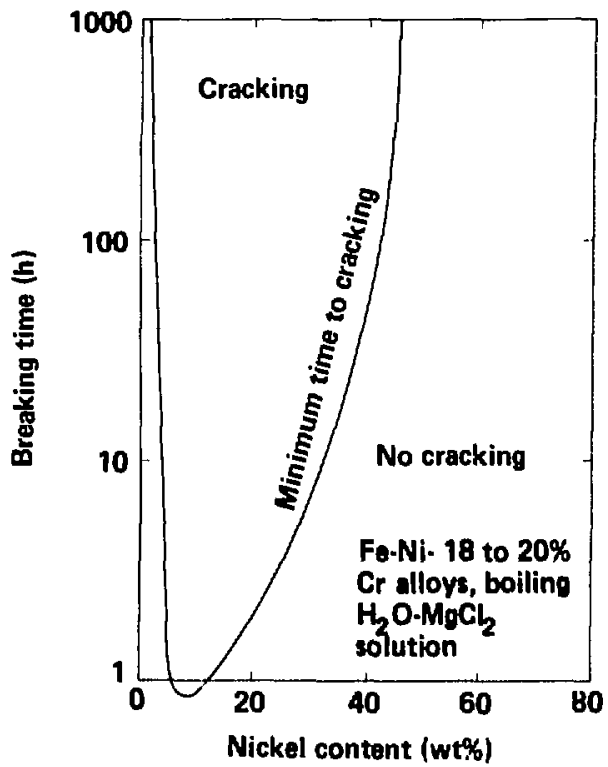

Figure 38. Relationship between breaking time and nickel content (after Copson, 1959).

\section{Convergence Monitors}

Convergence wire extensometers (CWEs) were designed and deployed to monitor relative displacements across the three drifts of the SFT-C facility. The design of the CWE units is such that they may be oriented to measure displacements across horizontal, vertical, or angled spans. One end of each CWE is a machined steel pin to which a length of $0.635-\mathrm{mm}$-diam stainlesssteel connecting wire is permanently attached (Fig. 39). The pin is slipped into a mating machined block permanently affixed to the drift surface. The opposite, active and of each CWE consists of a linear potentiometer housed in a brass weight that is attached to the opposite end of the stainless-steel connecting wire with a second machined pin (Fig. 40). The potentiometer shaft, which is also dead-weight-loaded, rests on a machined plate that is part of the second reference point. The connecting wire passes over a threaded pulley, which allows the CWE to be used in a variety of orientations while maintaining the vertical attitude of the dead weight system. Sixteen pairs of horizontally and vertically oriented CWEs were deployed (Figs. 22 and 23).

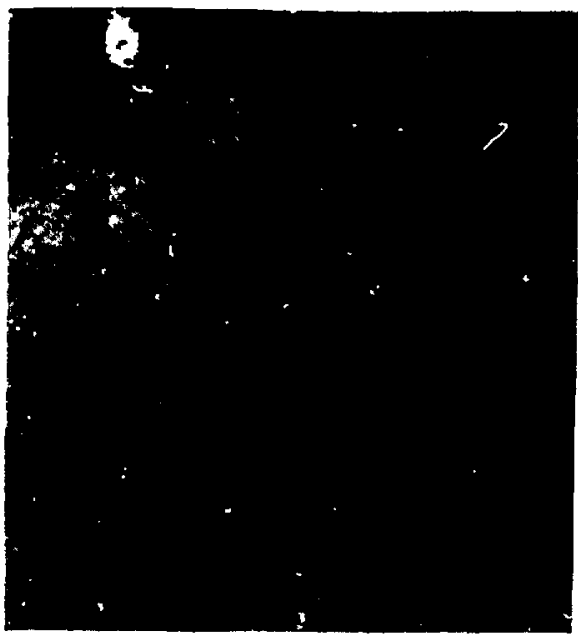

Figure 39. Inactive end of convergence wire extensometer showing spherical mount for tape extensometer. 
One of the important features of the CWE design is that it may be readily removed and replaced to allow free access in the storage drifts for such activities as emplacement and retrieval of the spent fuel. Removal and replacement without loss of reference point were accommodated by the machined attachment pin at the inactive end of the CWE on horizontally oriented units. On vertical units, stainless steel reference tabs at the active end of the CWE were also required so that the CWE could be removed from the floor. The reference tabs were simply $25-\mathrm{mm}$ square stainless steel plate stock with a washer attached. Three such tabs were glued to the concrete floor or a steel plate at each instrument location. Three adjustable leveling "feet" on each vertical CWE unit were mated with these tabs (Fig. 40).

A second feature of the CWE is the development of a four-wire resistance-temperature measurement system. This feature, referred to as a convergence wire temperature (CWT) monitor, is discussed in detail in the "Temperature Sensors" section. The relatively large coefficient of thermal expansion and length of the stainless-steel connecting wire made this feature essential.

The third feature is provision for tape extensometer measurements between the CWE reference points (Figs. 39 and 40). Tape extensometer readings provided a straightforward measurement of relative displacements independent of the DAS. In addition to being available for analysis before CWE data reduction algorithms were in place, the tape extensometer data also provided a check on the CWE electronically acquired data.

\section{Calibration}

Pre- and post-test laboratory calibrations of the linear potentiometers were performed using the same procedure as described for laboratory calibration of rod extensometer transducers. These calibrations examined the transducers for possible changes in slope (sensitivity).

At the start of the SFT-C, there was considerable uncertainty with regard to expected displacements. Therefore, the data reduction algorithm and associated sensitivity values were based on the average slope over the entire $25.4-\mathrm{mm}$ range of the transducer. We now know that actual displacements were less than $5 \mathrm{~mm}$. The top two rows of Table 27 present errors caused by using the slope over the full $25.4-\mathrm{mm}$ range of the potentiometers rather than the limited \pm 2.54 -mm $r$ inge. Both pre- and post-test errors are pre- sented. Since the errors generated are quite small (compared with other sources of errors described in "Error Analysis," below), we decided to continue to use individual full-scale slopes in the data reduction algorithms.

However, if the magnitude of the other sources of error can be reduced in future experiments, it may be worthwhile to use calibration data that was obtained over a more limited range of displacements. In that case, it would be preferable to use a slope that was determined over the smallest possible range, assuming that the expected range of displacements could be determined a priori.

The bottom two lines in Table 27 present errors caused by using pretest rather than post-test transducer sensitivities. Whereas the mean errors are negligible, errors for individual instruments are quite large. It is interesting that the errors for full-scale and $\pm 2.54-\mathrm{mm}$ rar.os are nearly identical, indicating that the changes in sensitivity were fairly uniform over the entire range. Since only

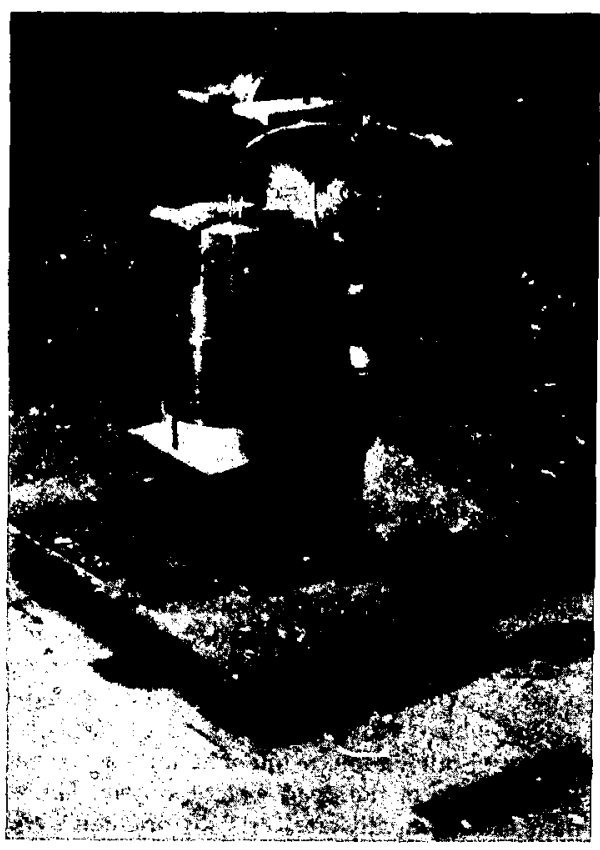

Figure 40. Typical canister drift vertical convergence wire extensometer installation. 
the initial and final sensitivities were measured, we do not know how the sensitivities changed as a function of time. If the change was linear, the mean errors would not exceed one half the values noted in Table 27.

\section{Error Analysis}

Seven sources of error were identified for the CWE units: (1) the calibration coefficient; (2 and 3) excitation and signal voltages; (4) the coefficient of thermal expansion; (5) wire length; (6 and 7 ) initial and current average wire temperatures. Equations (34) through (36) are used to evaluate errors in the calibration ccefficient. Maximum individual errors in the calibration coefficient over the operational range of $3 \mathrm{~mm}$ are (a) signal, $7.48 \times 10^{-5} \mathrm{~V}$; (b) excitation, $5.3 \times 10^{-4} \mathrm{~V}$; and (c) displacement, $2.54 \times 10^{-6} \mathrm{~m}$. The maximum RSS uncertainty in the value of $\mathrm{K}$ is calculated to be $2.16 \times 10^{-5}$ $\mathrm{V} \cdot \mathrm{m} / \mathrm{V}$.

In field use, CWE displacements are calculated using Eq. (37) as noted in the previous section. Errors are then calculated using Egs. (38) through (42) and Eqs. (51) and (52). Maximum individual errors are (a) calibration coefficient, $2.16 \times 10^{-5} \mathrm{~V} \cdot \mathrm{m} / \mathrm{V}$; (b) excitation, $5.30 \times 10^{-4} \mathrm{~V}$; (c) signal, $7.48 \times 10^{-5} \mathrm{~V}$; (d) coefficient of thermal expansion (assumed $\pm 5 \%$ due to lack of data), 8.3 $\times 10^{-7} \mathrm{~m} / \mathrm{m} \cdot{ }^{\circ} \mathrm{C}$; (e) wire length, $1.5 \mathrm{~mm}$; and (f) wire temperature (from CWT analysis), $0.848^{\circ} \mathrm{C}$ for short wires, $0.544^{\circ} \mathrm{C}$ for medium length wires, and $0.407^{\circ} \mathrm{C}$ for the long wire. The products of appropriate sensitivity factors and individual errors are provided in Table 28 for each range of CWE wire lengths, In addition, the error introduced by removing and replacing the canister drift CWE units is also shown. The mean error associated with removing and replacing the CWEs was $-27 \times 10^{-6} \mathrm{~m}$. Errors ranged from zero for the short units (which were never removed) to $-234 \times 10^{-6} \mathrm{~m}$ for the long unit. Maximum composite errors were calculated by the root-sums-ofsquares (RSS) approach.

Because we used pretest sensitivities that were determined over the full range of the transducer and did not account for changes in transducer sensitivities, an additional mean error of $3.8 \times 10^{-6} \mathrm{~m}$ and maximum error of $43.3 \times 10^{-6} \mathrm{~m}$

Table 27. Measured errors resulting from changes in transducer sensitivity for CWEs.

\begin{tabular}{|c|c|c|c|c|}
\hline \multirow[b]{2}{*}{ Comparison } & \multirow{2}{*}{$\begin{array}{l}\text { Number } \\
\text { calibrated }\end{array}$} & \multicolumn{3}{|c|}{ Magnitude of error $(\mu \mathrm{m})$} \\
\hline & & Mean & Std dev & Range \\
\hline \multicolumn{5}{|l|}{ Prelest full-scale vs } \\
\hline pretest $\pm \mathbf{2 . 5 4} \mathrm{mm}$ & 32 & -1.7 & 11.1 & -27.6 to 21.31 \\
\hline \multicolumn{5}{|l|}{ Post-test full-scale vs } \\
\hline post-test $\pm 2.54 \mathrm{~mm}$ & 26 & -1.5 & 12.7 & -32.9 to 32.8 \\
\hline \multicolumn{5}{|l|}{ Prelest full-scale vs } \\
\hline post-test full-scale & 26 & 3.8 & 8.9 & -6.6 to 35.7 \\
\hline \multicolumn{5}{|l|}{ Pretest $\pm 2.54 \mathrm{~mm}$ vs } \\
\hline post-test $\pm 2.54 \mathrm{~mm}$ & 26 & 3.6 & 9.0 & -6.6 to 43.3 \\
\hline
\end{tabular}

Table 28. Calculated maximum total errors associated with field deployment of convergence wire extensometers.

\begin{tabular}{|c|c|c|c|c|c|c|c|}
\hline \multirow[b]{2}{*}{$\begin{array}{l}\text { Wire length } \\
\text { (m) }\end{array}$} & \multicolumn{7}{|c|}{ Source and magnilude of error $(\mu \mathrm{m})$} \\
\hline & $\begin{array}{l}\text { Calib. } \\
\text { coeff. }\end{array}$ & Voltage & $\begin{array}{l}\text { Thermal } \\
\text { coeff. }\end{array}$ & Length & Temp. & $\begin{array}{l}\text { Removal/ } \\
\text { replacement }\end{array}$ & RSS \\
\hline 2.9 to 3.5 & 2.54 & 0.26 & 56.9 & 0.548 & 620 & $\mathbf{0}$ & B.2 \\
\hline 4.6 to 5.9 & 2.54 & 0.26 & 97.0 & 0.548 & 67.8 & 282 & 306 \\
\hline 8.0 & 2.54 & 0.26 & 146.0 & $0.54 B$ & 76.4 & 234 & 286 \\
\hline
\end{tabular}


exist. The maximum error value causes the calculated RSS uncertainties shown in the right-hand column to increase slightly to $94.7 \times 10^{-6} \mathrm{~m}$, $309 \times 10^{-6} \mathrm{~m}$, and $289 \times 10^{-6} \mathrm{~m}$, respectively.

\section{Reliability}

Of the 32 linear potentiometers deployed on the CWEs, 6 did not meet the post-test calibration acceptance criteria, as noted by their absence from Table 27. Units CWE031 and CWE131 exhibited erratic, unstable readings during calibration, In addition, CWE041, CWE051, and CWE112 were found to operate outside the specified $100-\mathrm{mV}$ band for hysteresis and repeatability. Physical damage was evident on CWE071, which had a damaged case that impeded the free movement of the shaft and wiper of the potentiometer. An axamination of the data plots for each of these six wansducers shows no erratic behavior during the period of data acquisition for the SFT-C. Furthermore, CWE071 was responsive to the cooling phase of the SFT-C. Thus, we conclude that only units CWE041, CWE051, and CWE112 (the ones showing hysteresis and lack of repeatability) may have had problems while in service, which, undetected, degraded the quality of their data. All other units functioned reliably during the 3.5-yr monitoring period.

\section{Fracture Monitors}

An instrument known as a fracture monitor system (FMS) was designed and deployed to measure three orthogonal components of motion along existing fractures and faults. Where the CWE units measure an integrated elastic and inelastic rock mass response over a long gauge length, the FMS focuses the measurement on a single, discrete geologic discontinuity or a closely spaced set of such discontinuities. The simple rug- ged design consists of two anchorages on opposite sides of the geologic discontinuity: one houses the three transducers and the other supports a bracket that transfers the motions across the discontinuity to the transducers (Fig. 41). Since the transducer body moves with the first anchorage and the transducer shaft moves with the second anchorage, displacements of the two sides of the discontinuity are sensed relative to each other.

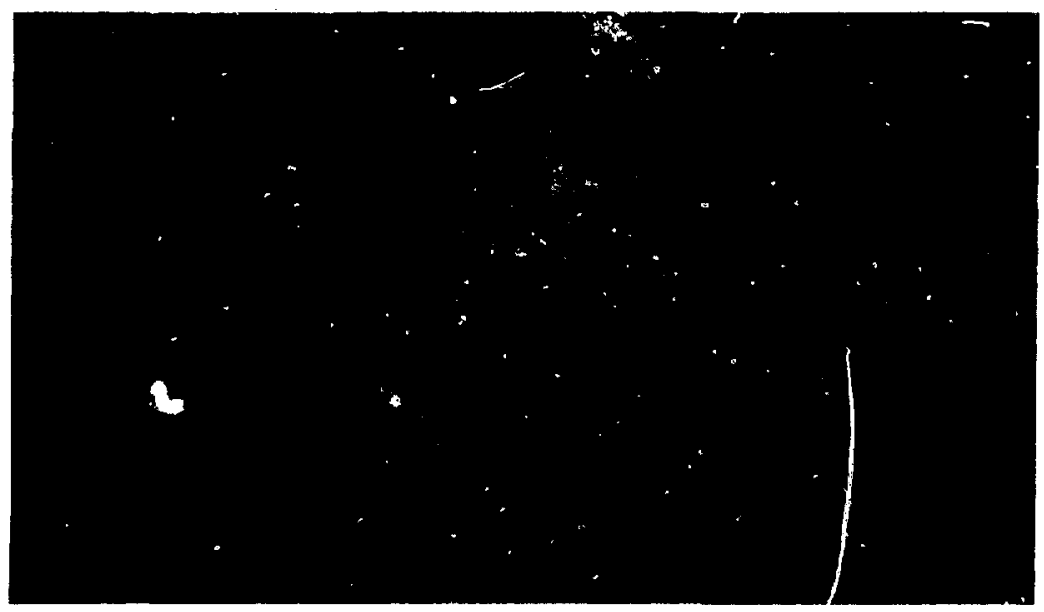

Figure 41. Typical fracture monitor system installation. 
The FMS units were installer at seven selected locations to monitor faults or zones of intense jointing (Fig. 22). These units were mounted so that strike-slip, dip-slip, and normal displacements were sensed.

Mechanical components were fabricated from electroless-nickel-plated carbon s.eel. Although these components were short, thermal expansion was still important because anticipated rock displacements were also small. A single type-K thermocouple was attached to each FMS to provide for compensation of thermal expansion. The transducers were Bourns Model 5184 rectilinear potentiometers.

\section{Calibration}

No provision was made in the FMS design for field calibration. Instead, the linear potentiometers were calibrated in the laboratory before and after the measurement period. Calibrations were performed over the full $25.4-\mathrm{mm}$ range of the transducers in 2.54-mm steps.

These calibrations examine the transducer for possible changes in slope (sensitivity). At the start of the SFT $-C$, there was considerable uncertainty with regard to expected displacements. Therefore, the data reduction algorithm and associated sensitivity values were based on the average slope over the entire 25.4-mm range of the transducer. We now know that actual displacements were less than $1 \mathrm{~mm}$. The top two rows of Table 29 present errors caused by using the slope over the full 25.4-mm range of the pitentiometers rather than the limited $\pm 2.54-m m$ range. Both pre- and prosttest errors are presented. Individual full-scale slopes are used in the data reduction algorithms.

Note that while the mean error introduced by this approach is negligible, errors for individual instruments can be quite large. It follows that it is preferable to use a slope that was determined over the smallest possible range if the expected range of displacements is known a priori.

The bnttom two lines in Table 29 present errors caused by using pretest rather than post-test transducer sensitivities. Once again, the errors for full-scale and \pm 2.54 -mm ranges are nearly identical, indicating that the changes in sensitivity were fairly uniform over the entire range. Since only the initial and final sensitivities were measured, we do not know how the sensitivities changed as a function of time. If the change was linear, the errors would not exceed one half the values noted in Table 29. The changes in sensitivity between pre- and post-test calibrations are negligible for the FMS transducers.

\section{Error Analysis}

The linear potentiometers were calibrated using the same procedure as for the CWE units. Equations (34) through (36) may be evaluated using maximum individual errors over the operational range of $1 \mathrm{~mm}$ : (a) signal, $2.76 \times 10^{-5} \mathrm{~V}$;

Table 29. Measured errors resulting from differences in transcucer sensitivity for fracture monitor systems.

\begin{tabular}{lcccc}
\hline Comparison & $\begin{array}{c}\text { Number } \\
\text { calibrated }\end{array}$ & Mean & Magnitude of error $(\mu \mathrm{m})$ & Range \\
\hline $\begin{array}{l}\text { Pretest full-scale vs } \\
\text { pretest } \pm 2.54 \mathrm{~mm}\end{array}$ & 21 & -1.4 & 12.4 & -24.8 to 34.4 \\
$\begin{array}{c}\text { Post-test full-5cale vs } \\
\text { post-test } \pm 2.54 \mathrm{~mm}\end{array}$ & 19 & -1.5 & 12.4 & -18.2 to 31.8 \\
$\begin{array}{l}\text { Pretest full }: \text { :ale vs } \\
\text { post-test full-scale }\end{array}$ & 19 & 0.6 & 3.2 & -4.0 to 7.2 \\
$\begin{array}{c}\text { Prelest } \pm 2.54 \mathrm{~mm} \text { vs } \\
\text { post-test } \pm 2.54 \mathrm{~mm}\end{array}$ & 19 & 0.8 & 4.0 & -9.3 to 6.6 \\
\hline
\end{tabular}


(b) excitition, $5.3 \times 10^{-4} \mathrm{~V}$; and (c) displacement, $2.34 \times 10^{-6} \mathrm{~m}$. The maximum RSS uncertainty in the value of $K$ is calculated to be $6.45 \times 10^{-5}$ $\mathbf{v} \cdot \mathbf{m} / \mathbf{V}$.

In field use, FMS displacements are calculated using Eq. (37), the same equation as for the CWE units. Errors may be calchlated using the innsitivity factors given by Eqs. (38) through (42) and Eqs. (51) and (52) with proper values of the various parameters inserted in the equations. Maximum individual errors are (a) calibration coefficient, $6.45 \times 10^{-5} \mathrm{~V} \cdot \mathrm{m} / \mathrm{V}$; (b) excitation, $5.3 \times$ $10^{-4} \mathrm{~V}$; (c) signal, $2.76 \times 10^{-5} \mathrm{~V}$; (d) coefficient of thermal expansion (assumed $5 \%$ due to lack of data), $8.3 \times 10^{-7} \mathrm{~m} / \mathrm{m} \cdot{ }^{\circ} \mathrm{C}$; (e) component length, $1.5 \mathrm{~mm}$; and (f) FMS temperature, $0.2^{\circ} \mathrm{C}$. The maximum RSS uncerteinty in the value of displacement measurements is salculated to be $9.63 \times 10^{-6} \mathrm{~m}$. Because we used pretest sensitivities that were determined over the full range of the transducer and did not account for changes in transducer sensitivities, an additional mean error of $1.5 \times 10^{-6} \mathrm{~m}$ and maximum error of $34.4 \times$ $10^{-6} \mathrm{~m}$ exist. These errors cause the calculated RSS uncertainty to increase to mean and maxi- mum values of $9.75 \times 10^{-6} \mathrm{~m}$ and $35.7 \times 10^{-6} \mathrm{~m}$, respectively.

\section{Reliability}

Two of the 21 linear potentiometers deployed on FMSs did not pass the post-test calitration acceptance criteria, as noted by their absence from Table 29. The shaft of FMSO23 was sticking and it was found to operate outside the specified $100-\mathrm{mV}$ band for hysteresis and repeatability. In addition, physical damage to the case of FMSO52 precluded movement of the shaft and wiper so this unit could not be calibrated. Individual data plots for these units revealed no problems with FMS023. However, FMSO52 began malfunctioning at 4.85 YOC (September 26, 1982) and was cleaned, lubricated, and returned to service at 5.36 YOC (March 31, 1983). It was functioning reliably when removed for recalibration. It appears that the malfunctions of both these units may be related to events that took place after the SFT-C, possibly during disassembly of the instruments or shipment of the components to the calibration laboratory.

\section{Borehole Closure Morutor}

A strain-gauged proving-ring transducer was designed and deployed to measure small diametrical displacements in the 0.61 -m-diam by 4.9-m-deep canister emplacement borehoies after the spent fuel was retrieved (Patrick and Rector, 1984). This instrument has been dubbed the canister borehole deformation gauge (CDG). The basic instrument consists of a steel proving ring with a $203.2-\mathrm{mm}$ outside diam, $190.5-\mathrm{mm}$ inside diameter, and $25.4-\mathrm{mm}$ ring width (Fig. 42). Sections of 25.4-mm-diameter bar stock and machined bearing surfaces are connected to the ring to transmit displacements from the borehole to the gauge. The proving ring is prestressed at the time of installation so both positive and negative borehole displacements may be sensed.

Micro-Measurements' SK-06-125AD-350 "Karma" foil strain gauges were used to measure strains in the proving ring resulting from changes in borehole diameter. Gauges were applied in a full bridge configuration at positions $90^{\circ}$ from the load axis. The test environment was at $100 \%$ relative humidity with temperatures decreasing from 60 to $30^{\circ} \mathrm{C}$ during the planned 6-month deployment period. Four layers of protective coating were applied in acc. rdance with manufacturer's suggestions to cumbat this environment. These consisted of M-Coat D (toulene-thinned acrylic), M-Coat W1 (microcrystalline wax), M-Coat FB (butyl rubber sealant), and M-Coat FN (Neoprene rubber sheet).

A single type- $\mathrm{K}$ thermocouple was mounted to each set of three proving rings to provide data to compensate for the effects of thermal expansion of the transducer components.

Two sets of three proving-ring assemblies were installed in each of two canister emplacement boreholes for a total of 12 transducers. Each set of three transducers was arranged on its support brackets in a 60-degree rosette. In addition, two transducers were installed in a third borehole: one in an unloaded configuration and one in a dead-weight-loaded configuration. Since neither of these transducers interacted with the borehole, their output signals were used to monitor transducer drift and zero offset while the experiment was in progress. These data thus provided a degree of confidence (before post-test calibrations were performed) that the data from the other 12 transducers were reliable. 


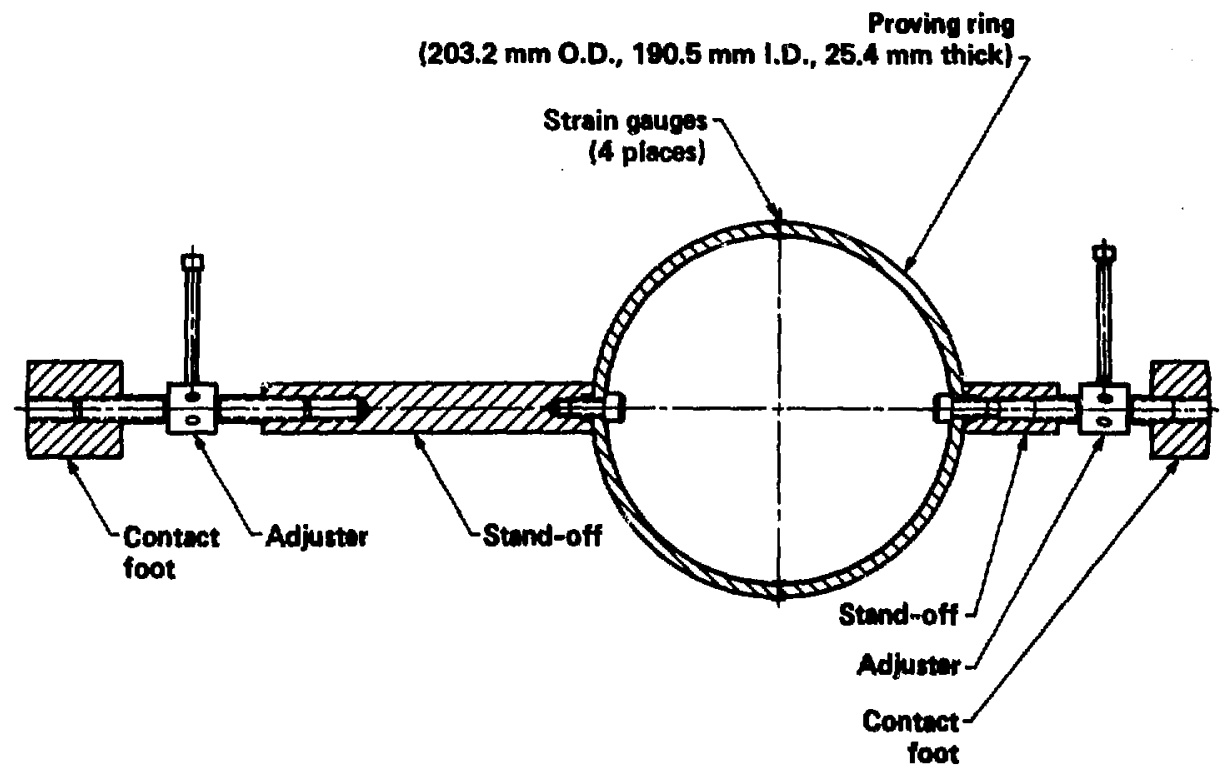

Figure 42. Schematic of caniater deformation gauge showing strain-gauged proving-ring concept.

\section{Calibration}

Laboratory calibrations were performed on the CDG units before installation and on all units that survived the 6-month deployment. The rings were calibrated on an Ormond beam-balance calibrator. A Bourns Model 141 rectilinear potentiometer was installed diametrically across the ring to measure ring displacements, and the ring was exercised 10 times through the $0.51-\mathrm{mm}(0.02-i n$.) range to ensure that all mechanical interfaces were stable, that the test frame hardware alignments were correct, and that the related hysteresis was minimized. Since the CDGs would be deployed in an elevated-temperature environment, both ambient-temperature $\left(23^{\circ} \mathrm{C}\right)$ and elevatedtemperature calibrations were conducted. To perform the elevated-temperature calibration, a styrofoam box was constructed around the ring, and the temperature of the proving-ring was raised to $49^{\circ} \mathrm{C}$ by means of a heat lamp and a small stirring fan. Following the elevated temperature calibration, a third calibration was performed at the ambient temperature to determine if the operation at an elevated temperature produced any changes in ambient temperature calibration characteristics. In general, errors associated with operating the CDGs at elevated temperatures were less than
$0.4 \%$ of full scale and in no case exceeded $0.7 \%$ of full scale. Furthermore, no significant permanent changes were detected by the third calibration. The mean transducer sensitivity was determined to be $8.811 \mathrm{mV} / \mathrm{mm}$ with a standard deviation of $0.0988 \mathrm{mV} / \mathrm{mm}(1.1 \%)$. Despite the small variability in transducer sensitivity, individual calibration coefficients were used for each CDG unit.

Post-test calibrations were performed using the same technique outlined above but only ambient temperature calibrations were performed.

\section{Error Analysis}

Five potential sources of error were identified: calibration coefficient $K$, gauge length, temperature, excitation voltage, and signal voltage. Examining first the calibration coefficient $K$, we have

$K=\frac{E}{S} D^{*}$,

where

$D^{*}$ is the displacement sensed by the transducer in $m$,

$E$ is the excitation voltage,

$S$ is the signal voltage. 
The sensitivity factors are calculated by differentiating Eq. (53), such that

$$
\theta_{D}=\frac{d K}{d D}=\frac{E}{S} \text {, }
$$

for displacement errors;

$\boldsymbol{\theta}_{\mathrm{E}}=\frac{\mathrm{dK}}{\mathrm{dE}}=\frac{\mathrm{D}^{*}}{\mathrm{~S}}$.

for excitation voltage errors;

$\theta_{S}=\frac{d K}{d S}=-\frac{D^{*} E}{S^{2}}$,

for signal voltage errors. Maximum individual sources of error are (a) displacement, $2.54 \times$ $10^{-6} \mathrm{~m}$; (b) excitation voltage, $5.3 \times 10^{-4} \mathrm{~V}$; and (c) signal voltage, $4.35 \times 10^{-6} \mathrm{~V}$. The maximum RSS uncertainty in $\mathrm{K}$ is calculated to be $5.08 \times$ $10^{-3} \mathrm{~V} \cdot \mathrm{m} / \mathrm{V}$.

For field use, the equation for calculating displacement from bridge voltage readings is

$D=K \frac{S}{E}-a L\left(T-T_{0}\right)$,

where

$D$ is the borehole displacement, $m$,

$K$ is the calibration factor, $V \cdot m / V$,

$E$ is the excitation voltage, $V$,

$S$ is the signal voltage, $V$,

$\alpha$ is the coefficient of expansion, $\mathrm{m} / \mathrm{m} \cdot{ }^{\circ} \mathrm{C}$,

$\mathrm{L}$ is the gauge length, $\mathrm{m}$,

$\mathrm{T}$ is the current temperature, ${ }^{\circ} \mathrm{C}$,

$\mathrm{T}_{0}$ is the initial temperature, a constant, ${ }^{\circ} \mathrm{C}$.

Sensitivity factors are calculated by differentiating Eq. (57) with respect to each of the sources of error:

$\theta_{K}=\frac{d D}{d K}=\frac{S}{E}$,

for errors in calibration coefficient;

$\theta_{\mathrm{E}}=\frac{\mathrm{dD}}{\mathrm{dE}}=\frac{-\mathrm{KS}}{\mathrm{E}^{2}}$,

for errors in excitation voltage;

$\theta_{\mathrm{S}}=\frac{\mathrm{dD}}{\mathrm{dS}}=\frac{K}{\mathrm{E}}$, for errors in signal voltage;

$\boldsymbol{\theta}_{\alpha}=\frac{\mathrm{dD}}{\mathrm{d} \alpha}=-\mathrm{L}\left(\mathrm{T}-\mathrm{T}_{\mathbf{0}}\right)$,

for errors in coefficient of expansion;

$\boldsymbol{\theta}_{\mathrm{l} .}=\frac{\mathrm{dD}}{\mathrm{dL}}=-\boldsymbol{\alpha}\left(\mathrm{T}-\mathrm{T}_{0}\right)$,

for errors in gauge length;

$\boldsymbol{\theta}_{\mathrm{T}}=\frac{\mathrm{dD}}{\mathrm{dT}}=-\alpha \mathrm{L}$,

for errors in current temperature;

$\boldsymbol{\theta}_{\mathrm{T}_{0}}=\frac{\mathrm{dD}}{\mathrm{dT}_{0}}=\alpha \mathrm{L}$,

for errors in initial temperature. The maximum uncertainty for each source of error is calculated as the product of the sensitivity factor and the associated maximum unit error. Maximum unit errors are (a) calibration coefficient, $5.08 \times$ $10^{-3} \mathrm{~V} \cdot \mathrm{m} / \mathrm{V}$; (b) excitation voltage, $8.0 \times 10^{-4} \mathrm{~V}$; (c) signal voltage, $4.9 \times 10^{-6} \mathrm{~V}$; (d) coefficient of thermal expansion, assumed $\pm 5 \%$; (e) length, $6.35 \mathrm{~mm}$; and (f) temperature, $0.2^{\circ} \mathrm{C}$. The composite RSS error is $1.51 \times 10^{-5} \mathrm{~m}$.

\section{Reliability}

Two criteria were applied in judging the reliability of the CDGs. First, the output signals of the devices were carefully examined to determine if there was any erratic behavior. The useful life of the transducer ended when erratic signals began. In general, such changes in transducer response were quickly followed by a complete loss of signal. Table 30 documents transducer reliability judged by this criterion.

Second, post-test calibrations were made to evaluate transducers which survived the 189-day test period. Table 31 summarizes changes between the pre- and post-test calibration characteristics of these transducers. Changes in sensitivity ranged from -0.751 to $-1.498 \%$ with an average of $-1.172 \%$. Shifts in zero offset ranged from 0.001 to $1.007 \mathrm{mV}$, with an average of 0.867 $\mathrm{mV}$, with two exceptions. The two exceptions are CDG034 and CDG091 which, as noted in Tables 30 and 31 , were determined to have failed based on erratic output signals. Also note that CDG095 
Table 30. Time periods of acceptable data from canister deformation gauges.

\begin{tabular}{ccccc}
\hline $\begin{array}{c}\text { Instrument } \\
\text { license } \\
\text { plate }\end{array}$ & $\begin{array}{c}\text { Transducer } \\
\text { rerial } \\
\text { number }\end{array}$ & $\begin{array}{c}\text { Siart of data } \\
\text { (YOC) }\end{array}$ & $\begin{array}{c}\text { End of dala } \\
\text { (YoC) }\end{array}$ & $\begin{array}{c}\text { Operating life } \\
\text { (dayn) }\end{array}$ \\
\hline CDG 031 & 01 & 5.30 & 5.67 & 135.1 \\
032 & 02 & 5.30 & 5.55 & 91.3 \\
033 & 03 & 5.30 & 5.52 & 81.2 \\
034 & 04 & 5.30 & 5.63 & 120.3 \\
035 & 05 & 5.30 & 5.50 & 73.0 \\
036 & 06 & 5.30 & 5.63 & 120.3 \\
091 & 07 & 5.34 & 5.60 & 95.0 \\
092 & 06 & 5.34 & 5.86 & 188.9 \\
093 & 09 & 5.34 & 5.86 & 188.9 \\
094 & 10 & 5.34 & 5.86 & 188.9 \\
095 & 11 & 5.34 & 5.86 & 188.9 \\
096 & 12 & 5.34 & 5.86 & 188.9 \\
072 & 13 & 5.34 & 5.06 & 186.9 \\
071 & 14 & 5.34 & 5.06 & 188.9 \\
\hline
\end{tabular}

- Test duration was 188.9 days.

Table 31. Changes in calibration characteristics of strain-gauged proving-ring transducers. ${ }^{\text {a }}$

\begin{tabular}{ccccccc}
\hline $\begin{array}{c}\text { Instrument } \\
\text { license } \\
\text { plate }\end{array}$ & $\begin{array}{c}\text { Transducer } \\
\text { serial number }\end{array}$ & $\begin{array}{c}\text { Sensitivity } \\
\text { (\% change) }\end{array}$ & $\begin{array}{c}\text { Zcro offet } \\
\text { (mV change) }\end{array}$ & $\begin{array}{c}\text { Span } \\
\text { (\% change) }\end{array}$ & $\begin{array}{c}\text { Pretest error } \\
\text { band (\%) }\end{array}$ & $\begin{array}{c}\text { Post-test error } \\
\text { band (\%) }\end{array}$ \\
\hline CDG 034 & 04 & +0.023 & 20.449 & +0.056 & $+0.50,-0.71$ & $+0.15,-0.17$ \\
091 & 07 & -0.598 & 3.210 & -0.511 & $+0.30,-0.18$ & $+0.16,-0.15$ \\
092 & 08 & -1.498 & 0.309 & -1.411 & $+0.24,-0.29$ & $+0.07,-0.13$ \\
093 & 09 & -1.497 & 0.817 & -1.401 & $+0.34,-0.19$ & $+0.11,-0.13$ \\
094 & 10 & -1.009 & 0.083 & -0.919 & $+0.34,-0.25$ & $+0.13,-0.16$ \\
096 & 12 & -1.442 & 0.001 & -1.357 & $+0.30,-0.40$ & $+0.12,-0.14$ \\
072 & 13 & -0.835 & 1.007 & -2.092 & $+0.21,-0.29$ & $+0.09,-0.13$ \\
071 & 14 & -0.751 & 0.628 & -0.827 & $+0.22,-0.26$ & $+0.37,-0.33$ \\
\hline
\end{tabular}

Calibration performed over a span of $0.51 \mathrm{~mm}$, nominal $10-\mathrm{V}$ excilation, average transducer sensitivity is 0.881105 mV/V.mm.

provided reliable readings throughout the test period but malfunctioned at the time of calibration.

All failures were judged to be the direct result of moisture leaking into the strain gauge or, more commonly, into the area where the gauge leads were connected to terminal strips. In future applications, additional environmental protection should correct this problem.

\section{Summary and Conclusions}

The objective of the instrumentation program developed for the SFT $-C$ was to ensure that an appropriate quantity and quality of data was obtained for three purposes:

- To meet the technical objectives of the test.
- To provide for radiation safety.

- To monitor the status of the test operating systems such as ventilation, electrical power, and the DAS.

Nearly 1000 instruments were deployed and about $15.3 \times 10^{6}$ data points were automatically 
acquired by the DAS. Additional data were acquired from manually recorded instruments such as dosimeters.

The DAS had an availability of $96 \%$ during the data collection period of 3.5 years while functioning essentially unattended for most of this period in a remote comer of the Nevada Test Site. This high availability is directly attributable to the redundant design, which utilized two HP1000 mini-computers that were configured to share the data acquisition load in normal operation and to switch so that one computer acquired all data in the event of a malfunction of the other computer.

The three objectives of the instrumentation program were met despite malfunctions and changes in operating characteristics of several types of instrumentation. Stress changes were not adequately determined because the vibrating-wire stressmeters failed too soon after deployment. This is the only data type that we believe was obtained with insufficient accuracy and for an in. sufficient time period. Although this shortfall precludes using changes in stress as a second independent basis for evaluating the computer code used to model the thermomechanical response of the rock, the availability of a large amount of good quality displacement data will support the evaluation.

Table 32 summarizes the results of error and reliability analyses developed in preceding chapters of this report. We offer several conclusions and suggestions based on our studies.

1. Currently available CAM and RAM systems are adequate for radiation safety purposes when deployed in an underground environment. Provisions for periodic recalibrations must be included in the monitoring plan. The units should be protected from contact with corrosive ground waters.

2. Long-term radiation dosimetry using the optical transmission technique (LiF) should be augmented with short-term TLD measurements using $\mathrm{CaF}_{2}$ thermoluminescent dosimeters.

3. The foil-type long-term neutron dosimetry used at the SFT-C is inadequate for accurate determinations of dose. Portable dose rate instrumentation provides adequate personnel neutron dosimetry.

4. Commercially available RTDs, thermocouples, and thermistors provide reliable, accurate, long-term temperature data. Sheaths and environmental sealing materi-Is must be carefully selected for the particular + ${ }^{+}$st environment.

5. The four-wire resistance measurement system developed for monitoring CWE temperatures was marginally adequate. Errors in temperature were a significant contributor to total error for the CWEs.

6. More accurate, higher-resolution techniques are needed to calibrate turbine flowmeters. Inadequacy of existing techniques required that we revert to manufacturer's specifications in the error analyses.

7. Systematic changes in watt transducer calibrations (outside of manufacturer's specifications) occurred during the SFT $-C$. These changes suggest the need for periodic calibrations if an accuracy of better than about 5\% is required for the energy balance.

8. Failure of $100 \%$ of the original O-ringsealed vibrating-wire stressmeters led to a hermetically sealed design. These units functioned much more reliably with only 2 of 18 units providing erratic readings. The possibility of filling the stressmeter cavity with fluid should be considered.

9. An attempt at post-test calibrating the vibrating-wire stressmeters after retrieving them by means of an overcoring technique was a limited success. However, the attempt revealed major differences belween the actual and assumed gauge sensitivities. Further development of calibration techniques is needed if these gauges are to be used with accuracy.

10. The burst-line technique for inflating hydraulic extensometers was found to be marginally adequate. A nitrogen-over-hydraulic system was deployed on a second set of extensometers to control inflation and maintain adequate anchor pressure. Anchorage was demonstrably better where controlled inflation was used, even when anchorage pressure later decreased to zero due to leakage.

11. Major losses of data resulted from failure of two types of linear potentiometers. These failures are believed to have reșulted from degradation of the resistive element, which was brought on by chemical vapor action. Consideration should be given to deploying fluid-filled transducers.

12. Changes in transducer sensitivities occurred in potentiometers, LVDTs, and electronag- 
Table 32. Summary error values and reliability statistics for instrumentation deployed at the Spent Fuel Teat-Climax.

\begin{tabular}{|c|c|c|c|c|c|c|c|}
\hline \multirow[b]{2}{*}{$\begin{array}{l}\text { Instrument } \\
\text { type }\end{array}$} & \multirow[b]{2}{*}{$\begin{array}{l}\text { Number } \\
\text { deployed }\end{array}$} & \multicolumn{2}{|c|}{ Error analysis } & \multicolumn{3}{|c|}{ Reliability analysis } & \multirow[b]{2}{*}{$\begin{array}{l}\text { Comments/ } \\
\text { recommendations }\end{array}$} \\
\hline & & $\begin{array}{l}\text { Calc. RSS } \\
\text { error }\end{array}$ & $\begin{array}{l}\text { Mean calib. } \\
\text { error pre- } \\
\text { and post-test }\end{array}$ & $\begin{array}{l}\text { Number } \\
\text { malfunctions } \\
\text { (\%) }\end{array}$ & $\begin{array}{l}\text { Mean time } \\
\text { to fajlure }\end{array}$ & $\begin{array}{l}\text { Mode of } \\
\text { failure }\end{array}$ & \\
\hline $\begin{array}{l}\text { 1. Remote area } \\
\text { radiation monitors }\end{array}$ & 10 & - & - & $\mathbf{0}(0)$ & $\mathbf{N} / \mathbf{A}$ & $\mathbf{N} / \mathbf{A}$ & $\begin{array}{l}\text { Senditivity changed with time requir- } \\
\text { ing recalibration. }\end{array}$ \\
\hline $\begin{array}{l}\text { 2. Continuous air } \\
\text { radiation monitors }\end{array}$ & $\begin{array}{l}14 \\
\text { (2 chambers) }\end{array}$ & - & - & 0 (0) & $\mathbf{N} / \mathbf{A}$ & $\mathbf{N} / \mathbf{A}$ & $\begin{array}{l}\text { Sensitivity changed with time requir- } \\
\text { ing recalibration. }\end{array}$ \\
\hline $\begin{array}{l}\text { 3. Radiation } \\
\text { dosimetere }(\gamma)\end{array}$ & 25 & $\pm 11 \%$ & - & 0 (0) & $\mathbf{N} / \mathbf{A}$ & $\mathbf{N} / \mathbf{A}$ & $\begin{array}{l}\text { Awgment with short-lerm dosimetry. } \\
\text { More study of annealing required. }\end{array}$ \\
\hline $\begin{array}{l}\text { 4. Radiation } \\
\text { dowimeters (n) }\end{array}$ & 10 & $\pm 30 \%$ & - & $0(0)$ & $\mathbf{N} / \mathbf{A}$ & $\mathbf{N} / \mathbf{A}$ & $\begin{array}{l}\text { Inadequate for low neutron dose } \\
\text { measurements. }\end{array}$ \\
\hline 5. $\mathrm{CaF}_{2} \operatorname{TLD}(\gamma)$ & 18 & $\pm \mathbf{5 \%}$ & - & $\mathbf{0}(\mathbf{0})$ & $\mathbf{N} / \mathbf{A}$ & $\mathbf{N} / \mathbf{A}$ & $\begin{array}{l}\text { Excellent adjunct to long-term } \\
\text { dosimetry. }\end{array}$ \\
\hline 6. $\mathrm{MgB}_{4} \mathrm{O}, \mathrm{TLD}(\gamma)$ & 18 & - & - & $18(100 \%)$ & $\mathbf{N} / \mathbf{A}$ & $\begin{array}{l}\text { Erratic } \\
\text { readings during } \\
\text { calibrations. }\end{array}$ & $\begin{array}{l}\text { Theoretically better than } \mathrm{CaF}_{2} \text { bat } \\
\text { unsiable in practice. }\end{array}$ \\
\hline \multirow[t]{2}{*}{ 7. RTD } & 20 & $0.038^{\circ} \mathrm{C} @ 0^{\circ} \mathrm{C}$ & $\begin{array}{l}0.032^{\circ} \mathrm{C}, 0.090^{\circ} \mathrm{C} \\
@ 23{ }^{\circ} \mathrm{C}\end{array}$ & O (0) & $\mathbf{N} / \mathbf{A}$ & $\mathbf{N} / \mathbf{A}$ & Flawleas performance \\
\hline & & $0.041^{\circ} \mathrm{C} @ 40^{\circ} \mathrm{C}$ & $\begin{array}{l}0.039^{\circ} \mathrm{C}, 0.112^{\circ} \mathrm{C} \\
\text { ( } 40^{\circ} \mathrm{C}\end{array}$ & & & & \\
\hline 8. Thermocouples & 515 & $\begin{array}{l}0.12^{\circ} \mathrm{C} 90-200^{\circ} \mathrm{C} \\
0.13^{\circ} \mathrm{C} @ 200-400^{\circ} \mathrm{C} \\
0.14^{\circ} \mathrm{C}\left(000-1000^{\circ} \mathrm{C}\right.\end{array}$ & $\begin{array}{l}\text { See Figs. 11-14 } \\
\text { for distr. of } \\
\text { errors }\end{array}$ & $4(0.8 \%)$ & $\begin{array}{l}\text { Did not fail } \\
\text { in service }\end{array}$ & $\begin{array}{l}\text { Corrosion of } \\
304 \mathrm{~L} \text { stainless } \\
\text { or Inconel } 600 \\
\text { sheath. }\end{array}$ & $\begin{array}{l}\text { Failure oceurred at time of post-teat } \\
\text { calibration. }\end{array}$ \\
\hline 9. Thermistors & 19 & $0.022^{\circ} \mathrm{C}$ & $\begin{array}{l}-, 0.091^{\circ} \mathrm{C} @ 19^{\circ} \mathrm{C} \\
0.006,025^{\circ} \mathrm{C} @ 23^{\circ} \mathrm{C} \\
--0.019 @ 30^{\circ} \mathrm{C}\end{array}$ & 0 (0) & $\mathbf{N} / \mathbf{A}$ & $\mathbf{N} / \mathbf{A}$ & Flawleas performance. \\
\hline \multicolumn{8}{|c|}{$\begin{array}{l}\text { 10. Convergence wire } \\
\text { temperature monitors: }\end{array}$} \\
\hline $\begin{array}{l}4.6-5.9 \mathrm{~m} \mathrm{loms} \\
8.0 \mathrm{~m} \text { lons }\end{array}$ & 11 & $\begin{array}{l}0.54^{\circ} \mathrm{C} \\
0.407^{\circ} \mathrm{C}\end{array}$ & $\begin{array}{l}-0.090^{\circ} \mathrm{C} \\
-0.248^{\circ} \mathrm{C}\end{array}$ & $2(6.2 \%)$ & $\begin{array}{l}\text { Did not fail } \\
\text { in service. }\end{array}$ & $\begin{array}{l}\text { Voltage/current } \\
\text { reference moved } \\
\text { during post-leat } \\
\text { calibration. }\end{array}$ & $\begin{array}{l}\text { Loss of post-test calibration does not } \\
\text { affect data acquired during teats. }\end{array}$ \\
\hline
\end{tabular}


Table 32. (Continued)

\begin{tabular}{|c|c|c|c|c|c|c|c|}
\hline \multirow[b]{2}{*}{$\begin{array}{c}\text { Instrument } \\
\text { type }\end{array}$} & \multirow[b]{2}{*}{$\begin{array}{l}\text { Number } \\
\text { deployed }\end{array}$} & \multicolumn{2}{|c|}{ Error analysis } & \multicolumn{3}{|c|}{ Reliability analyais } & \multirow[b]{2}{*}{$\begin{array}{l}\text { Counmenta/ } \\
\text { reconmendations }\end{array}$} \\
\hline & & $\begin{array}{l}\text { Calc. RSS } \\
\text { error }\end{array}$ & $\begin{array}{l}\text { Mean calib. } \\
\text { error pre- } \\
\text { and post-test }\end{array}$ & $\begin{array}{c}\text { Number } \\
\text { malfunctions } \\
\text { (\%) }\end{array}$ & $\begin{array}{l}\text { Mean time } \\
\text { to failure }\end{array}$ & $\begin{array}{l}\text { Mode of } \\
\text { failure }\end{array}$ & \\
\hline 11. Air temperature TCs & 6 & $\pm 0.005^{\circ} \mathrm{C}$ & $\pm 0.005^{\circ} \mathrm{C}$ & O (0) & $\dot{\mathbf{N}} / \mathbf{A}$ & N/A & $\begin{array}{l}\text { Used individual TC calibration to mia- } \\
\text { imize erross. }\end{array}$ \\
\hline 12. Dewpoint cell (LiCl) & 4 & \pm 0.0187 Torr & $\begin{array}{l} \pm 0.2 \% \\
\pm 0.14{ }^{\circ} \mathrm{C}\end{array}$ & O (0) & N/A & $\mathbf{N} / \mathbf{A}$ & Funetioned well. \\
\hline 13. Turbine flowmeter & 3 & $\pm 0.1 \%$ & - & $0(0)$ & $\mathbf{N} / \mathbf{A}$ & $\begin{array}{l}\text { Periodic cleaning } \\
\text { of turbine was } \\
\text { necessary. }\end{array}$ & $\begin{array}{l}\text { Poot resolution of calibration tech- } \\
\text { niques and suopected } 18 \% \text { syotematic } \\
\text { error led to use of manufacturer's specs } \\
\text { for error analysis. }\end{array}$ \\
\hline $\begin{array}{l}\text { 14. Watt transducers } \\
\text { (auxiliary heater) }\end{array}$ & 6 & - & $-1.3 \%,+2.5 \%$ & $0(0)$ & $\mathbf{N} / \mathbf{A}$ & $\mathbf{N} / \mathbf{A}$ & $\begin{array}{l}\text { One unit damaged in shipping conld } \\
\text { not be post-test calibrated. Systematic } \\
\text { shift in calibration was observed. }\end{array}$ \\
\hline $\begin{array}{l}\text { 15. Watt transducers } \\
\text { (electrical simulators) }\end{array}$ & 6 & - & $-3.5 \%,+3.2 \%$ & $0(0)$ & $\mathbf{N} / \mathbf{A}$ & $\mathbf{N} / \mathbf{A}$ & $\begin{array}{l}\text { Systematic shift in wlibration was } \\
\text { observed. }\end{array}$ \\
\hline $\begin{array}{l}\text { 16. Watt transducers: } \\
\text { Heater drift lighting } \\
\text { Can. drift lighting }\end{array}$ & $\begin{array}{l}4 \\
3\end{array}$ & - & $\begin{array}{l}-2.7 \%,+0.5 \% \\
-3.7 \%, 1.8 \%\end{array}$ & $\begin{array}{l}0(0) \\
0(0)\end{array}$ & $\begin{array}{l}\text { N/A } \\
\text { N/A }\end{array}$ & $\begin{array}{l}\mathbf{N} / \mathbf{A} \\
\mathbf{N} / \mathbf{A}\end{array}$ & Two units damaged in shipping. \\
\hline $\begin{array}{l}\text { 17. Vibrating-wire } \\
\text { stressmelers: }\end{array}$ & & & & & & & \\
\hline Original & 18 & - & - & $18(100 \%)$ & 273 days & $\begin{array}{l}\text { Corrosion of } \\
\text { vibrating wire. }\end{array}$ & Resulted in the likely total lose of data. \\
\hline Replacement & 18 & - & $\mathbf{N} / \mathrm{A}, \mathbf{6 0 \%}$ & $2(11 \%)$ & N/A & Erratic readings & $\begin{array}{l}\text { Most readings reliable, data are proba- } \\
\text { bly ok. }\end{array}$ \\
\hline $\begin{array}{l}\text { 18. Mine-by series } \\
\text { extensometers (data } \\
\text { for typical } 5 \mathrm{~m} \text { rod) }\end{array}$ & $\begin{array}{l}12 \text { units, } \\
60 \text { anchors }\end{array}$ & $56 \mu: n$ & $\begin{array}{l}\text { Change in sens. pro- } \\
\text { duced mean errcr } \\
=-3.8 \mu \mathrm{m}\end{array}$ & $9(15 \%)$ & $\begin{array}{l}\text { N/A } \\
5 \$ 0 \text { days }\end{array}$ & $\begin{array}{l}\text { Anchor slip at low } \\
\text { loads. } \\
\text { Transducer } \\
\text { failure }\end{array}$ & $\begin{array}{l}\text { Due to inadequate inflation with bunt } \\
\text { line system. Erratic output signals. }\end{array}$ \\
\hline $\begin{array}{l}\text { 19. GxE-series } \\
\text { extensometer } \\
\text { original Boums } \\
\text { potentiometer, } 5 \text {-m rod }\end{array}$ & $\begin{array}{l}14 \text { units, } \\
56 \text { anchors }\end{array}$ & $33 \mu \mathrm{m}$ & - & $\begin{array}{l}43(77 \%) \\
10(18 \%)\end{array}$ & $\begin{array}{l}223 \text { days } \\
1119 \text { days }\end{array}$ & $\begin{array}{l}\text { Transducer } \\
\text { failure; } \\
\text { rad fracture. }\end{array}$ & $\begin{array}{l}\text { Resulted in massive loss of early-time } \\
\text { displacement data. Stress corrosion } \\
\text { cracking. }\end{array}$ \\
\hline $\begin{array}{l}\text { 20. GxE replacement } \\
\text { Bourns pot. } \\
\text { 5-m rod }\end{array}$ & $\begin{array}{l}6 \text { units } \\
24 \text { anchors }\end{array}$ & $33 \mu \mathrm{m}$ & $\begin{array}{l}\text { Change in sens. } \\
\text { produced mean error } \\
=-30.8 \mu \mathrm{m}\end{array}$ & $0(0)$ & $\mathbf{N} / \mathbf{A}$ & $\mathbf{N} / \mathbf{A}$ & $\begin{array}{l}\text { Transducer sensitivity changed with } \\
\text { time. }\end{array}$ \\
\hline
\end{tabular}


Table 32. (Continued)

\begin{tabular}{|c|c|c|c|c|c|c|c|}
\hline \multirow[b]{2}{*}{$\begin{array}{l}\text { Instrument } \\
\text { type }\end{array}$} & \multirow[b]{2}{*}{$\begin{array}{l}\text { Number } \\
\text { deployed }\end{array}$} & \multicolumn{2}{|c|}{ Error analysis } & \multicolumn{3}{|c|}{ Retiaon... $/$ analysis } & \multirow[b]{2}{*}{$\begin{array}{l}\text { Comments/ } \\
\text { recommendations }\end{array}$} \\
\hline & & $\begin{array}{l}\text { Calc. RSS } \\
\text { error }\end{array}$ & $\begin{array}{l}\text { Mean calib. } \\
\text { error pre- } \\
\text { and post-test }\end{array}$ & $\begin{array}{l}\text { Number } \\
\text { malfunctions } \\
\text { (\%) }\end{array}$ & $\begin{array}{l}\text { Mean time } \\
\text { lo failure }\end{array}$ & $\begin{array}{l}\text { Mode of } \\
\text { failure }\end{array}$ & \\
\hline $\begin{array}{l}\text { 21. GxE replacement } \\
\text { Vernitec pot. } \\
\text { 5-m rad }\end{array}$ & $\begin{array}{l}3 \text { units } \\
12 \text { anchors }\end{array}$ & $33 \mu \mathrm{m}$ & - & $12(100 \%)$ & 210 days & Transducer failure & $\begin{array}{l}\text { Unsealed units failed rapidly after } \\
\text { deployment. }\end{array}$ \\
\hline $\begin{array}{l}\text { 22. GxE replacement } \\
\text { LVDT } \\
\text { 5-m rod }\end{array}$ & $\begin{array}{l}3 \text { units } \\
12 \text { anchors }\end{array}$ & $112 \mu \mathrm{m}$ & $\begin{array}{l}\text { Change in sens. } \\
\text { produced mean error } \\
=-22.8 \mu \mathrm{m}\end{array}$ & $0(0)$ & N/A & $\mathbf{N} / \mathbf{A}$ & $\begin{array}{l}\text { Transducer sensitivity changed with } \\
\text { time. }\end{array}$ \\
\hline $\begin{array}{l}\text { 23. GxE replacement } \\
\text { proximeter } \\
5 \text {-m rod }\end{array}$ & $\begin{array}{l}3 \text { units } \\
12 \text { units }\end{array}$ & $63 \mu \mathrm{m}$ & $\begin{array}{l}\text { Change in sens. } \\
\text { produced mean error } \\
=+190.8 \mu \mathrm{m}\end{array}$ & O (0) & N/A & $\mathbf{N} / \mathbf{A}$ & $\begin{array}{l}\text { Transducer sensitivity changed with } \\
\text { time. }\end{array}$ \\
\hline $\begin{array}{l}\text { 24. Convergence wire } \\
\text { extensometers: }\end{array}$ & & & & & & & \\
\hline $\begin{array}{l}2.9-3.5 \mathrm{~m} \text { long } \\
4.6-5.9 \mathrm{~m} \text { long } \\
8.0 \mathrm{~m} \text { long }\end{array}$ & $\begin{array}{l}20 \\
11 \\
1\end{array}$ & $\begin{array}{l}84 \mu \mathrm{m} \\
306 \mu \mathrm{m} \\
286 \mu \mathrm{m}\end{array}$ & $\begin{array}{l}\text { Change in sens. } \\
\text { produced mean error } \\
=3.8 \mu \mathrm{m}\end{array}$ & $\begin{array}{l}3(9.4 \%) \\
\text { hysteresis }\end{array}$ & - & Excessive & $\begin{array}{l}\text { Observed in post-test calibration, not } \\
\text { evident in data. }\end{array}$ \\
\hline $\begin{array}{l}\text { 25. Fracture monitor } \\
\text { systems }\end{array}$ & 21 & $10 \mu \mathrm{m}$ & $\begin{array}{l}\text { Change in sens. } \\
\text { produced mean error } \\
=0.8 \mu \mathrm{m}\end{array}$ & $1(4.8 \%)$ & 900 days & Erratic readings & $\begin{array}{l}\text { A 6-month period of erratic perfor- } \\
\text { mance corrected } 6 \text { months before the } \\
\text { end of the test. }\end{array}$ \\
\hline $\begin{array}{l}\text { 26. Borehole closure } \\
\text { monitor }\end{array}$ & 14 & $15 \mu \mathrm{m}$ & $\begin{array}{l}\text { Change in sens. } \\
\text { produced mean error } \\
=1.2 \mu \mathrm{m}\end{array}$ & 7 (50\%) & 102 days & $\begin{array}{l}\text { Electrical shorts } \\
\text { due to ingress of } \\
\text { water to terminal } \\
\text { strips. }\end{array}$ & Planned test duration 189 days. \\
\hline
\end{tabular}


netic proximeters. While mean errors produced by these changes were a few tens of micrometres, extreme values were as large as one-half millimetre.

13. The coefficient of thermal expansion of borehole extensometer connecting rods must be better known. Substantial improvements in system accuracy will result.

14. Convergence wire extensometers proved to be reliable instruments for measuring displacements across underground openings. As noted in item 5 , errors in temperature readings seriously degraded the potential accuracy of these units. It is also clear that the coefficient of expansion of the wire must be better known.

15. Fracture monitors functioned with excellent accuracy and reliability.

16. The borehole closure monitors developed for the SFT-C functioned quite well for a prototype instrument. Improvement in environmental sealing should greatly extend the useful life of these specialty instruments.

\section{Acknowledgments}

Overall guidance for this and other NNWSI projects at LLNL is provided by L. Ramspott. We thank E. Binnall, Lawrence Berkeley National Laboratory, W. Brough, LLNL, and R. Zimmerman, Sandia National Laboratories, for their careful reviews of this report. Its technical clarity and utility were improved by their many helpful suggestions.

R. Noyes and J. Pelles, EG\&G-Las Vegas, provided laboratory calibrations for many of the instruments, while B. Bailey, D. Jackson, R. Sievert, and W. Webb provided field support for instrument installation and calibrations.

Special appreciation is extended to S. Carey and K. Young who typed the manuscript. Editorial services were provided by $M$. Donohue. 


\section{References}

Abey, A. E., and J. R. Washington (1980), Stressmeter Placement at Spent Fucl Test in Climax Granite, Lawrence Livermore National Laboratory, Livermore, CA, UCID-18629.

Brough, W. G. and W. C. Patrick (1982), Instrumentation Report No. 1: Specification, Design, Calibration, and Installation of Instrumentation for an Experimental, High-Level Nuclear Waste Storage Facility, Lawrence Livermore National Laboratory, Livermore, CA, UCRL-53248.

Carlson, R. C., W. C. Patrick, D. G. Wilder, W. G. Brough, D. N. Montan, P. Harben, L. B. Ballou, and H. C. Heard (1980), Spent Fuel Test-Climax: Technical Measurements Interim Report, FY 1980, Lawrence Livermore National Laboratory, Livermore, CA, UCRL-53064.

Copson, H. R. (1959), Physical Metallurgy of Stress Corrosion Fracture (Interscience Publishers, NY), p. 247.

DuBois, A. O., M. Hood, E. P. Binnall, and L. Anderson (1981), Extensometer Performance During Heater Experiments at Stripa, Lawrence Berkeley National Laboratory, Berkeley, CA, LBL-13531.

Dutta, P., R. Hatfield, and P. Runstadler, Jr. (1981), Calibration Characteristics of IRAD Gage Vibrating Wire Stressmeter at Normal and High Temperature, Technical Report 80-2, vols. 1 and 2. Submitted to Lawrence Livermore National Laboratory by IRAD Gage, Lebanon, New Hampshire, Contractor Report UCRL-15426.

Heuze, F. E., T. R. Butkovich, and J. C. Peterson (1981), An Analysis of the 'Mine-by' Experiment, Climax Granite, Nevada Test Site, Lawrence Livermore National Laboratory, Livermore, CA, UCRL-53133.

Isherwood, D., J. Harrar, and E. Raber (1982), Characterization of Climax Granite Ground Water, Lawrence Livermore National Laboratory, Livermore, CA, UCRL-53309.

Mao, N. (1984), Overcoring and Calibration of IRAD Gage Stressmeters at Spent Fuel Test in Climax Granite, Lawrence Livermore National Laboratory, Livermore, CA, in preparation.

McLaughlin, W. L., A. C. Lucas, B. M. Kapsar, and A. Mjller (1978), "Electron and Gamma-Ray Dosimetry Using Radiation-Induced Color Centers in LiF," in Proc. of Second International Meeting on Radiation Processing, Miami, Florida.

Montan, D., and W. Patrick (1981), Thermal Calculations for the Design, Construction, Operation, and Evaluation of the Spent Fuel Test-Climax, Nevada Test Site, Lawrence Livermore National Laboratory, Livermore, CA, UCRL-53238.

Nyholm, R. A., W. G. Brough, and N. L. Rector (1982), SFT-Climax Data Acquisition System Integration Report, Lawrence Livermore National Laboratory, Livermore, CA, UCRL-53304.

Nyholm, R. A. (1983), Spent Fucl Test-Climax Data Acquisition System Operations Manual, Lawrence Livermore National Laboratory, Livermore, CA, UCID-19834.

Patrick, W. C., and M. C. Mayr (1981), Excavation and Drilling Activities at a Spent Fuel Test Facility in Granitic Rock, Lawrence Livermore National Laboratory, Livermore, CA, UCRL-53227.

Patrick, W., L. Ballou, T. Butkovich, R. Carlson, W. Durham, G. Hage, E. Majer, D. Montan, R. Nyholm, N. Rector, D. Wilder, and J. Yow, Jr. (1982), Spent Fuel Test-Climax Technical Measurements Interim Report FY81, Lawrence Livermore National Laboratory, Livermore, CA, UCRL 53294.

Patrick, W., L. Ballou, T. Butkovich, R. Carlson, W. Durham, G. Hage, E. Majer, D. Montan, R. Nyholm, N. Rector, D. Wilder, and J. Yow, Jr. (1983), Spent Fuel Test-Climax Technical Measurements Interim Report FY82, Lawrence Livermore National Laboratory, Livermore, CA, UCRL-53294-82.

Patrick, W. C., T. R. Butkovich, R. C. Carlson, W. B. Durham, H. C. Ganow, G. L. Hage, E. L. Majer, D. N. Montan, R. A. Nyholm, N. L. Rector, F. J. Ryerson, H. Weiss, and J. L. Yow, Jr. (1984), Spent Fuel Test-Climax: Technical Measurements Interint Repart Fiscal 83, Lawrence Livermore National Laboratory, Livermore, CA, UCRL-53294-83.

Patrick, W. C., R. Carlson, and N. Rector (1981), Instrumentation Report \#2: Identification, Evaluation, and Remediat Actions Related to Transducer Failures at the Spent Fuel Test-Climax, Lawrence Livermore National Laboratory, Livermore, CA, UCRL-53251.

Patrick, W. C., N. L. Rector, and T. R. Butkovich (1984), The Application of Proving-Ring Technology to Measure Thermally Induced Displacements in Large Boreholes in Rock, Proceedings of the 5th International Congress on Experimental Mechanics, Montreal, Quebec, Canada, June 10-14, 1984, Pp. 189196.

Powell, R. L., W. J. Hall, C. H. Hyink, Jr., and L. L. Sparks (1974), Cryogenics Division, National Bureau of Standards; and G. W. Burns, M. G. Scroger, and H. H. Plumb, Heat Division, National Bureau of Standards, Thermocouple Reference Tables Based on the IPTS-68. 
Quam, W. and T. DeVore (1981), Climax Spent Fuel Dosimetry Progress Report, September 1980-September 1981, Lawrence Livermore National Laboratory Contractor Report, Livermore, CA, UCRL-15419.

Quam, W. and T. DeVore (1982), Climax Spent Fuel Dosimetry Progress Report, September 1981-September 1982, Lawrence Livermore National Laboratory Contractor Report, Livermore, CA, UCRL-15419-1.

Quam, W. and T. DeVore (1984a), Climax Spent Fuel Dosimetry Progress Report, September 1982-January 1984, Lawrence Livermore National Laboratory Contractor Report, Livermore, CA, UCRL-15419-2.

Quam, W. and T. DeVore (1984b), Climax Spent Fuel Dosimetry Short Term Exposure, 8 March 1983, Lawrence Livermore National Laboratory Contractor Report, Livermore, CA, UCRL-15419-3.

Ramspott, L. D., L. B. Ballou, R. C. Carlson, D. N. Montan, T. R. Butkovich, J. E. Duncan, W. C. Patrick, D. G. Wilder, W. G. Brough, and M. C. Mayr (1979), Technical Concept for a Test of Geologic Storage of Spent Reactor Fuel in the Climax Granite, Nevada Test Site, Lawrence Livermore National Laboratory, Livermore, CA, UCRL-52796.

Raschke, K. E., W. C. Patrick, T. C. Roy, and T. Straume (1983), Radiation Dosimetry and Monitoring for a Test of Geologic Storage of Spent Nuclear Fuel, Lawrenre Livermore National Laboratory, Livermore, CA, UCRL-53498.

Wilcox, T, and R, Van Konynenburg (1981), Radiation Dose Calculations for Geologic Media Around Spent Fuel Emplacement Holes in the Climax Granite, Nevada Test Site, Lawrence Livermore National Laboratory, Livermore, CA, UCRL-53159.

Wilder, D. G., and W. C. Patrick (1980), Geotechnical Status Report for Test Storage of Spent Reactor Fuel in Climax Granite, Nevada Test Site, Lawrence Livermore National Laboratory, Livermore, CA, UCRL85096; also published in AEG Bulletin, vol. XVIJI, No, 1, pp. 355-367 (1981).

Wilder, D. and J. Yow, Jr. (1981), Fracture Mapping at the Spent Fuel Test-Clintax, Lawrence Livermore National Laboratory, Livermore, CA, UCRL-53201. 